العدد الخامس (مايو 2021)

"الجزوم التربويةًة " الثاني

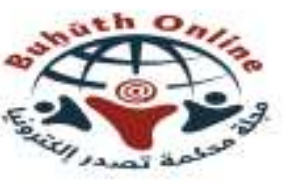

العلاقة بين اضطراب الخوف من فقدان الهاتف المحمول ( النوموفوبيا )

ومستوى التحصيل الأكاديمي لطلاب جامعة الكويت الترول

\author{
قيروان عبدالله أبوشيبة \\ باحثة ماجستير - قسم علم النفس التربوي \\ كلية التربية ، جامعة الكويت ، الكويت \\ qairwanabushaibah@gmail.com \\ أ.د. عيسي تحما البلهان \\ قسم علم التفس التربوي التبله \\ كلية التربية - جامعة الكويت - الكويت
}

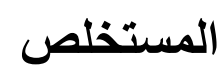

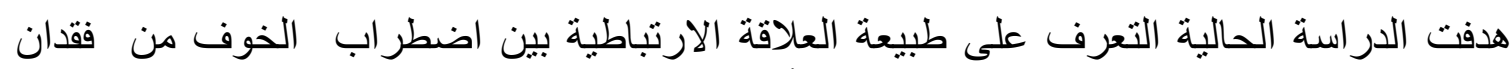

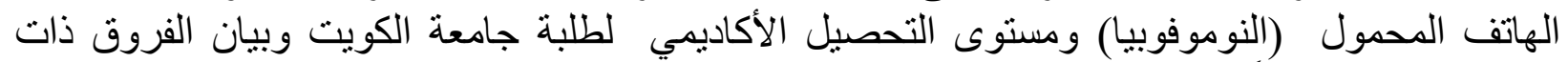

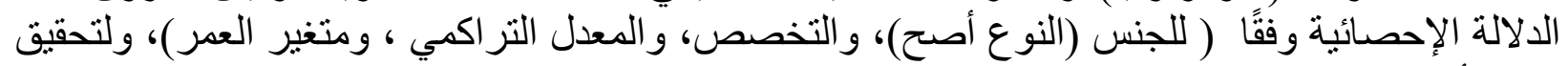

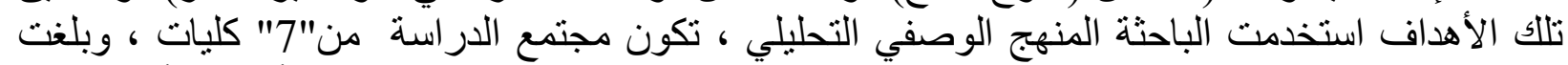

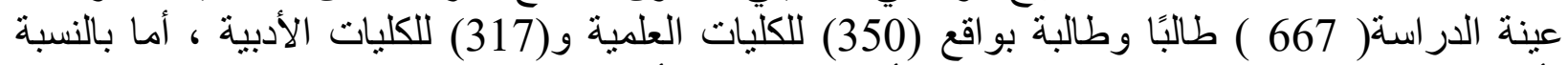

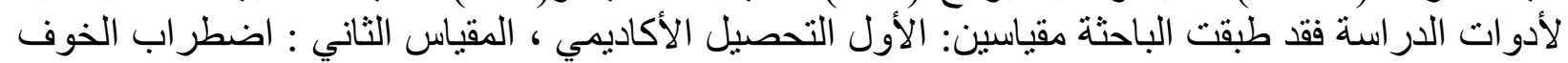

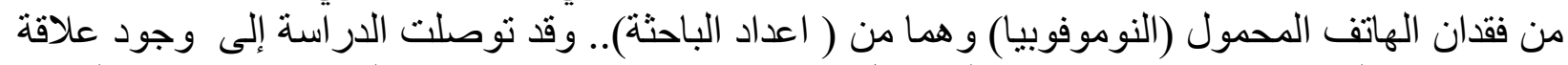

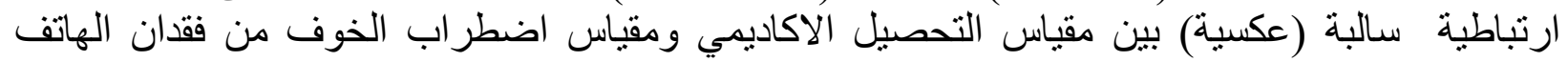

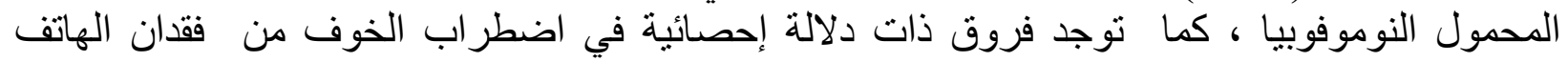

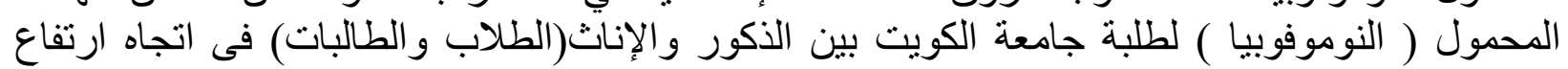

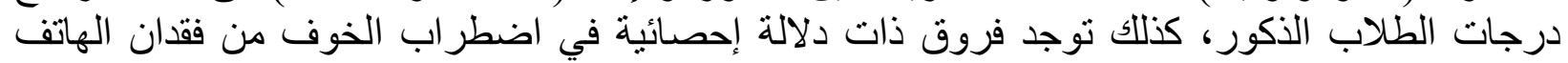

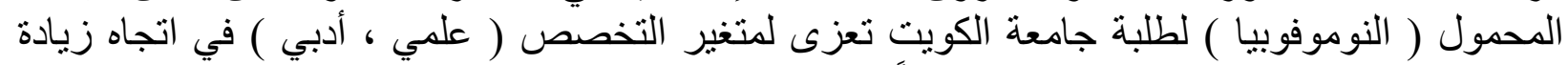

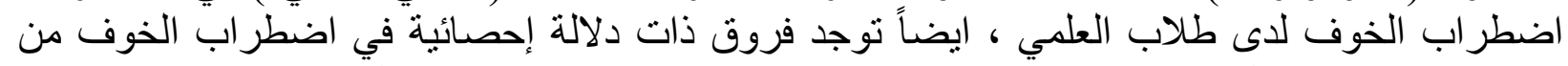

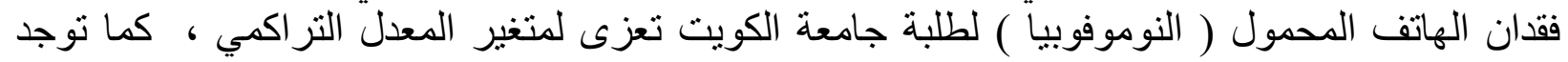

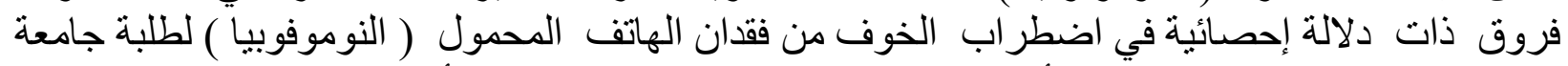

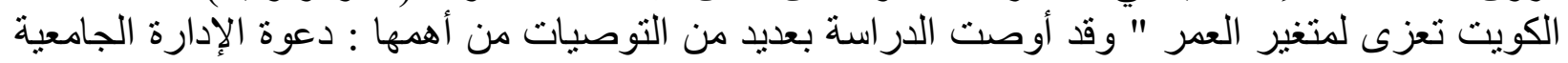

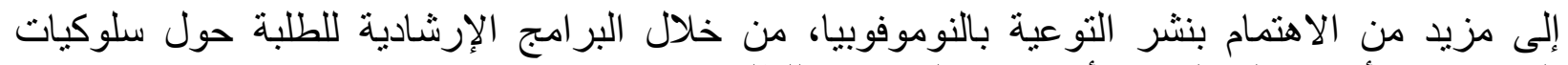

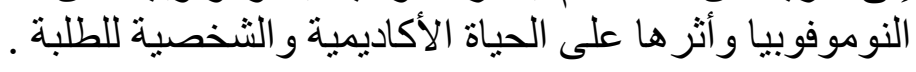

الكلمات المفتاحية : اضطراب الخوف من الهاتف المحمول - النوموفوبيا - الهاتف المحمول التحصيل الاكاديمي - طلبة جامعة الكويت الخيت من 
المقدمة

شهدت الالفية الثالثة عديد من التغييرات المتعاقبة والسريعة في كافة مجالات الحياة ، و التي مني

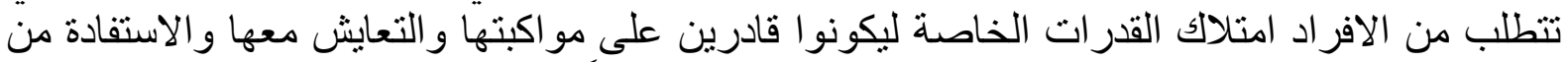

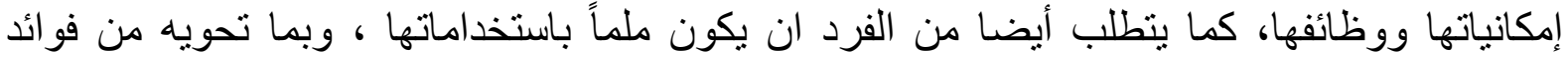

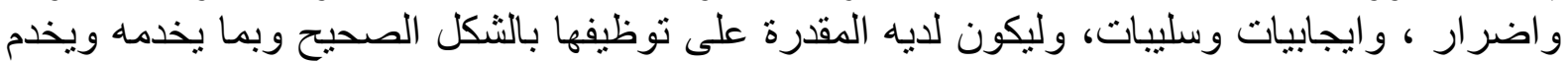

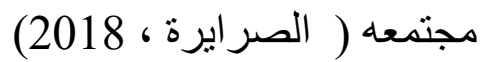

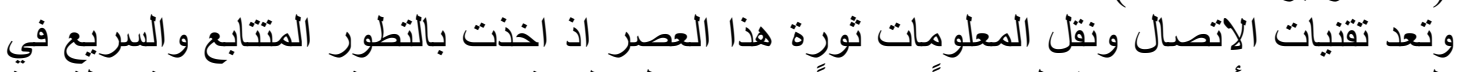

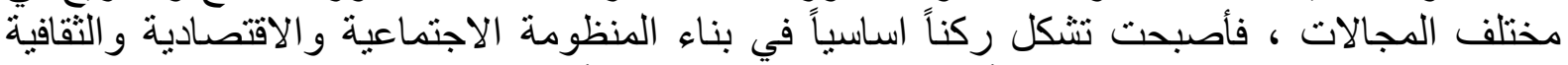

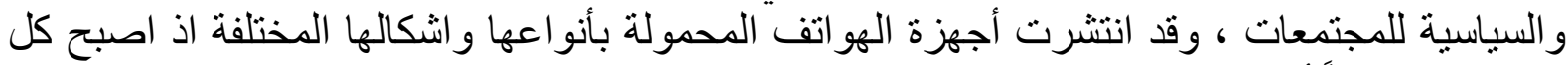

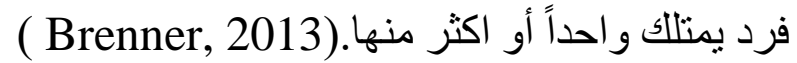

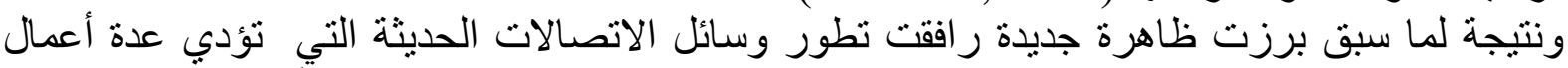

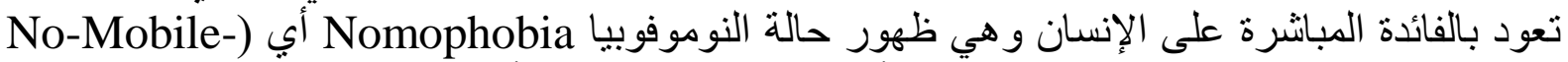
(Phone-Phobia

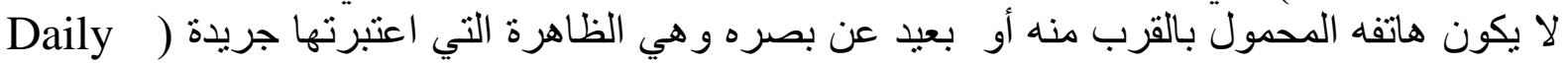

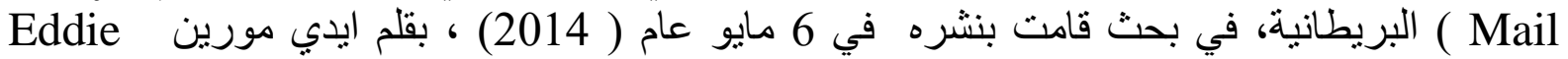
(بانها " اكبر فوبيا في العالم" . ( Maureen

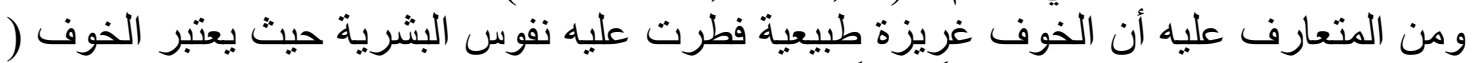

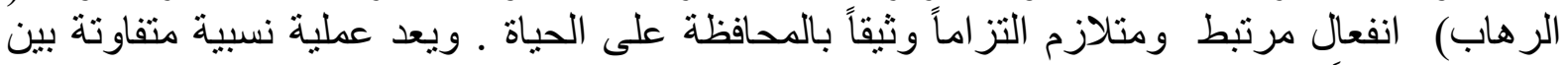

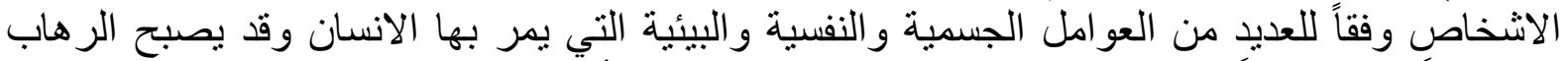

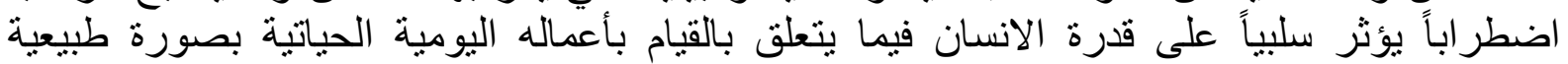

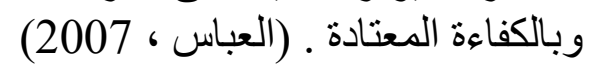

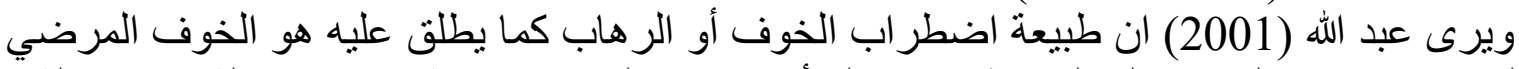

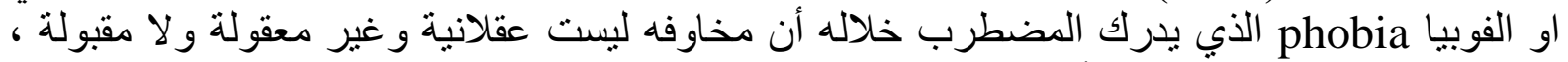

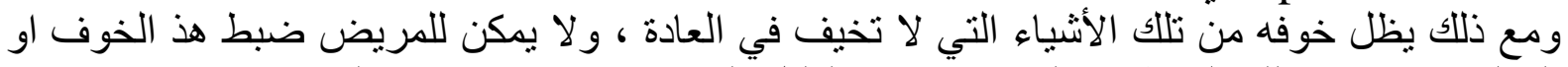

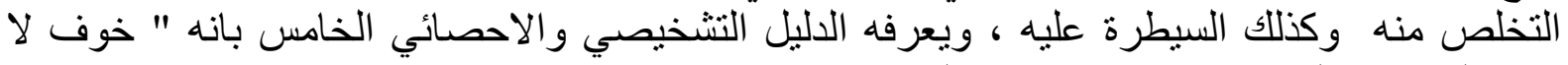

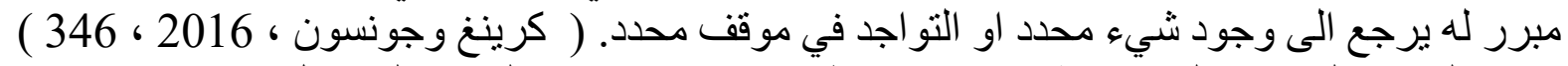

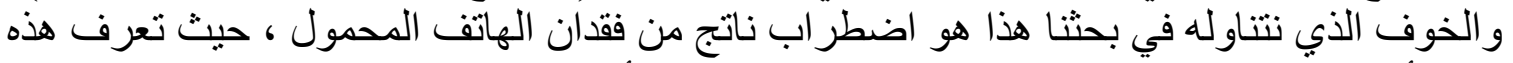

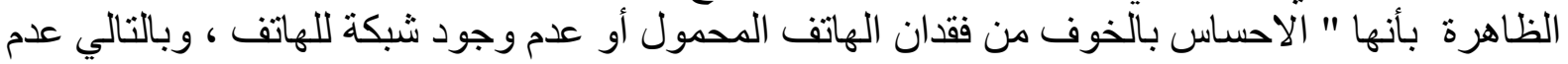

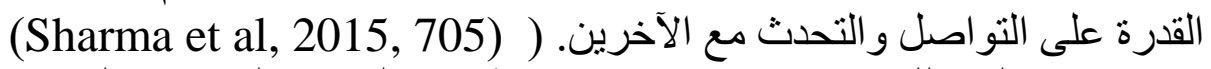

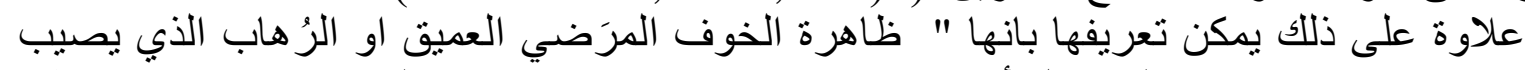

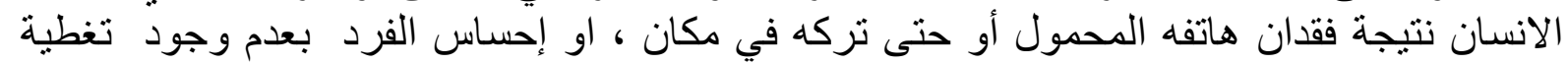

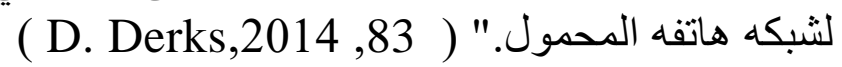
وقد ظهر هذا المصطلح بمسميات عديدة منها الخوف من فقدان الهاتف المحمول

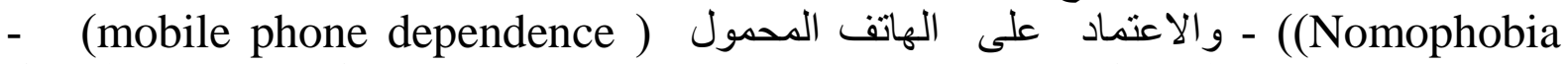

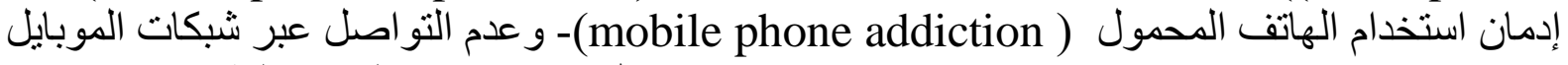
Presence ) و التواجد خارج نطاق تغطية (Not to communicate via mobile networks) ( Bragazzi,2014, 156) (outside the scope of coverage

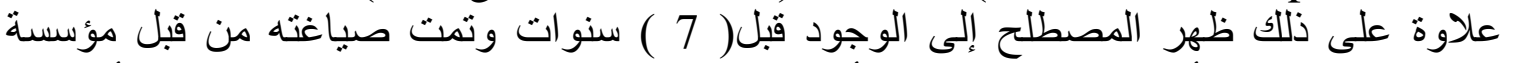
Secur Envoy

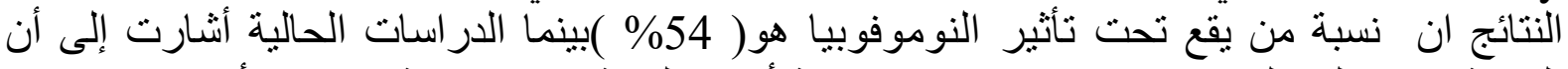

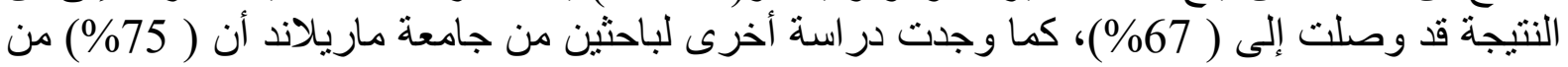




\section{العلاقة بين اضطراب الخوف من فقدان الهاتف المحمول ( النوموفوبيا ) ومستوى التحصيل الأكاديمي لطلاب جامعة الكوات الكويت}

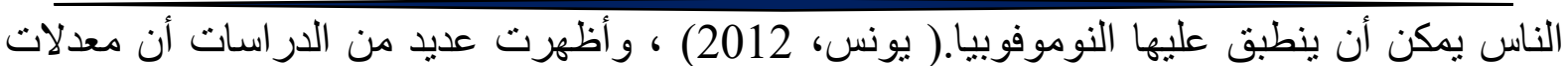

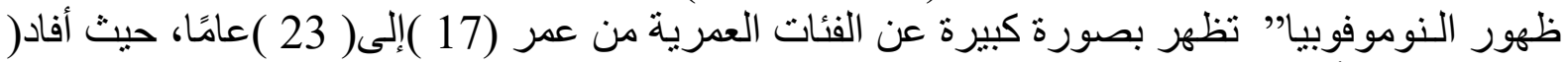

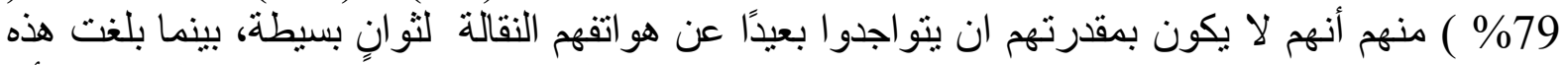

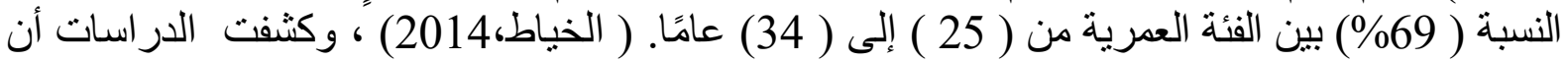

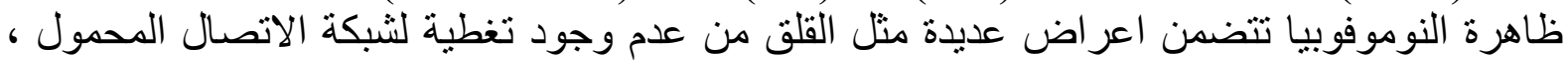

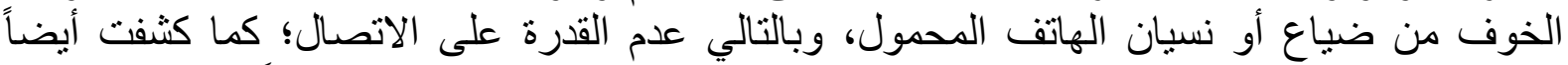

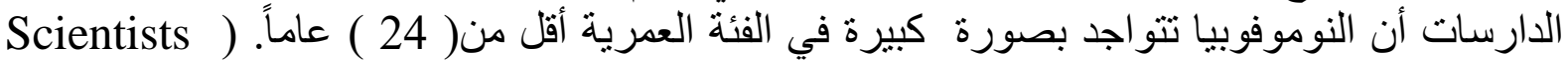

(Study Nomophobia, 2015

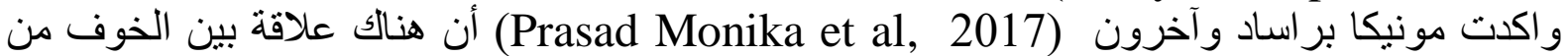

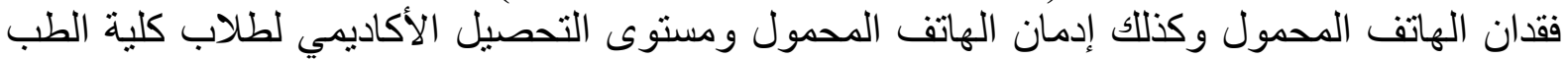

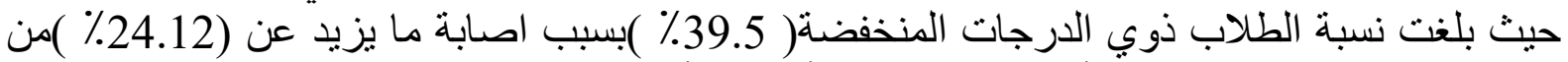
الطلاب بمرض النوموفوبيا ، الأمر الذي اثر على أدائه النهم الأكاديمي بطريقة سلبية.

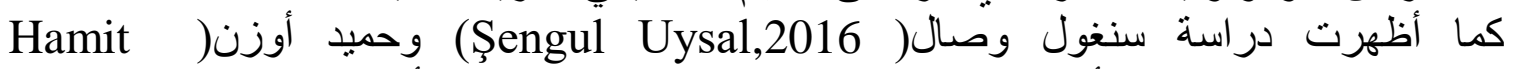

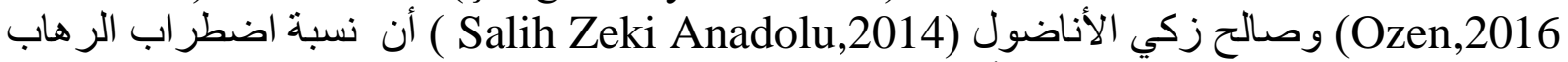

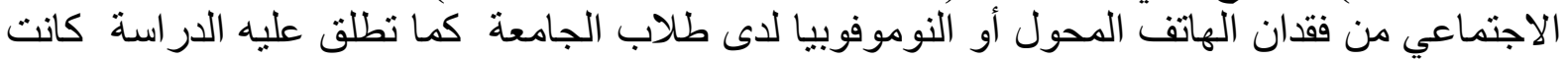

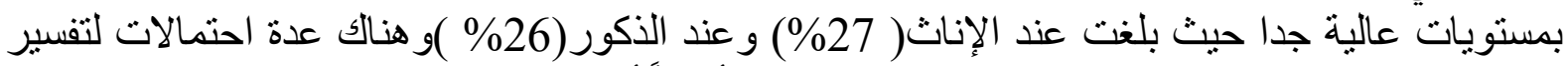

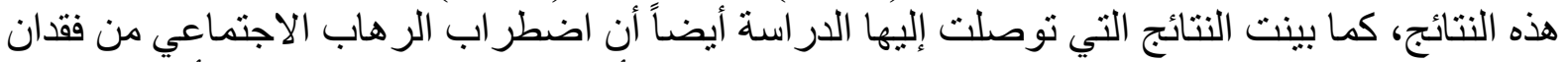

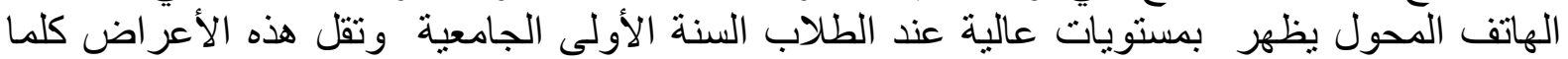

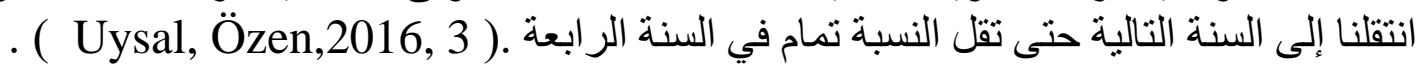

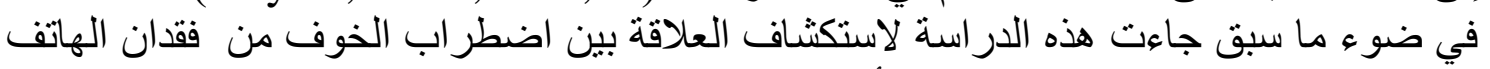

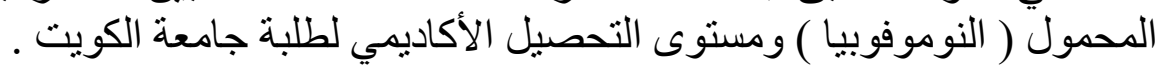

\section{مشكلة الاراسة - ماسة}

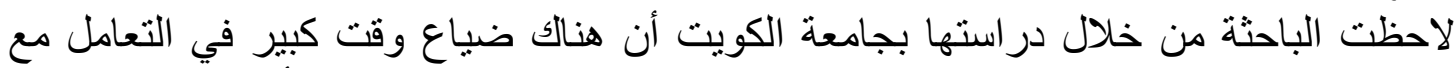

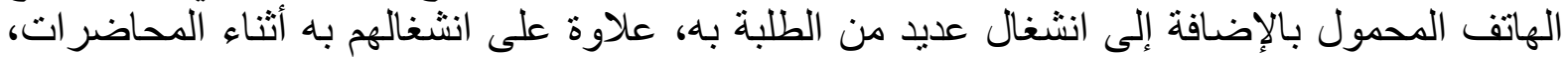

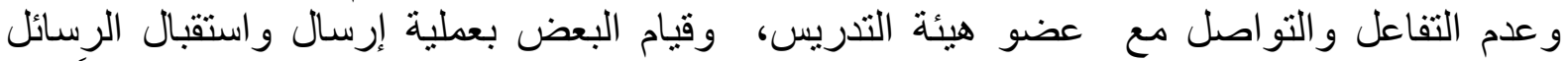

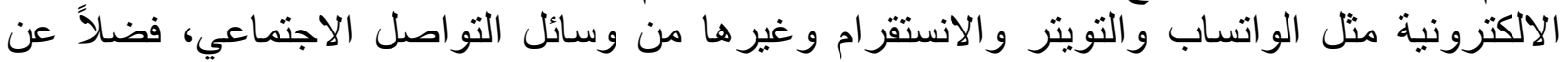

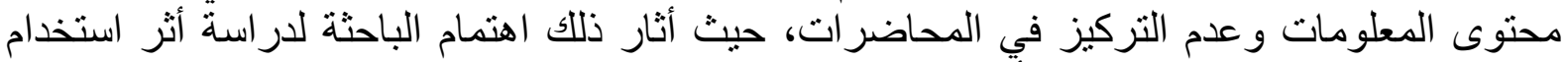

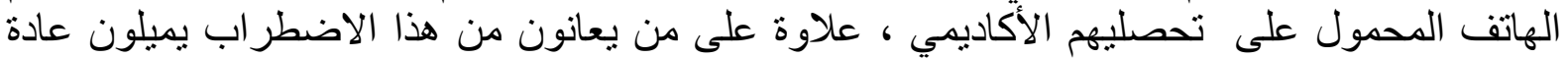

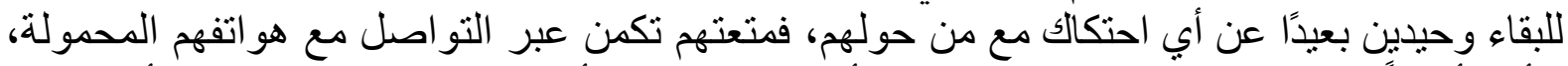

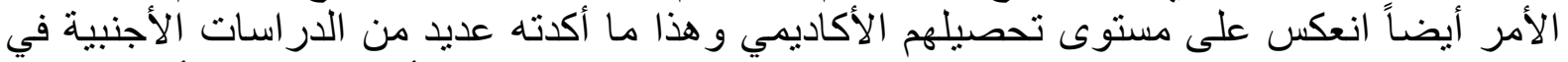

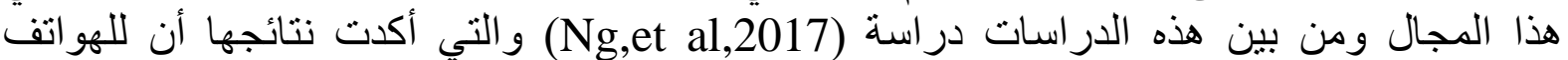

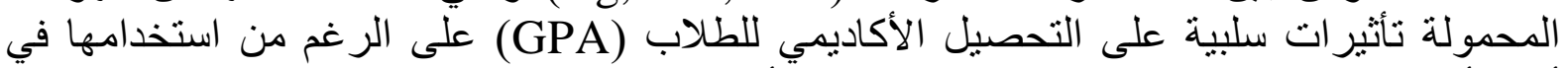

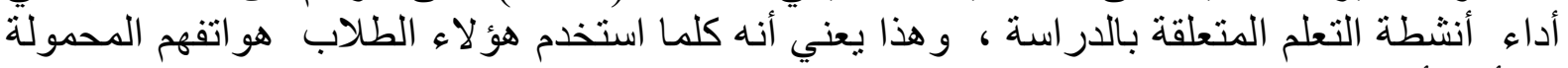

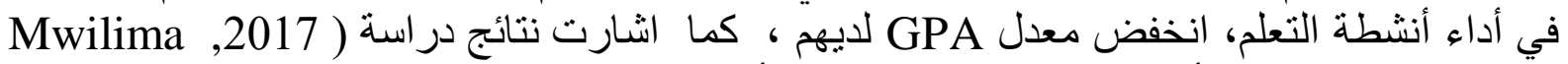
طولة Hangula

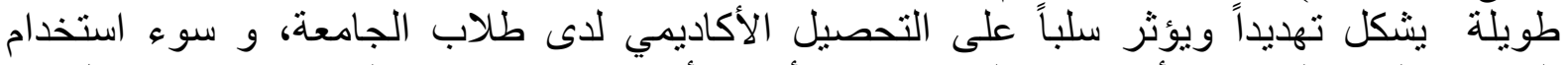

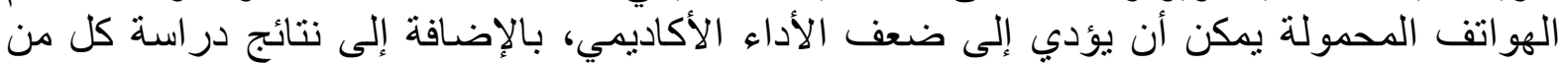
و التي بنيت أن هنالك بين استخدام الهاتف المحمول و التحصيل

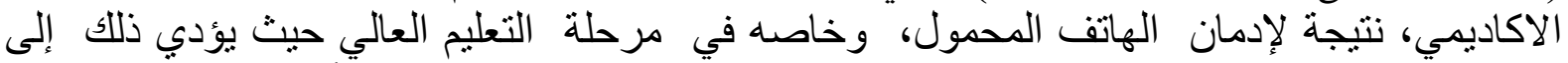

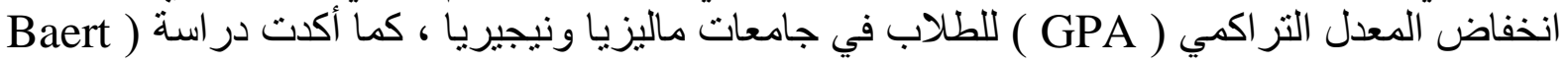




\section{العلاقة بين اضطراب الخوف من فقدان الهاتف المحمول ( النوموفوبيا ) ومستوى التحصيل الأكاديمي لطلاب جامعة الكوات الكويت}

(et al, 2018

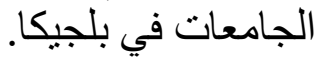
وتثير دراسة (Felisoni \& Godoi , 2018) إلى أن فقدان الاتصال بالهاتف المحمول

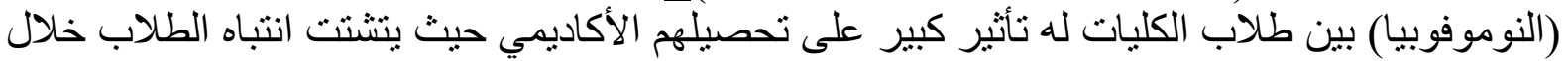

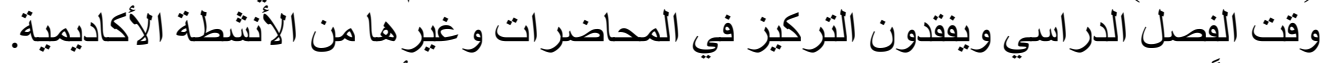

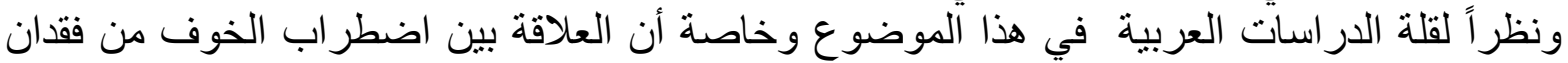

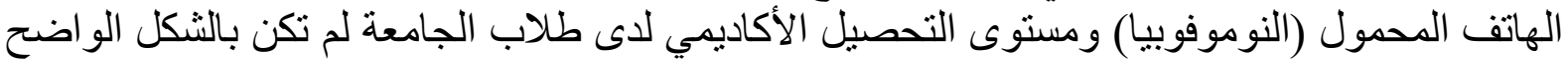

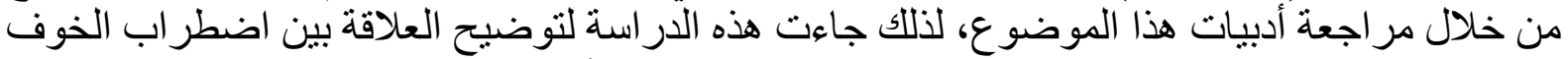

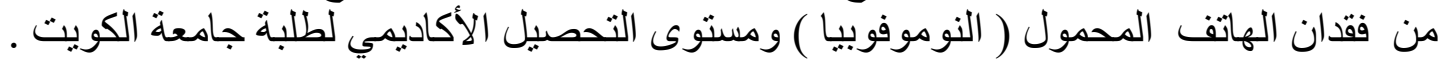

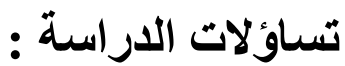 تتحدد تساؤلات الدر اسة في التالي :} 1. هل هناك علاقة ارتباطية بين اضطر اب الخوف من فقدان الهاتف المحمول (النوموفوبيا) ومستوى

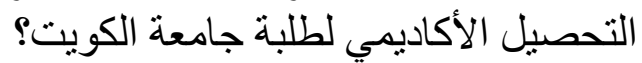
2. لا نوجد فروق بين الطلاب والطالبات في أثر اضطراب الخوف من فقدان الهاتف المحمول

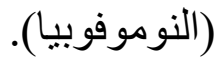
3. لاتوجد فروق بين طلاب التخصصات الأدبية وطلاب التخصصات العلمية في اضطر اب الخوف من

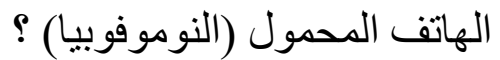
4. لا توجد فروق بين المرتفعين والمنخفضين في المعدل التراكمي في اضطراب الخوف من فقدان

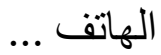
5. لا توجد فروق ذات دلالة إحصائية في اضطر اب الخوف من فقدان الهاتف المحمول ( النوموفوبيا ) و التحصيل الأكاديمي بين الطلاب الأصغر واتلفه الأكبر عمرًا.

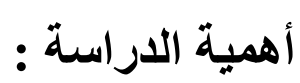

تتضح أهمية هذه الدر اسة علي المستوي النظري علي النحو التالي :

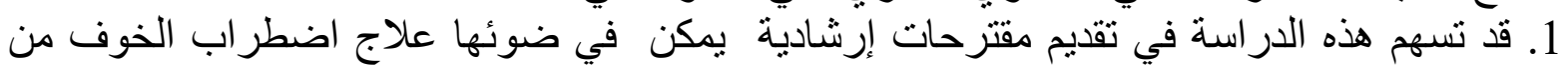

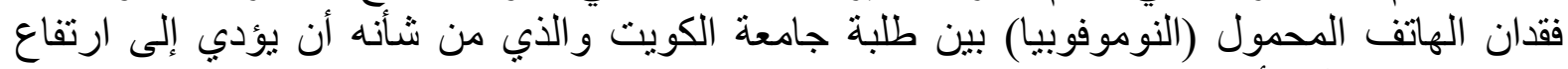
مستوى التحصيل الأكاديمي للطلاب. 2. تحاول هذه الدراسة إضافة جديد إلي المكتبة التربوية عن واقع اضطر الباب الخوف من فقدان الهاتف

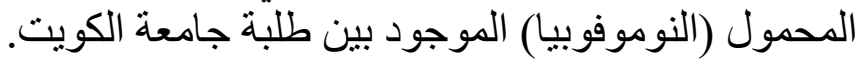

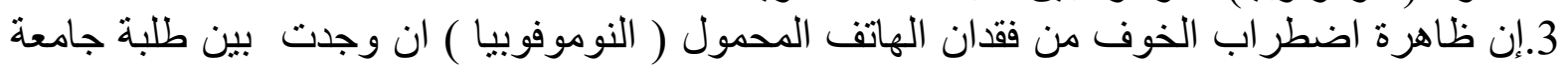

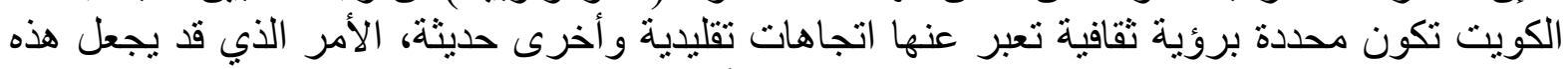

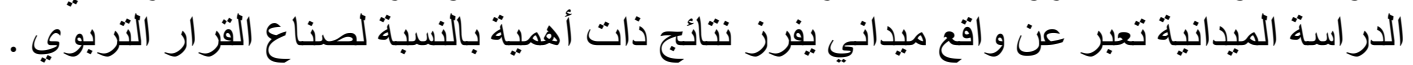

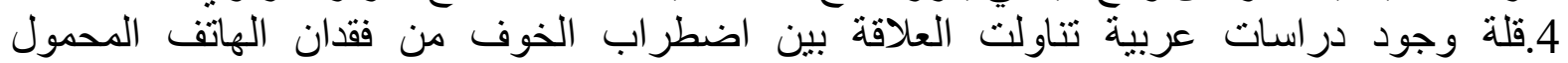

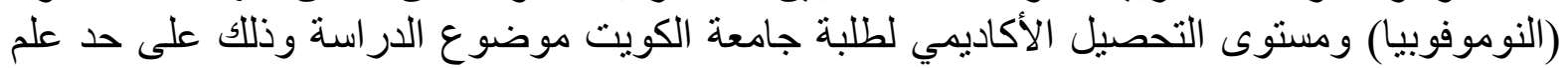

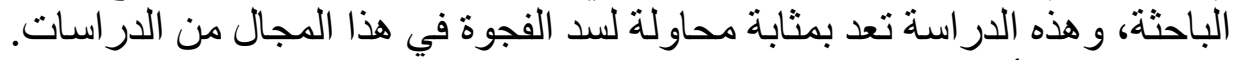
بينما تتضح الأهية التطبيقية فيما يلي:

1.نسليط الضوء على هذه الظاهرة وبيان أهميتها وطر ائق الوقاية منها وتقيميم الإرشادات المتعلقة بها.

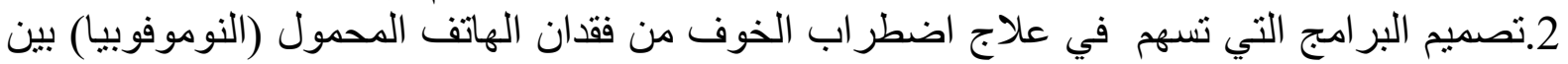

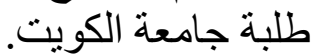


العلاقة بين اضطراب الخوف من فقدان الهاتف المحمول ( النوموفوبيا ) ومستوى التحصيل الأكاديمي لطلاب جامعة الكوانف الكميت

3. الاستفادة من المقترحات التي ستسفر عنها الدراسة لبحوث لاحقة مستقلية تفيد المجتمع في دولة

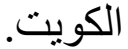

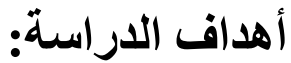

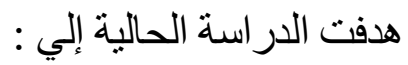
1. الكثف عن العلاقة الارتباطية بين اضطراب الخوف الإبـ من فقدان الهاتف المحمول (النوموفوبيا)

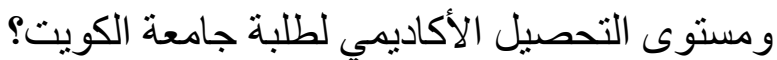
2. التعرف على الفروق بين الطلاب والطالبات في أثر اضطر الثرب الخوف من فقان الهاتف الدحمول

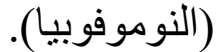
3. بيان الفروق بين طلاب التخصصات الأدبية وطلاب التخصصات العلمية في اضطر اب الخوف من

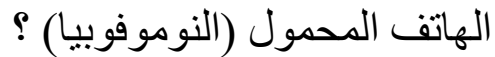
4. التعرف على الفروق بين المرتفعين والمنخفضين في المعدل التراكمي في اضطراب الخوف من فقدان الهاتق ....

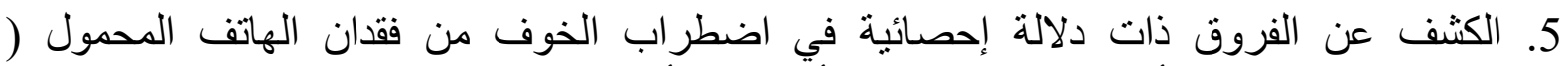
النوموفوبيا ) و التحصيل الأكاديمي بين الطلاب الأصغر و الأكبر عمرًا.

\section{مصطلحات الاراسة}

\section{PHOBIA}

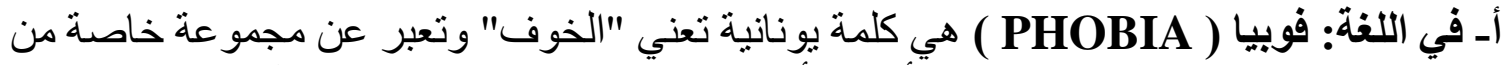

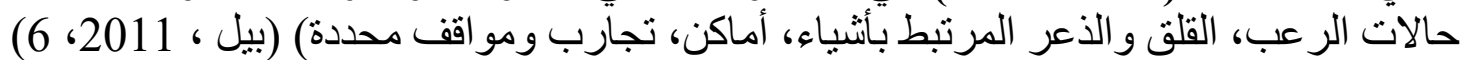

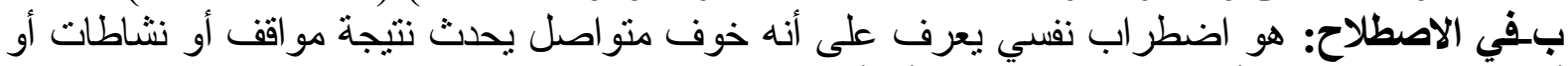

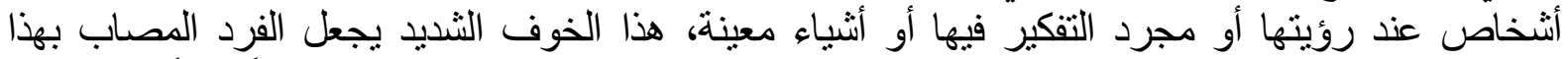

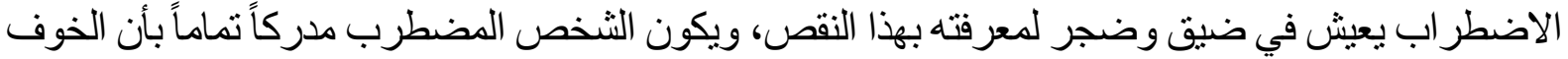

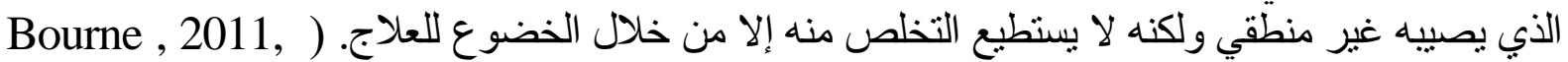

2-2 اضطراب الخوف من فقدان الهاتف المحمول ( النوموفوبيا - NOMOPHOBIA )

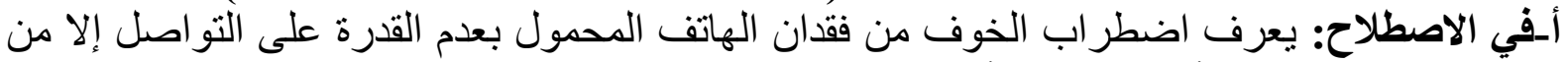

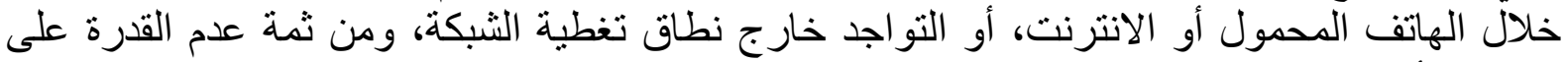

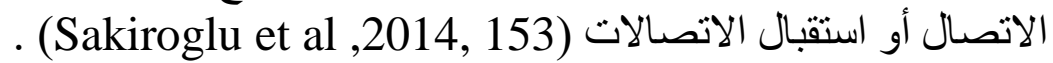

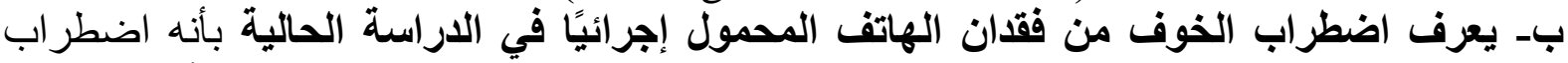

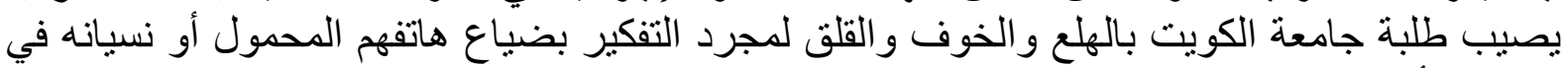

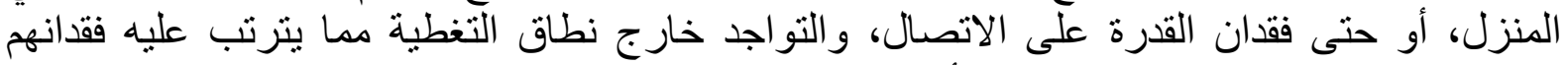
لتركيز هم و انخفاض مستوى تحصليهم الأكاديمي. ابعاد للنوموفوبيا

استخلصت در اسة يلدير ايم (2014) أربعة أبعاد للنوموفوبيا تلتمثل في: البعائ

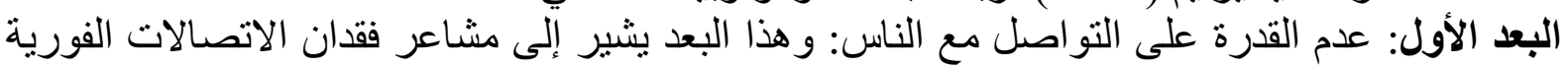

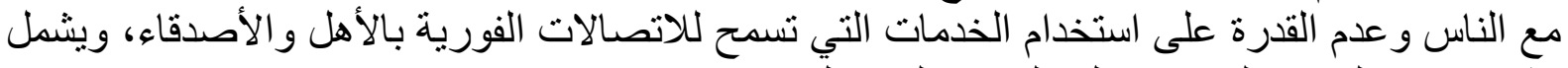

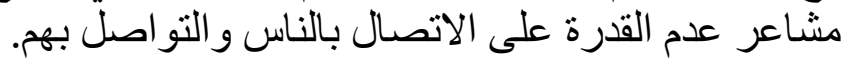
البعد الثاني: فقدان الترابط: ويرتبط هذا البعد بمشاعر فقدان الاتصال في كل مكان وتتمثل في قطع هوية

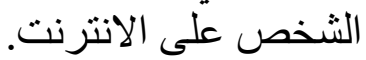


العلاقة بين اضطراب الخوف من فقدان الهاتف المحمول ( النوموفوبيا ) ومستوى التحصيل الأكاديمي لطلاب جامعة الكوات الكويت

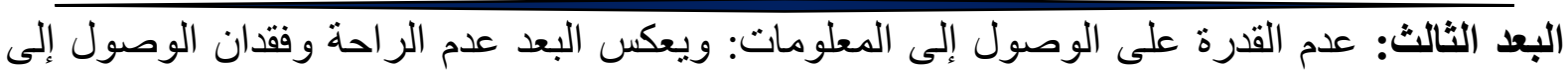

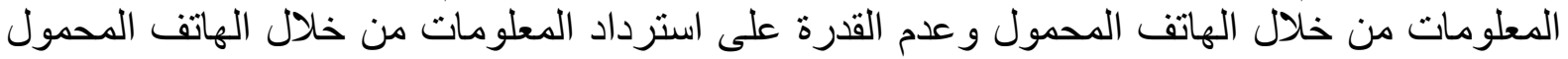

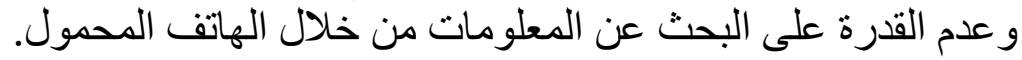

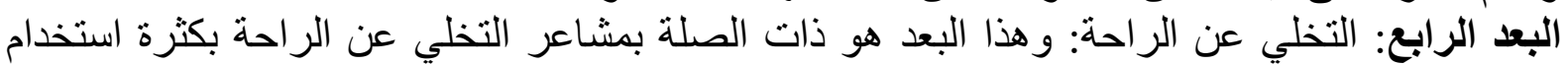

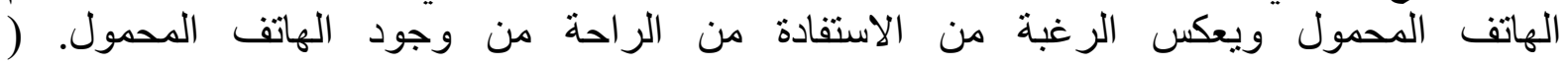

.(Yildirim,2014

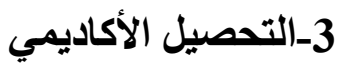

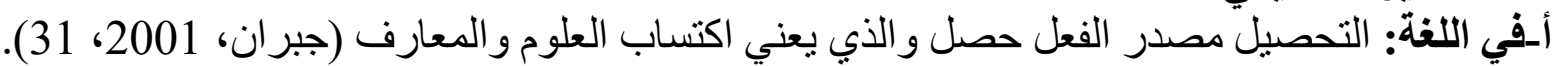

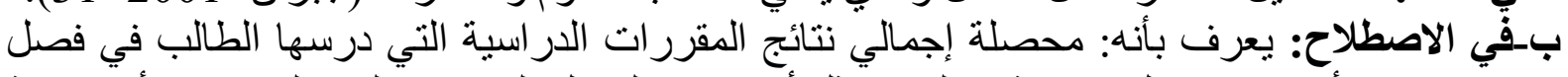

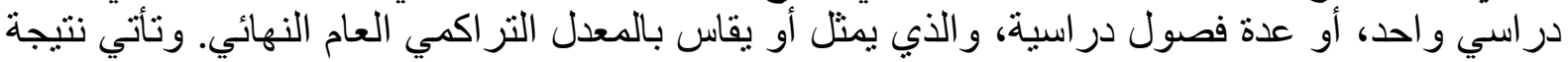

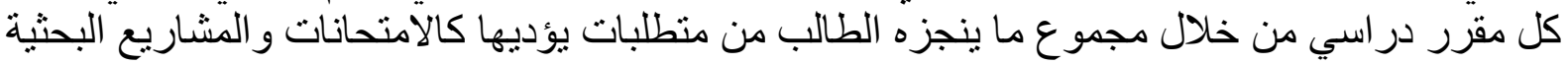

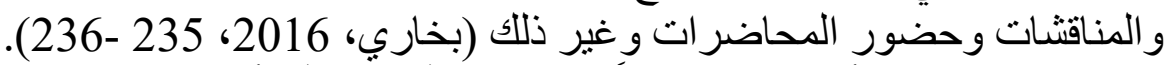

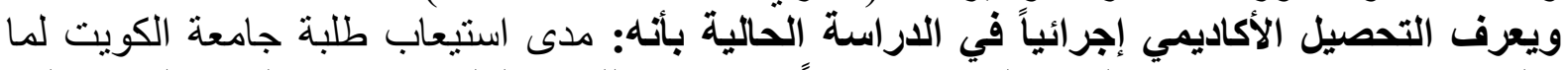

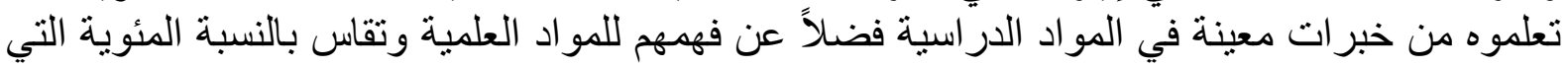

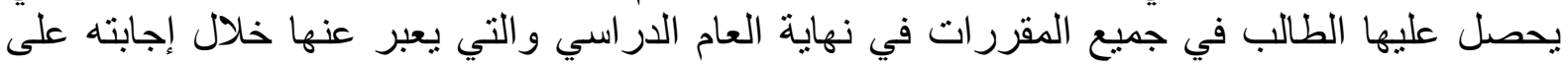

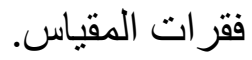

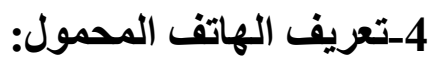
في اللغة: بطلق على الهاتف النقال عدة تسميات: الهاتف النقال، الهاتف المحمول، الهاتف الهُ النقات الخلوي. وهو

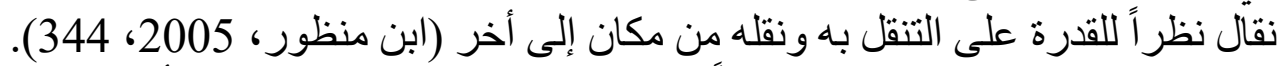

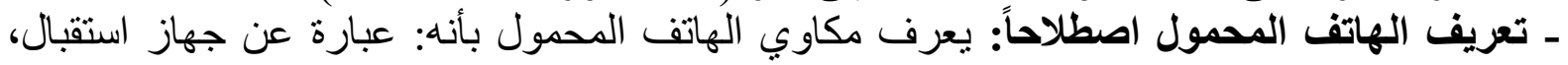

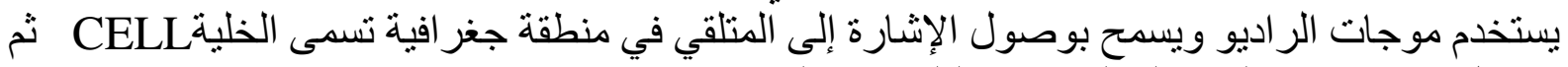

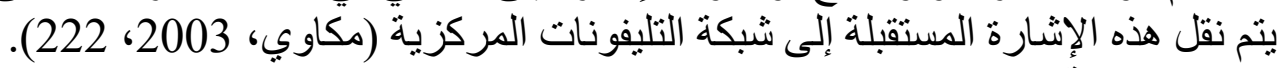
حدود الاراسة الاستة 1 ـ الحدود الموضوعية: اضطراب الخوف من فقدان الهاتف المحمول ( النوموفوبيا ) ومستوى

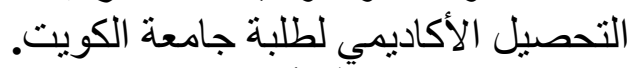
2. الحدود البثرية: أجريت الدراسة على عينه من طلبة جامعة الكويت بثقيه الأدبي و العلمي، (الذكور

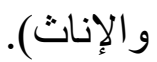
3. الحدود الزمنية: أجريت بالفترة الزمنية 2018- 2019 وذللك متضمناً الحصول على المراجع

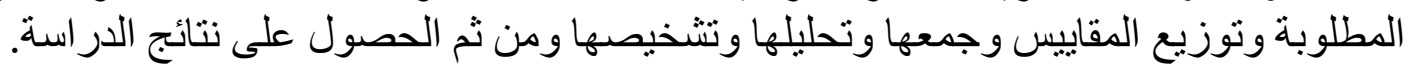

دراسات السابقة

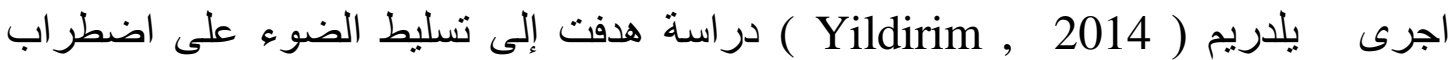

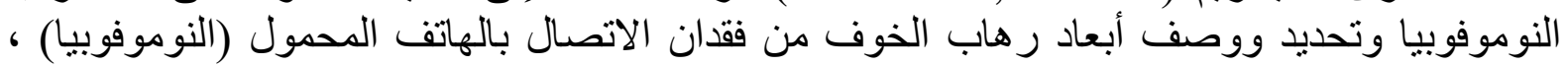

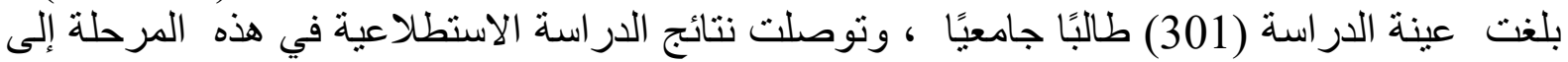

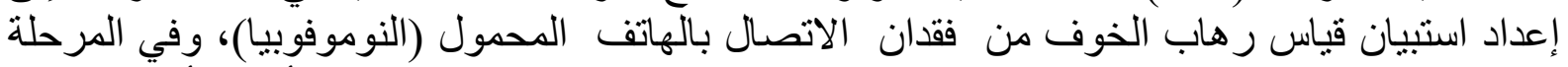

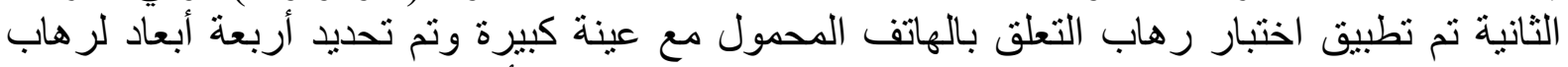

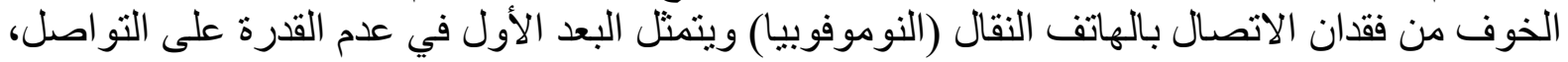

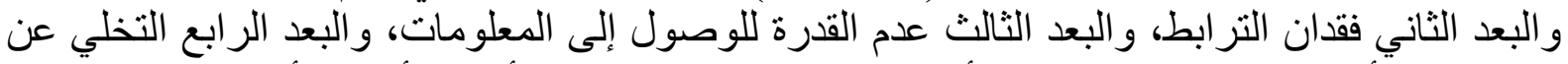

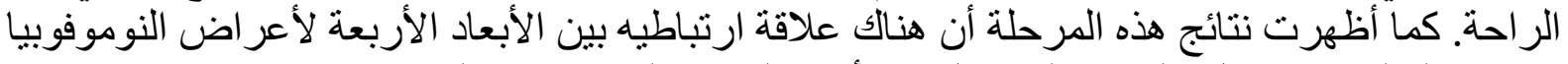

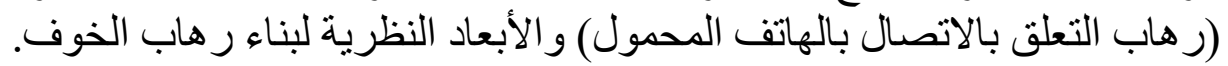




\section{العلاقة بين اضطراب الخوف من فقدان الهاتف المحمول ( النوموفوبيا ) ومستوى التحصيل الأكاديمي لطلاب جامعة الكوات الكويت}

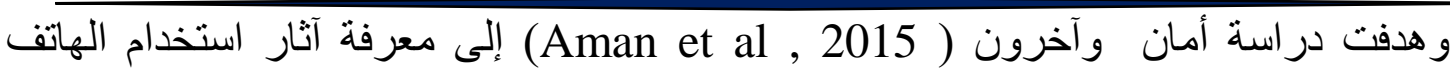

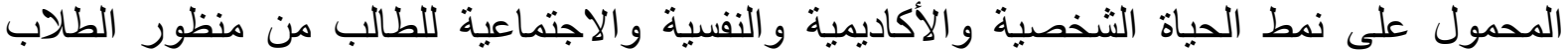

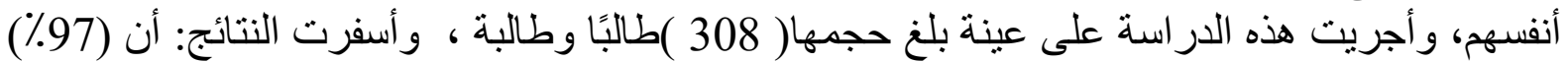

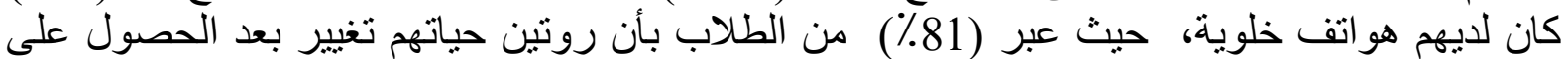

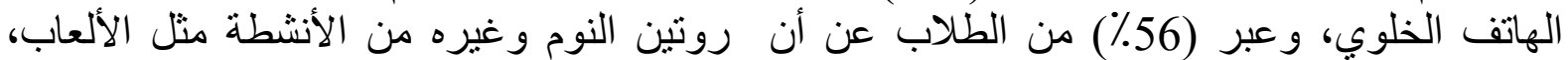

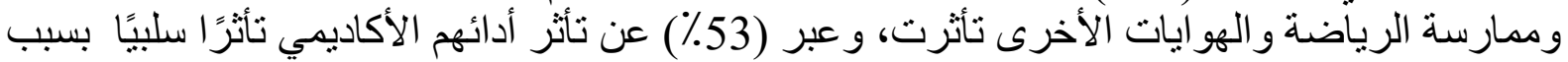

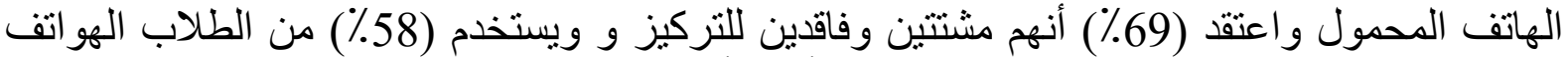

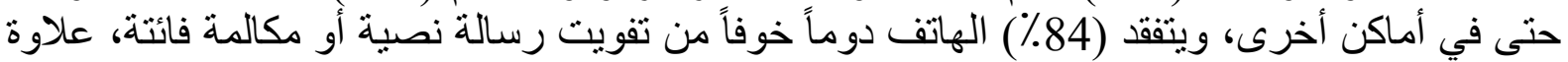

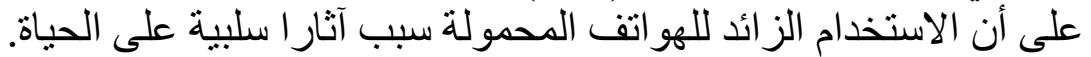

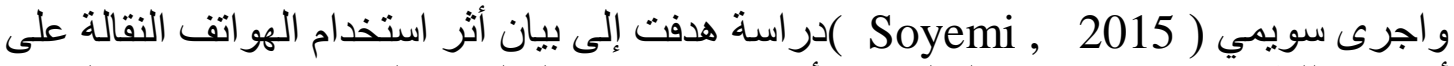

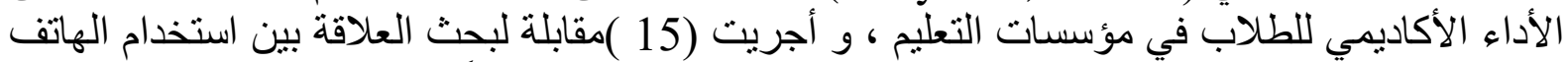

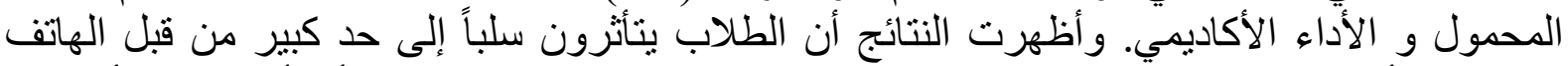

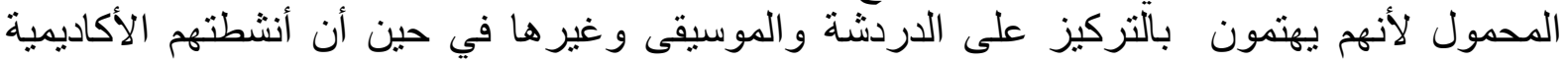

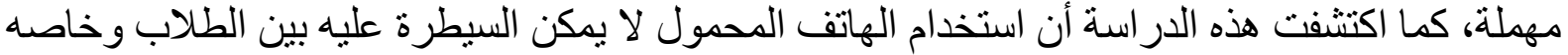
في المر احل الأولى من الجامعة و الذي يعد السبب الرئيسي لضعف الني لأداء الأكاديمي بين الطلاب.

ثم اجرى سونداري (2015, Sundari ) دراسة هدفت إلى التعرف على الجى مدى استخدام الهاتف

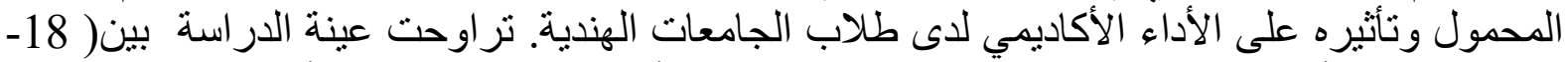

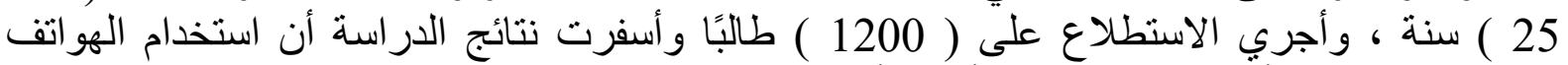
المحمولة في الكلية أدى إلى انخفاض الأداء الأكاديمي.

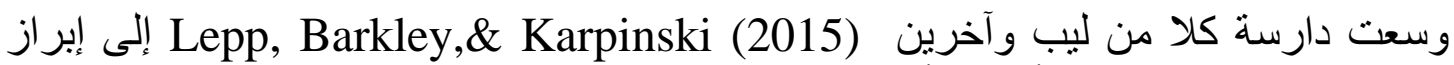

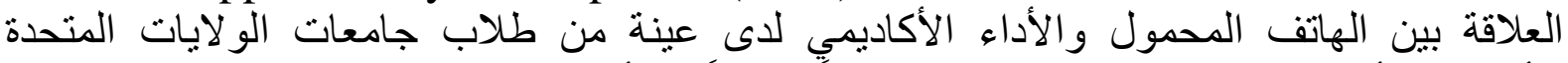

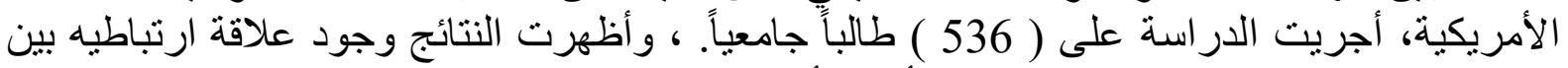

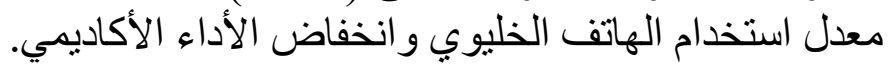

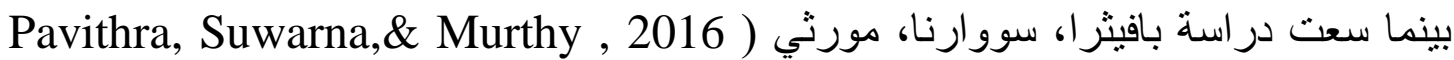

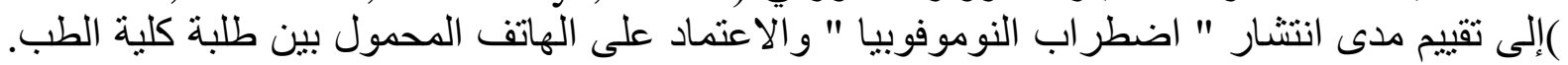

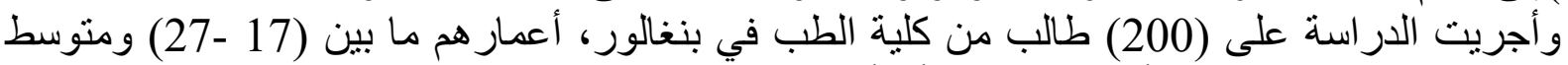

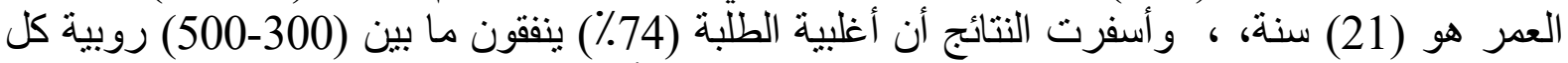

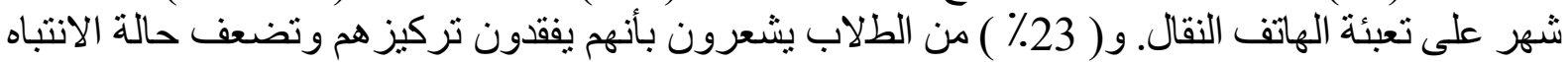

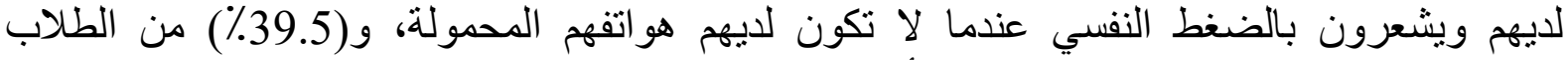

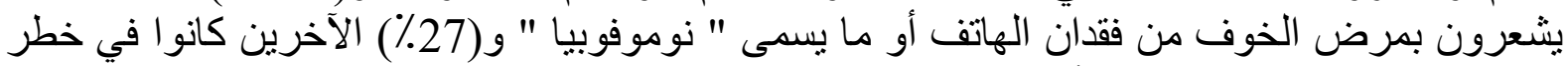
تطور الثعور بالنوموفوبيا، كما أوضحت النتائج زيادة انتشار نوموفوبيا بينا بين جيل الثباب.

كما اجرى ماهيير وآخرون ( Mihir et al 2016) دراسة هدفت إلى تقييم مشاركة الهاتف

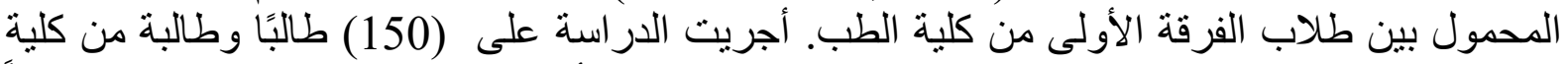

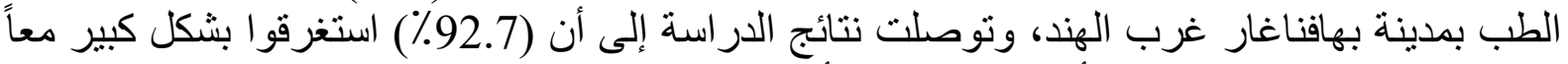

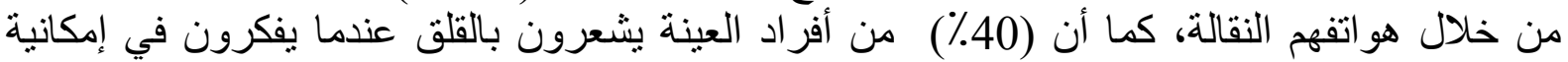

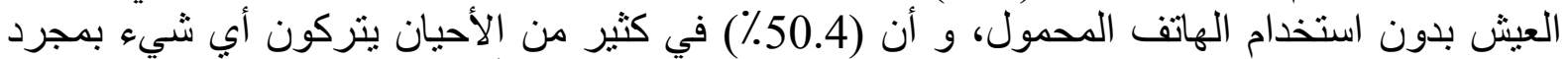

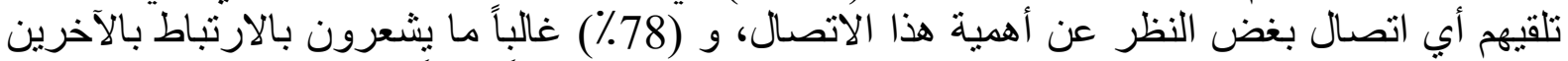

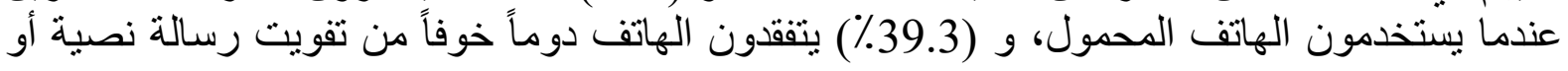


العلاقة بين اضطراب الخوف من فقدان الهاتف المحمول ( النوموفوبيا ) ومستوى التحصيل الأكاديمي لطلاب جامعة الكواب الكويت المحول

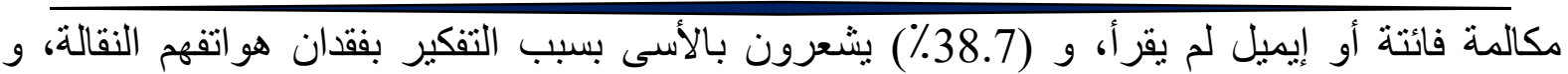

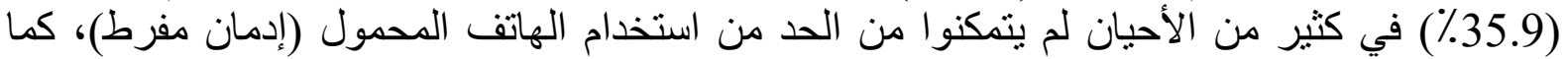

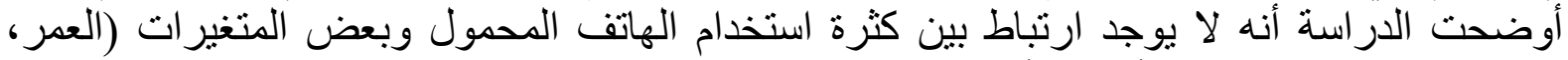
و النوع، ودخل الفرد، و عدد أفراد الأسرة، و الإنفاق على الهاتف).

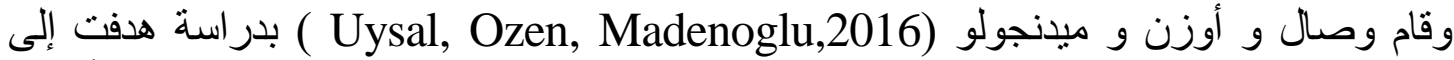

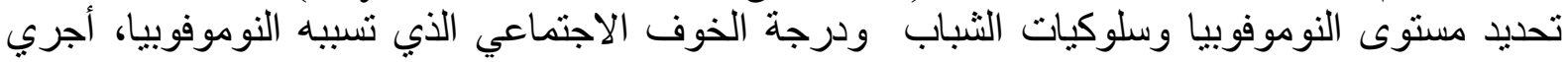

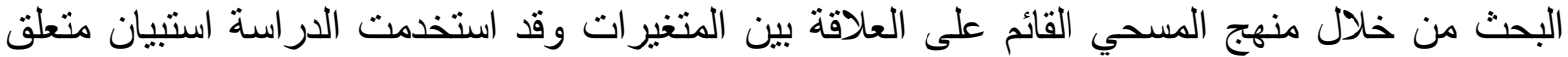

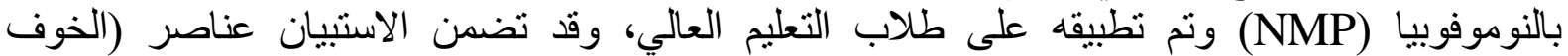

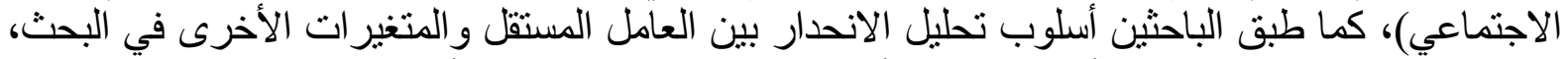

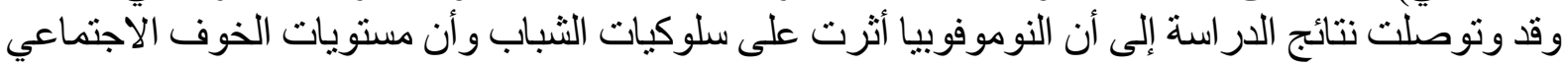
تزيد بصفة مستمرة في وجود النوموفوبيا.

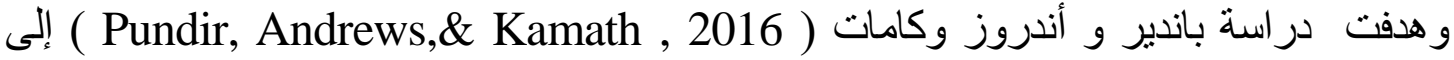

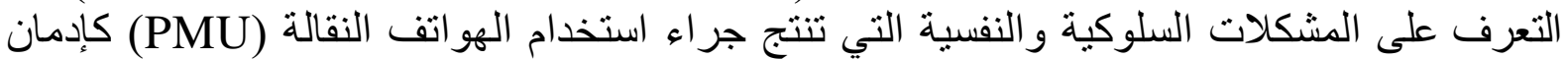

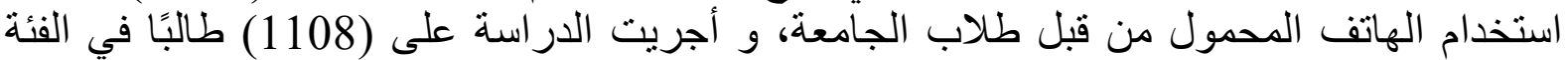

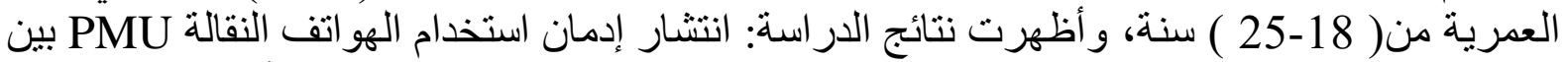

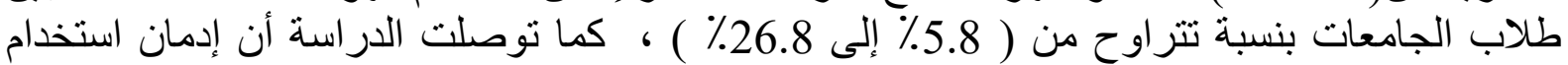

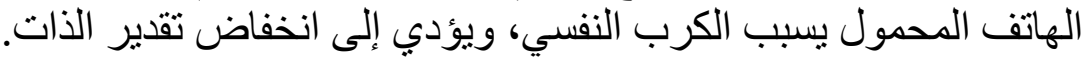

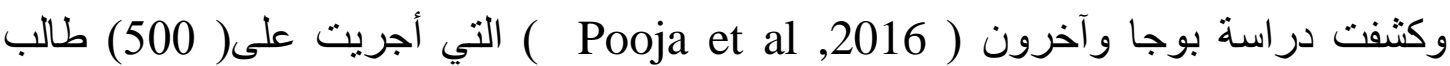

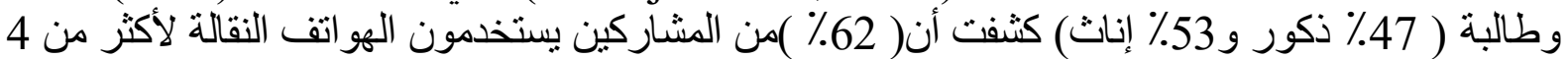

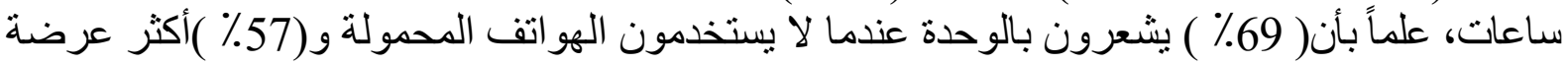
ل الخطر الإصابة نوموفوبيا.

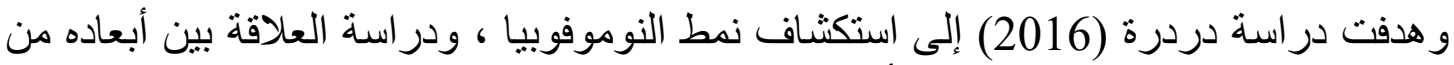

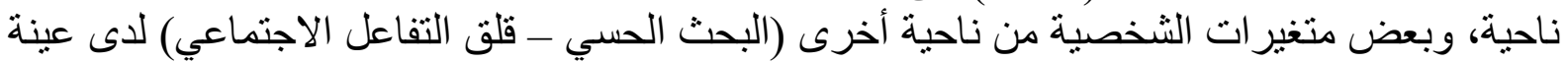

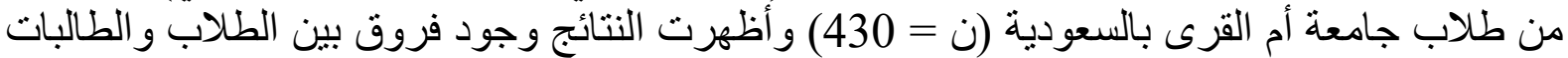

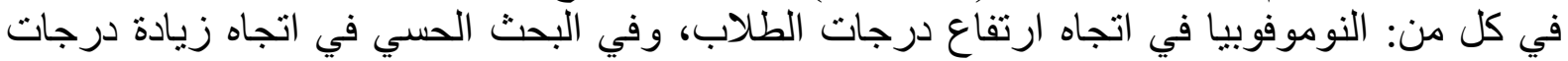

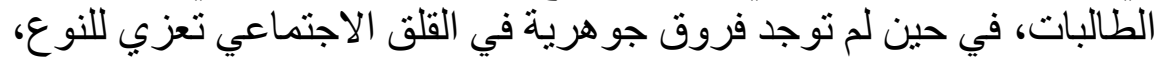

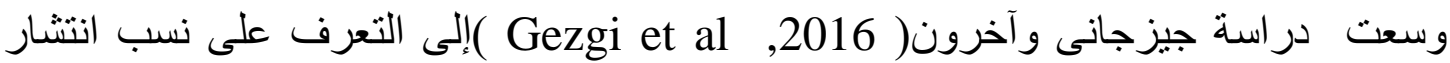

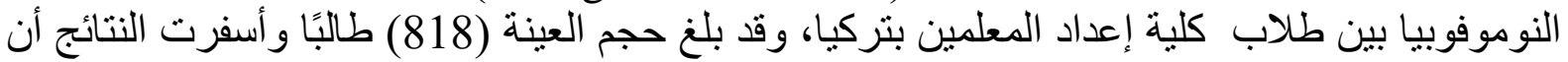

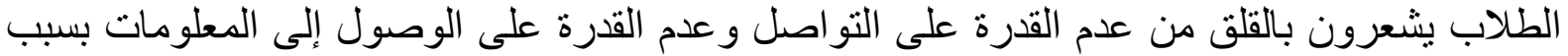

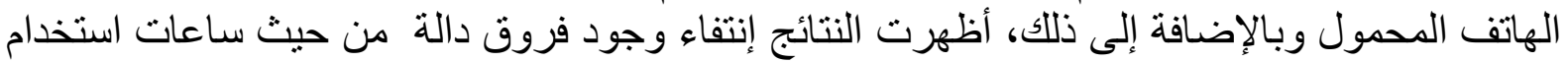

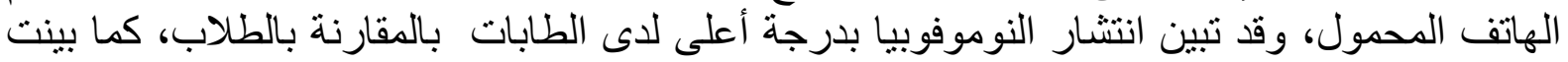

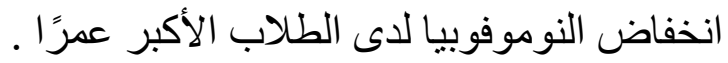

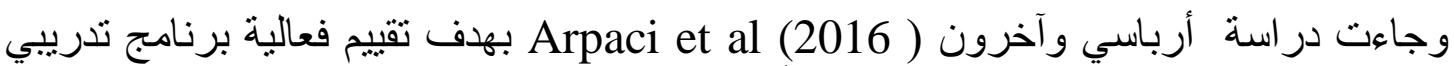

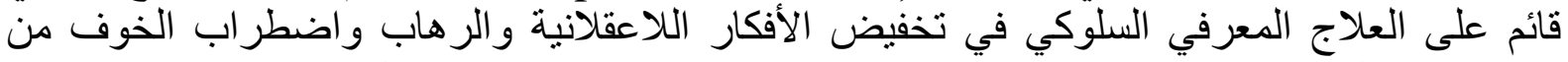

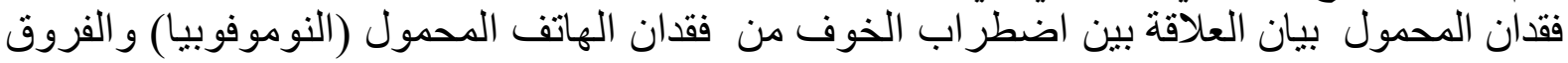

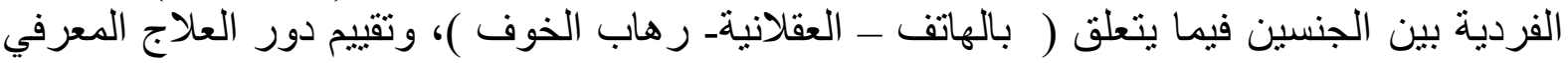

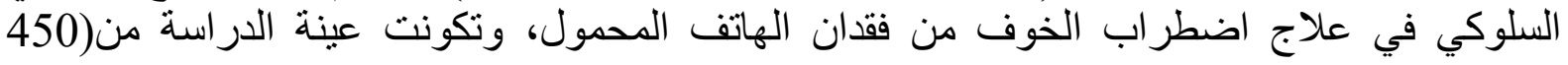




\section{العلاقة بين اضطراب الخوف من فقدان الهاتف المحمول ( النوموفوبيا ) ومستوى التحصيل الأكاديمي لطلاب جامعة الكوات الكويت}

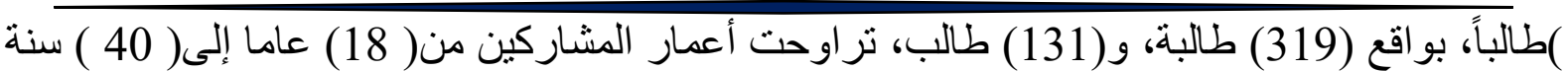

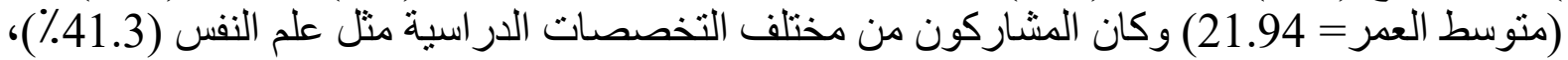

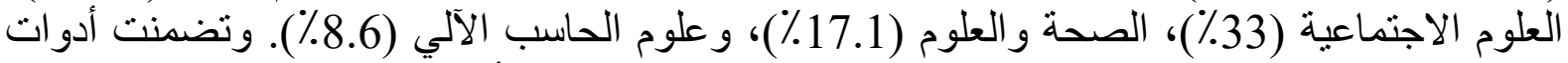

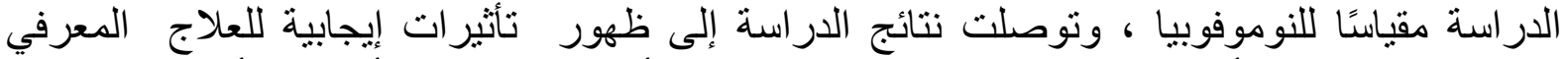

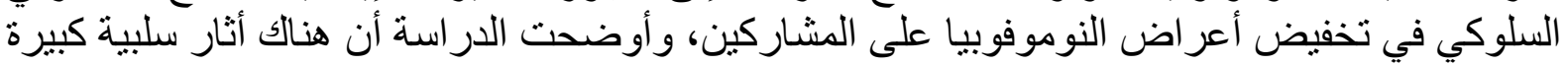

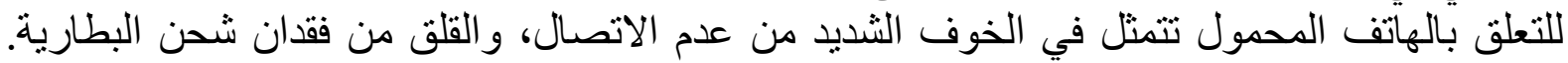

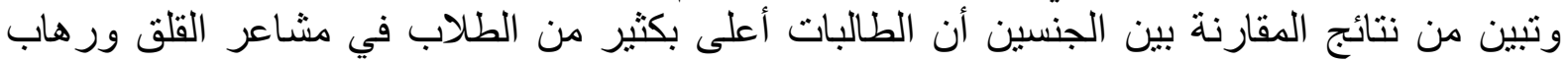
الخوف من فقدان الهاتف المحمول.

وقام كلا من ديريك و آخرين ( 2016, Dirik, and Pekel ) بدراسة هدفت إلى: تقييم إدمان

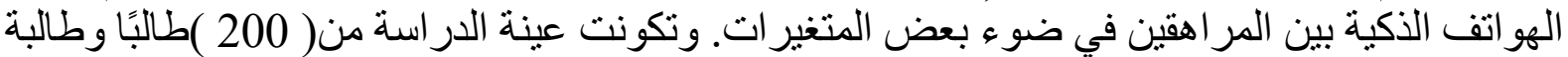

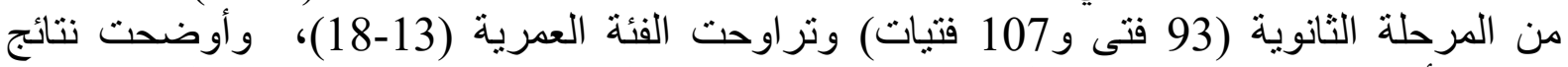

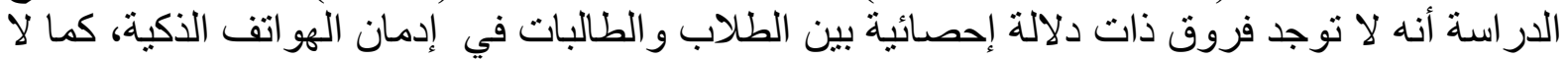

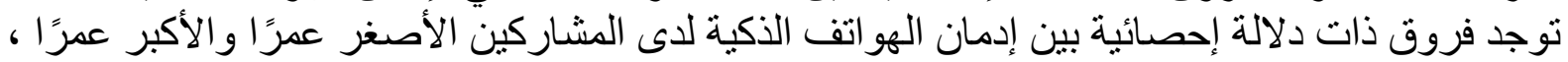

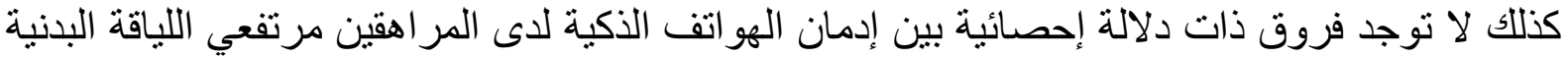

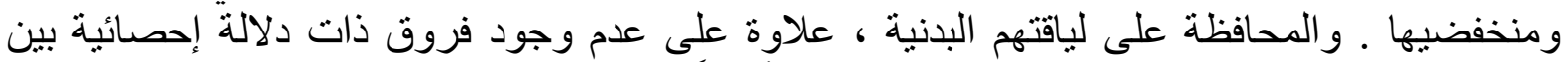

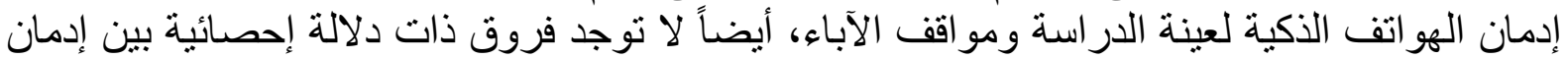

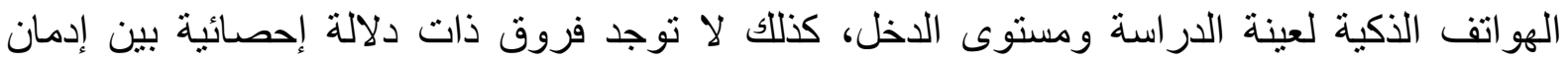
الهو اتف الذكية لعينة الدراسة و التحصيل الأكاديمي.

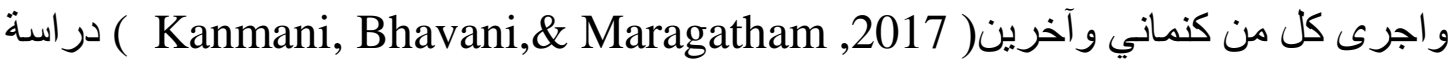

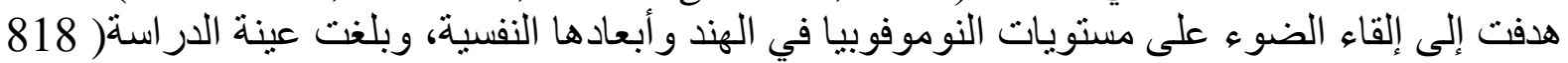

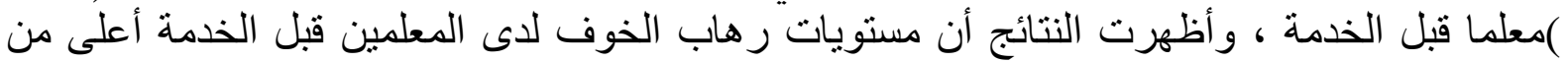

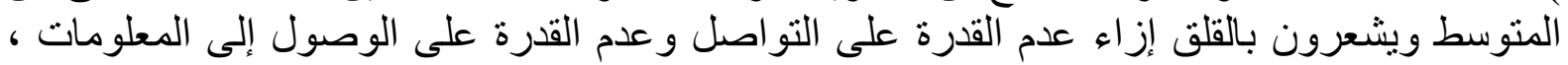

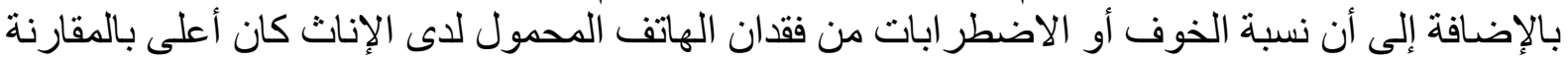

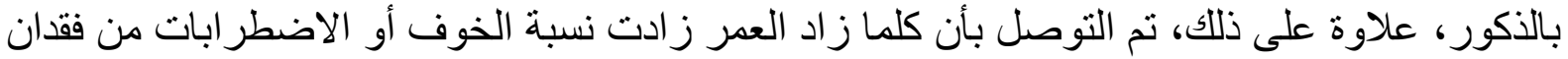

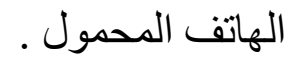

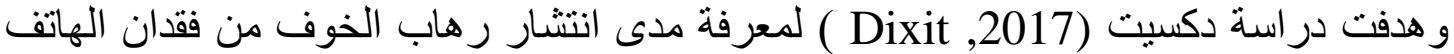

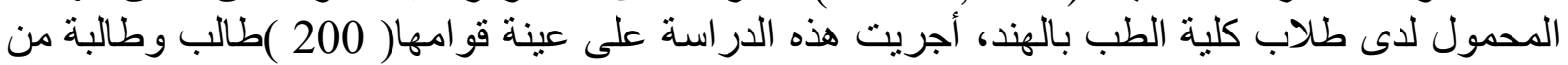

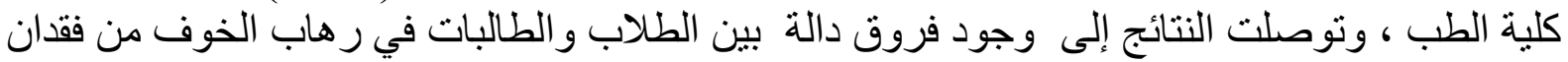

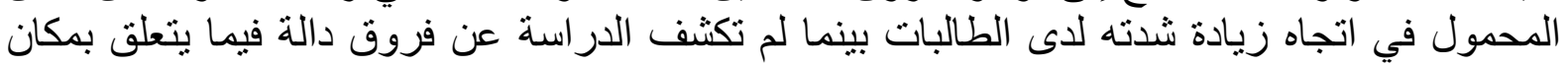

وقام البلهان وآخرون (Al-Balhan et al 2018 ) بدراسة الخوف من فقدان الهاتف المحمول (

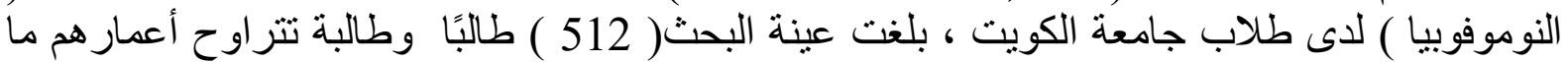

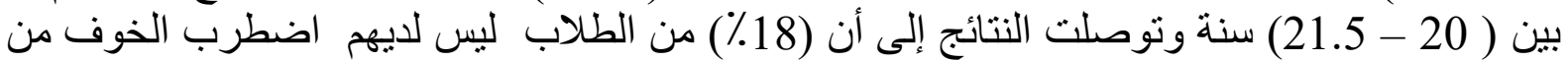

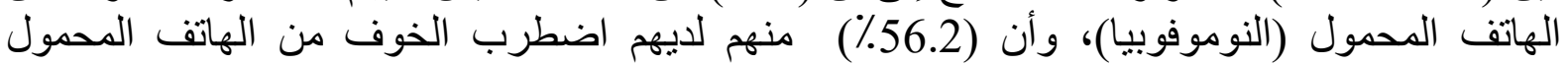

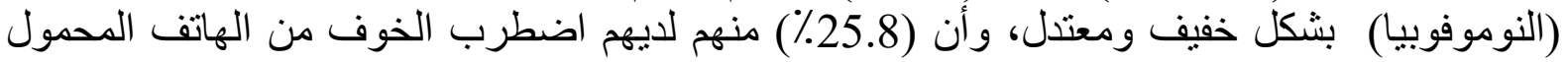
(النوموفوبيا) بشكل شديد

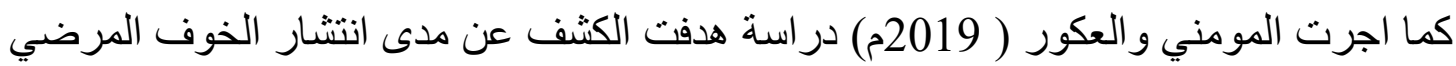
من فقدان الهاتف النقال (النوموفوبيا) لاى طلبة جامعة اليرموك، بالإضافة إلى فحص القدرة التنبؤية 


\section{العلاقة بين اضطراب الخوف من فقدان الهاتف المحمول ( النوموفوبيا ) ومستوى التحصيل الأكاديمي لطلاب جامعة الكوات الكويت}

للعو امل الديمغر افية (الجنس، والكلية، وعدد سنوات امتلاك الهاتف، وطبيعة السكن، ومكان الإقامة،

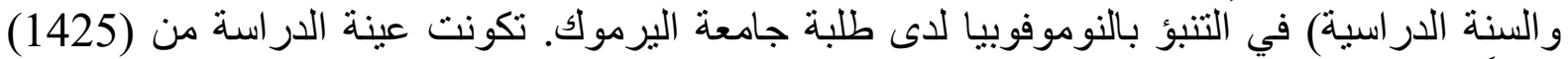

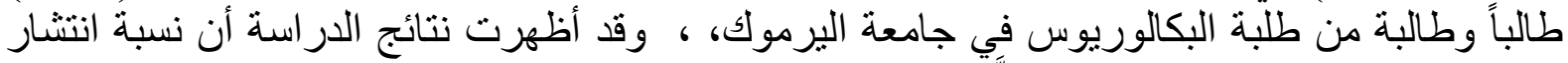

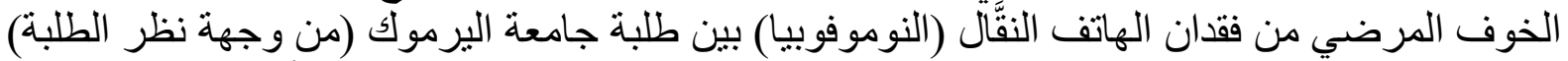

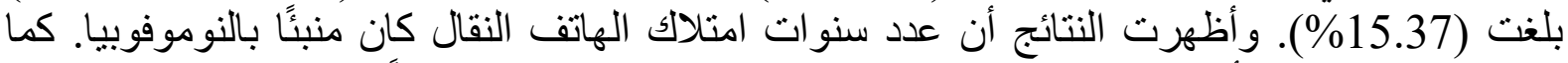
كثفت النتائج وجود أثر نسبي للمتنبئ (الجنس) لصالح الطلبة الإناث مقارناً بنظر ائهم الطلبة الذكور.

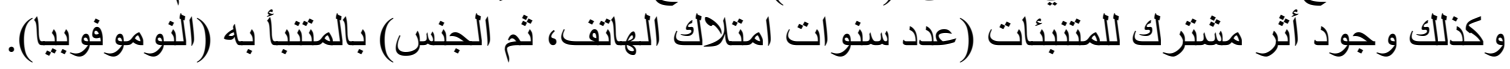

\section{تعليق عام على الدراسات السابقة :}

من خلال استعر اض الباحثة للار اسات السابقة التي تناولت موضوع الدار اسة الحالية يتبين من

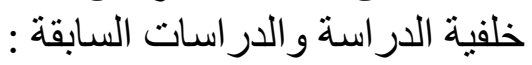

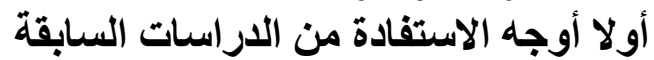

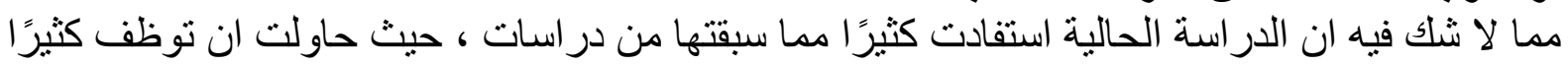
من الجهود السابقة للوصول الى تشخيص دقيق للمشكلة ومعالجتها بشكل شمولي ومن جوانب الاستفادة

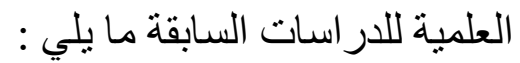

1. استفادت الدر اسة الحالية من جميع الدر اسات السابقة في صياغة الدابة دقيقة لعنوان للار اسة الحالي.

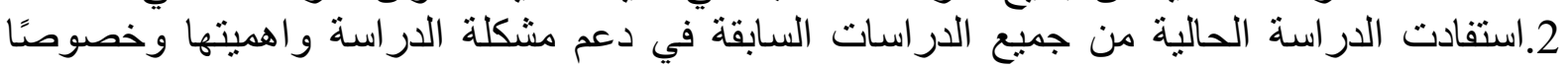

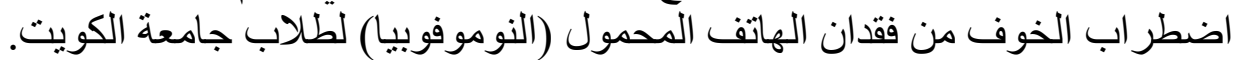

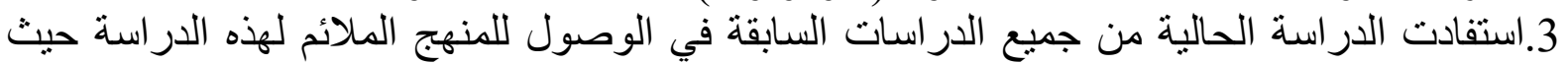

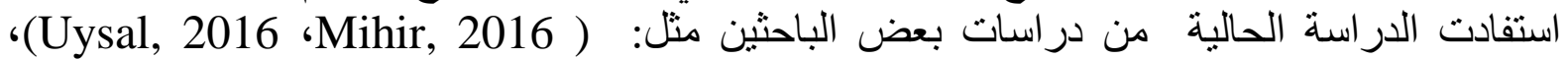

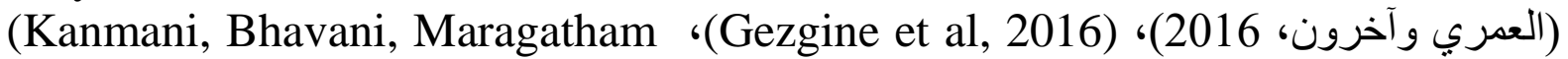
(2017، (Dixit (2017) (دردرة 2016)، (2016)، ودر اسة المومني و العكور( 2019م).

أوجه الاتفاق والاختلاف بين الدراسة الحالية والاراسات السابقة

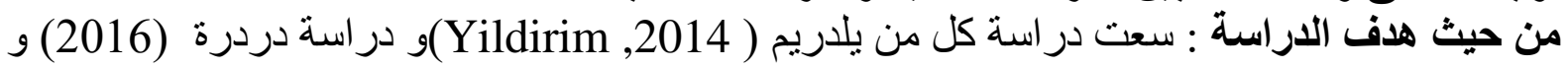

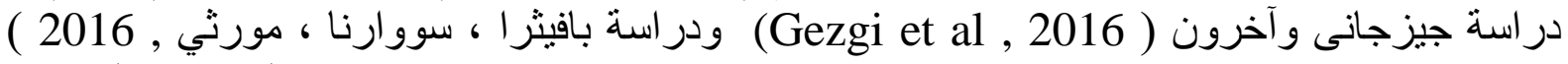
(Pavithra, Suwarna, Murthy

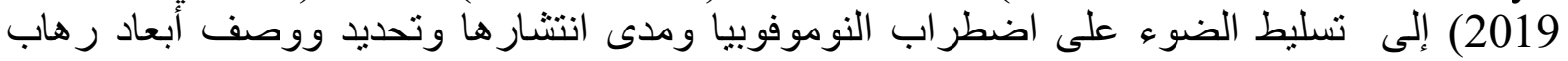

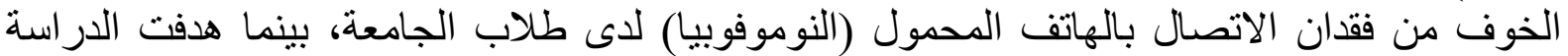

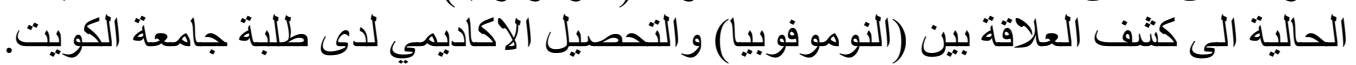

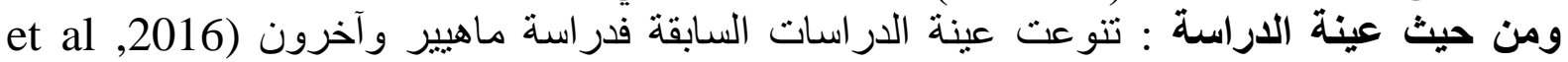

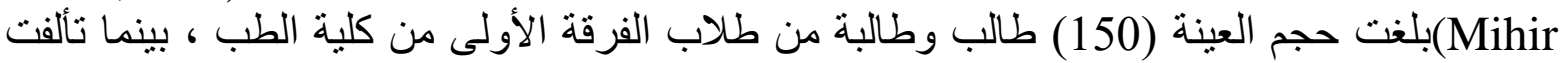

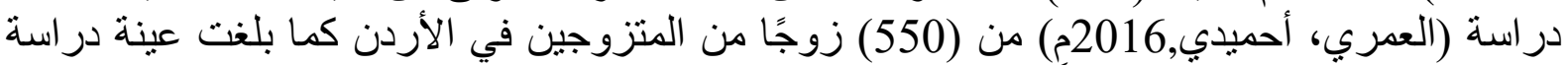

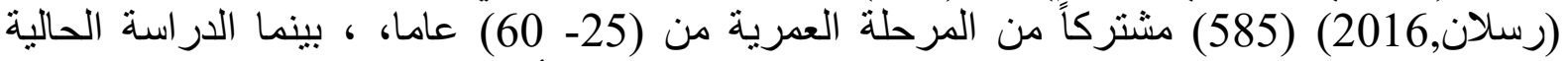

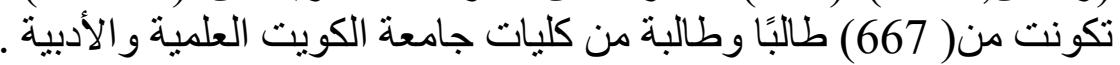

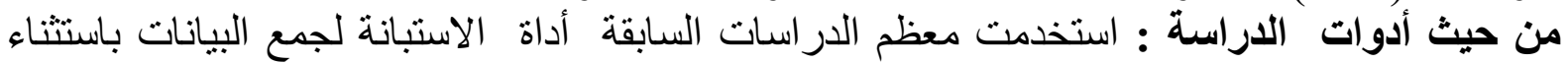

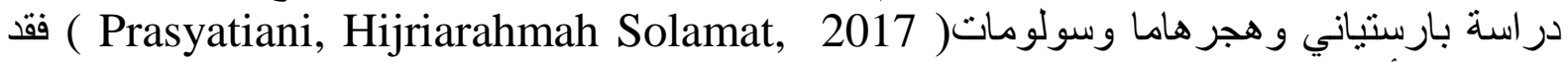

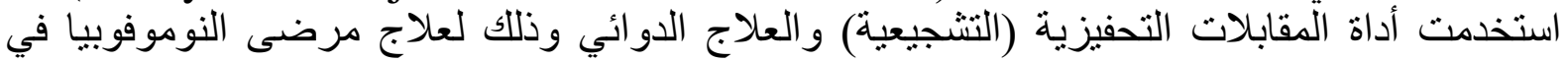

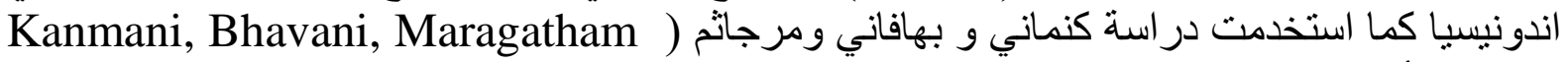

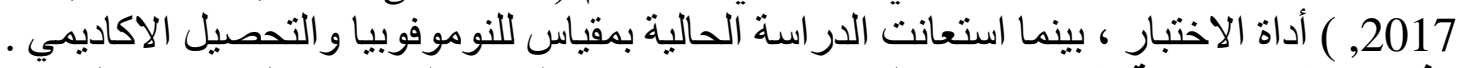

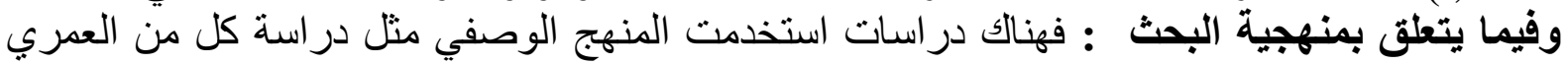

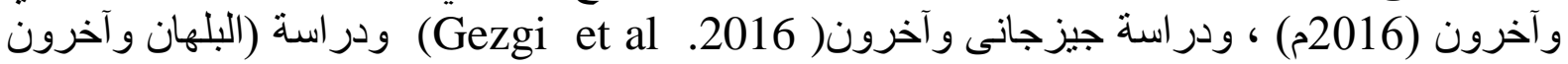


العلاقة بين اضطراب الخوف من فقدان الهاتف المحمول ( النوموفوبيا ) ومستوى التحصيل الأكاديمي لطلاب جامعة الكوات الكويت

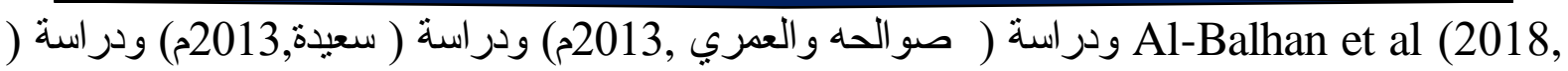
ديريك وسيرارسلان وييكل ( 2016, Dirik, and Pekel ) المنهج الوصفي وهو ما استعانت به الدراسة

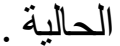
ـ لم نجد من بين هذه الدراسات ما تناول هذا الموضوع بالبحث و الاستقصاء على مستوى دولة الكويت

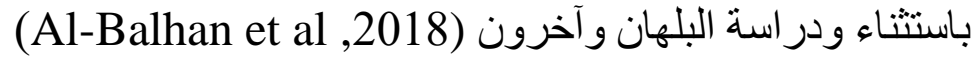

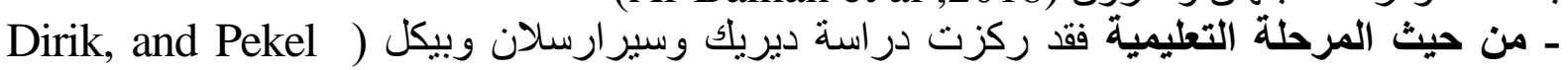

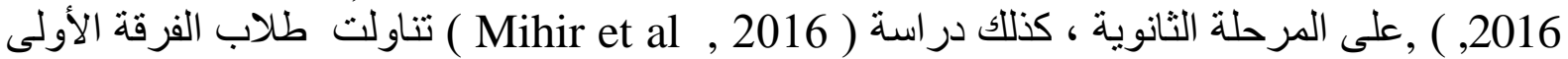

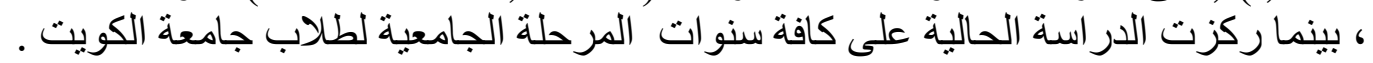

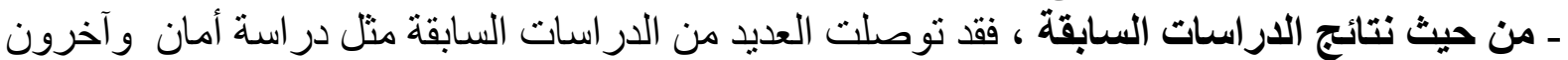
Sundari ( ) ودراسة سونداري (Soyemi , 2015 ) ودرنة (Aman et all , 2015)

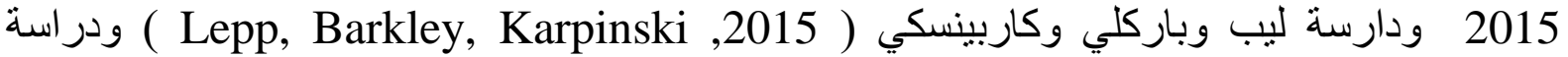
Prasad

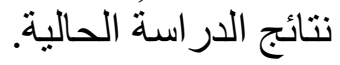

\section{فروض البحث \\ تتحدد فروض البحث في الفرض الرئيس التالي :}

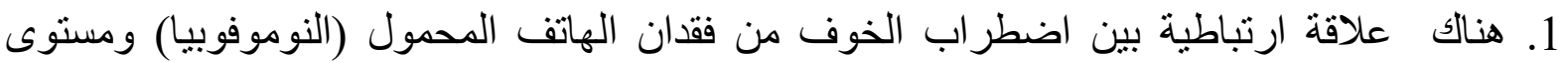

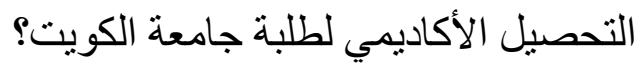
2. لا نوجد فروق بين الطلاب والطالبات في أثر اضطراب الخوف من فقان الهاتف المحمول

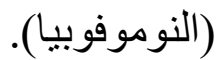
3. لاتوجد فروق بين طلاب التخصصات الأدبية وطلاب التخصصات العلمية في اضطر اب الخوف من

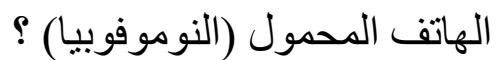
4. لا توجد فروق بين المرتفعين والمنخفضين في المعدل التراكمي في اضطراب الخوف من فقدان

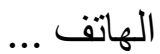
5. لا توجد فروق ذات دلالة إحصائية في اضطر اب الخئ الخوف من فقدان الهاتف المحمول ( النوموفوبيا ) و التحصيل الأكاديمي بين الطلاب الأصغر واتئ والأكبر عررًا.

\section{الدبيات الدراسة الديات النظريات التي فسرت النوموفوبيا:

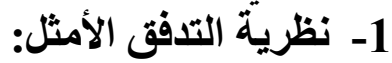

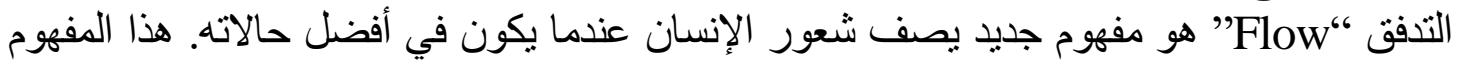

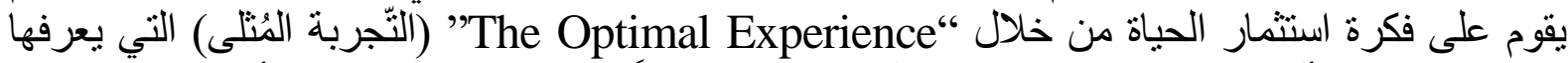
"Mihály“"

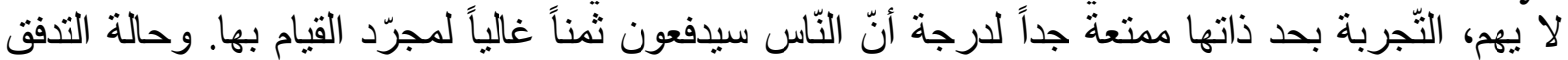

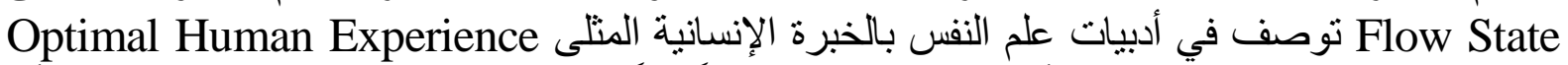

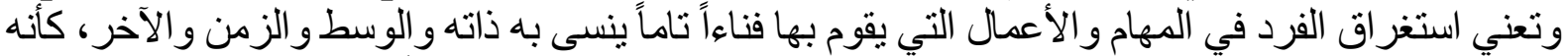

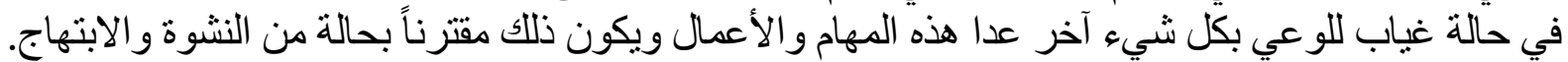

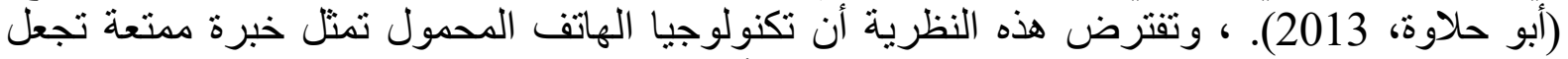

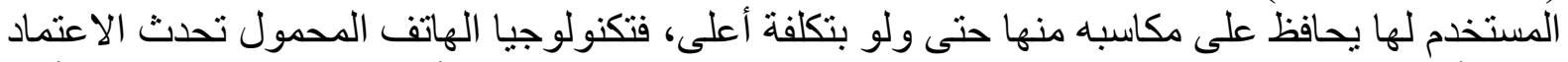

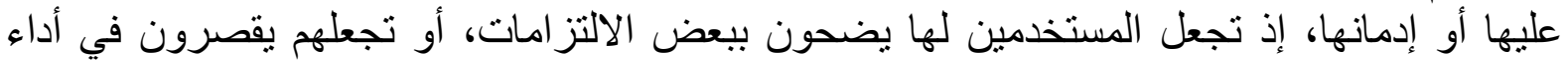

بعض النشاطات الاجتماعية. ( Salehan, Negahban, 2013 (Sa). 
العلاقة بين اضطراب الخوف من فقدان الهاتف المحمول ( النوموفوبيا )

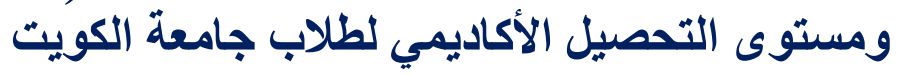

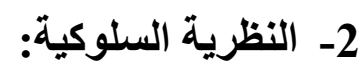

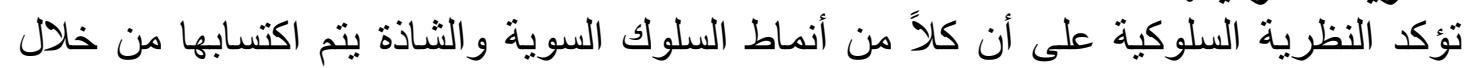

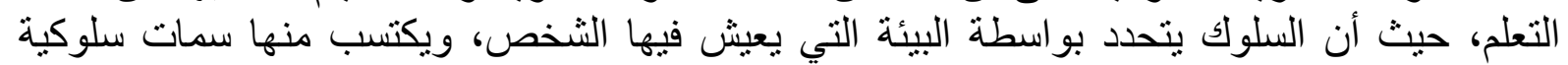

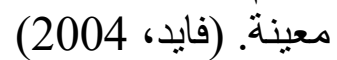

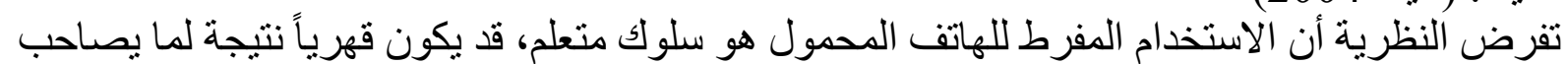

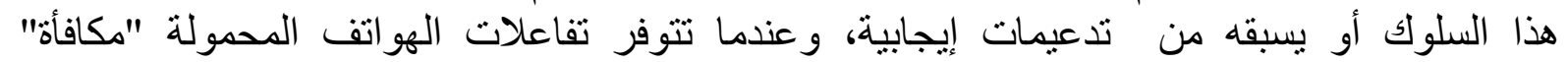

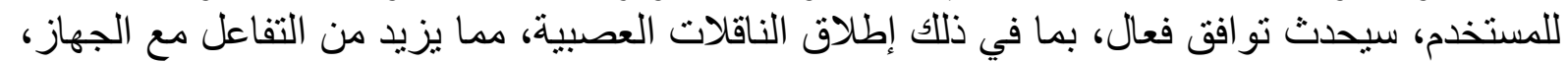

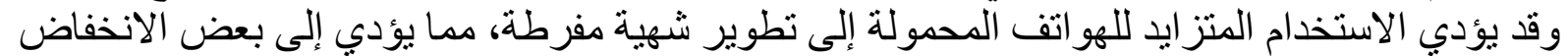

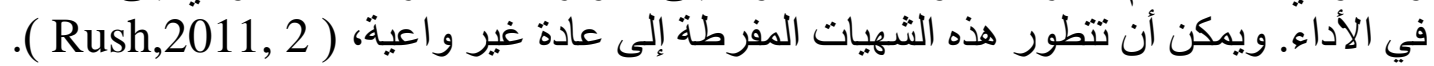

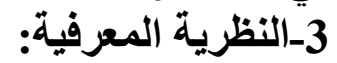

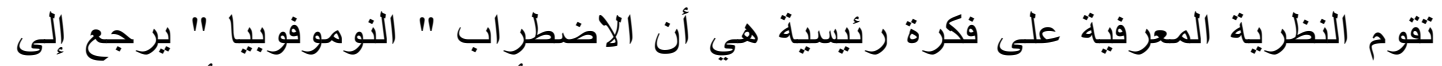

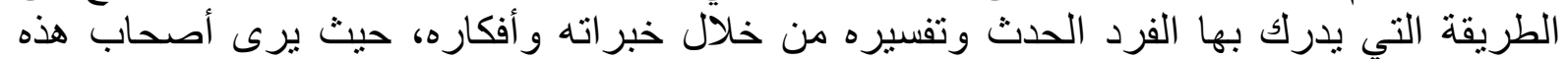

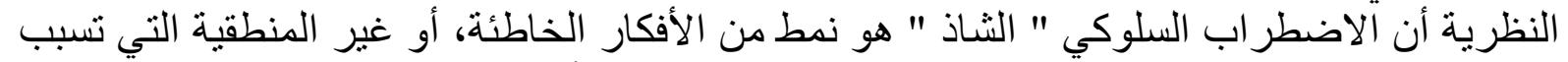

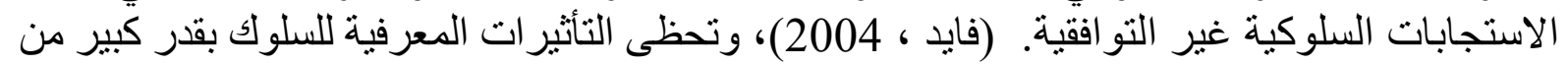

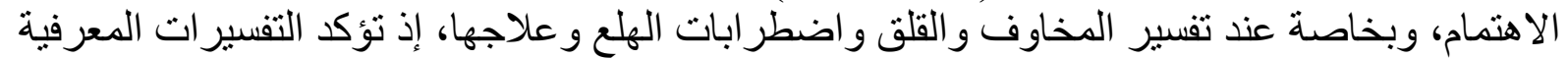

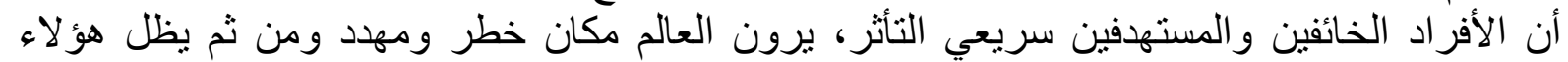

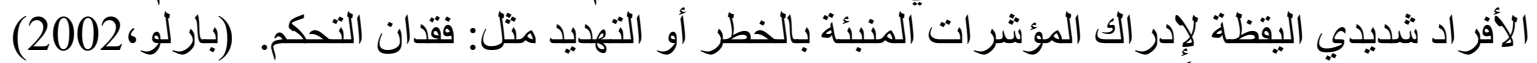

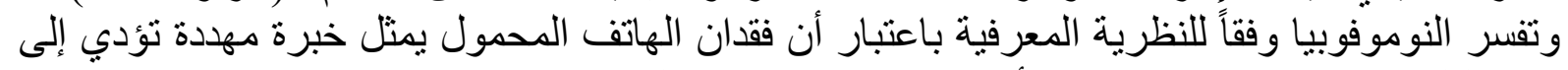
تفاقم القلق الناتج عن مجمو عة من الأفكار اللاعقلانية و غير النانير المنطقية.

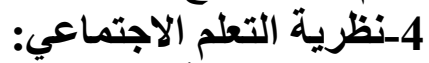
يرجع أصحاب نظرية التعلم الاجتماعي أسباب الإصابة بالرهاب إلى عوامل الإبل بيئية، فالعالم

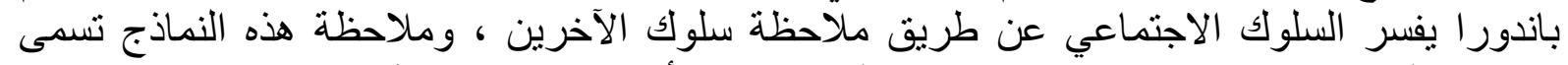

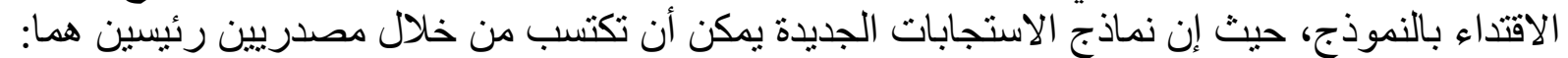

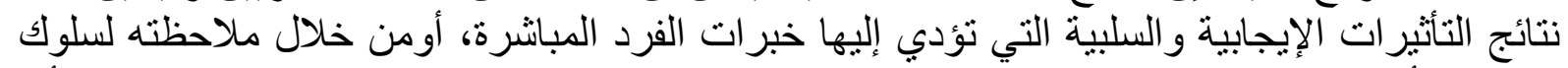

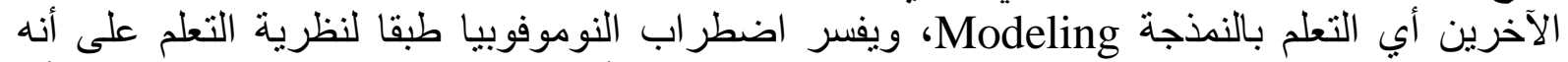

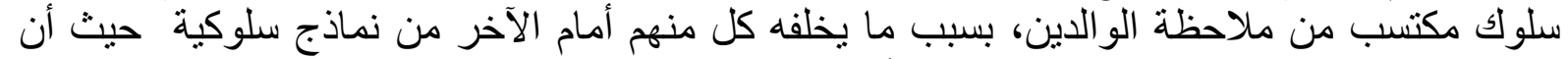

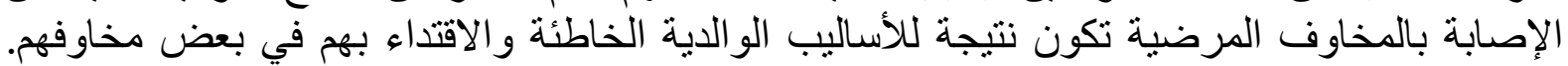

$$
\text { (يحيي، 2003). }
$$

\section{5-نظرية التعلق (الارتباط): 5 إنة}

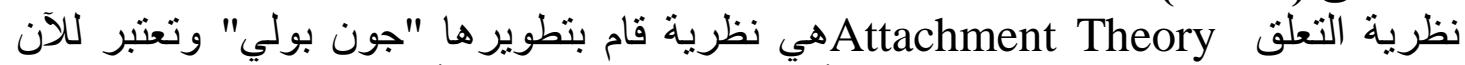

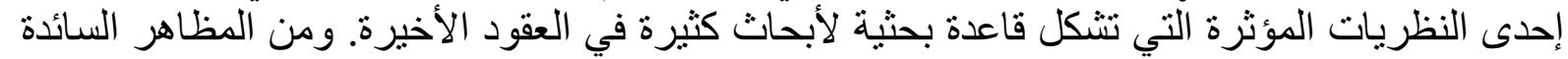

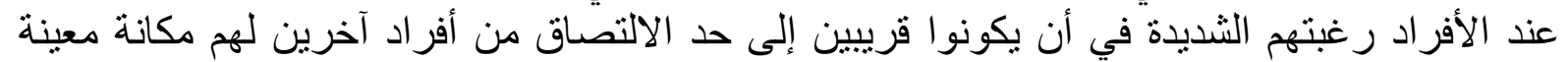

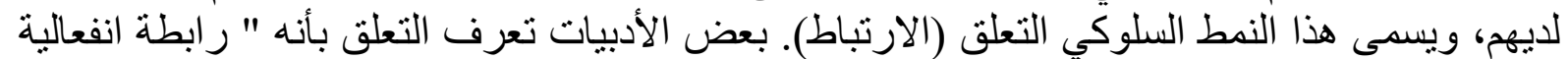

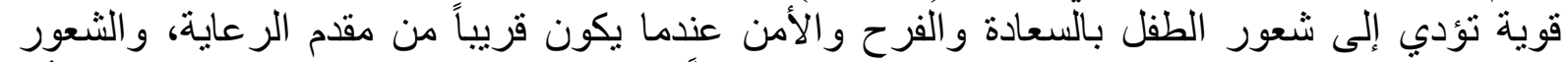

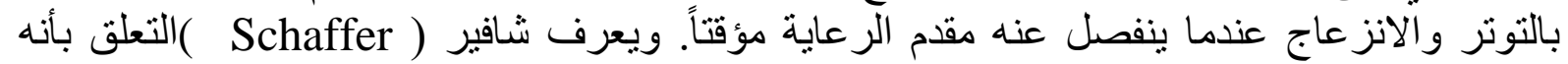

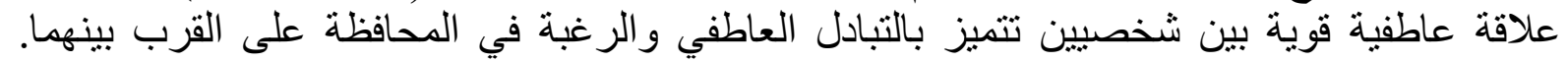

وتعرف النوموفوبيا بأنها الخوف من أن تصبح بلا اتصال بدون هاتف محمول، أو الثُعور (يمينة، 2015).

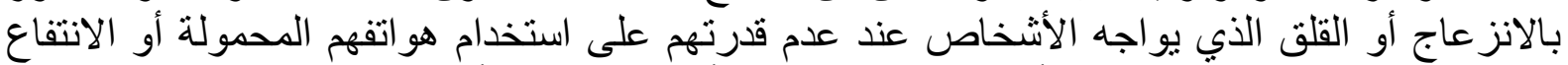

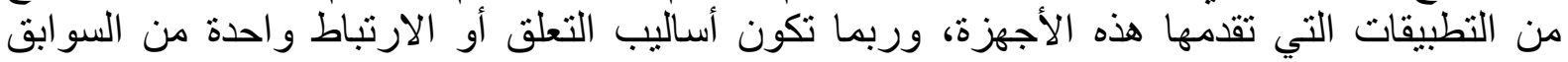




\section{العلاقة بين اضطراب الخوف من فقدان الهاتف المحمول ( النوموفوبيا ) ومستوى التحصيل الأكاديمي لطلاب جامعة النوات الكويت}

الموقفيه الخاصة بالنوموفوبيا، حيث تم تعريف الارتباط بأنه التخصيص الزائد للمصادر المعرفية

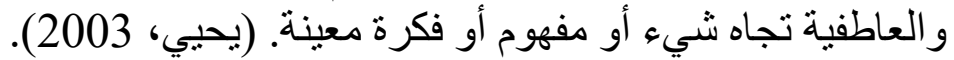

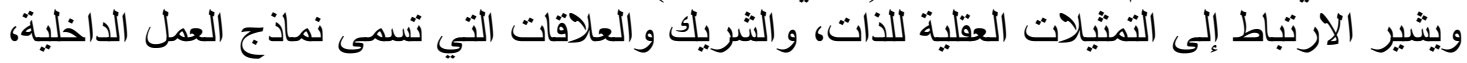

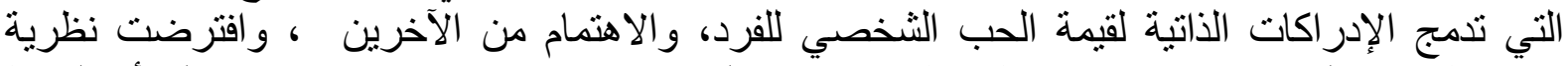

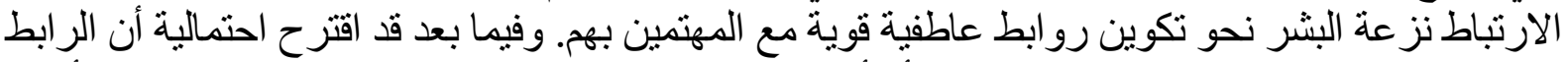

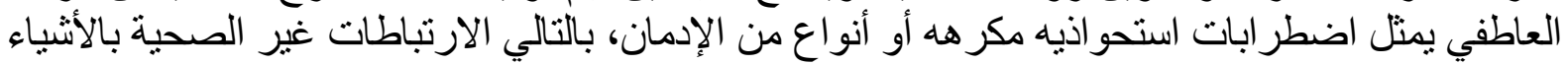

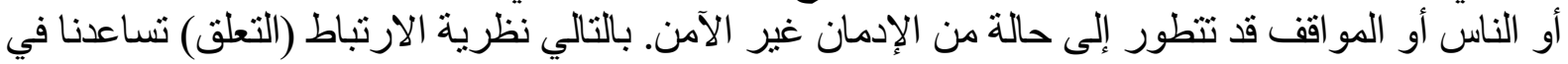

فهم سو ابق المضاعفات السلوكية المرتبطة بالنوموفوبيا. (Arpaci et al,2016).

Academic Achievement التحصيل الأكاديمي

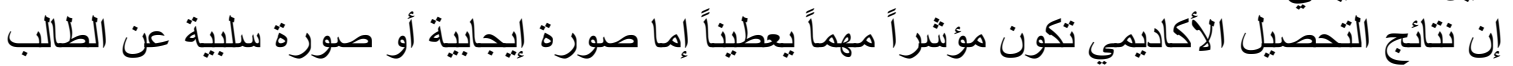

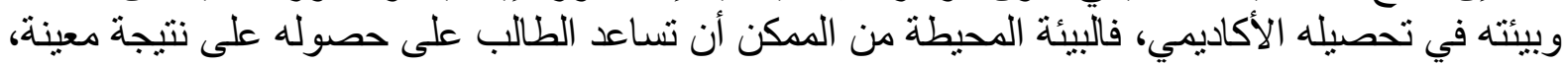

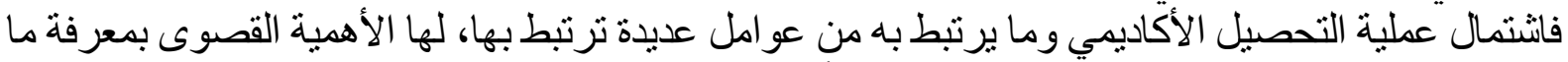

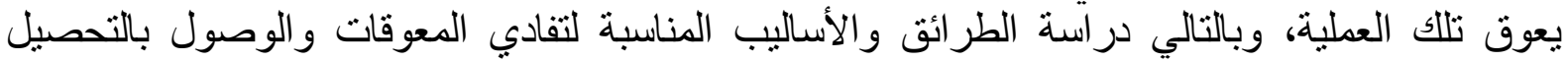

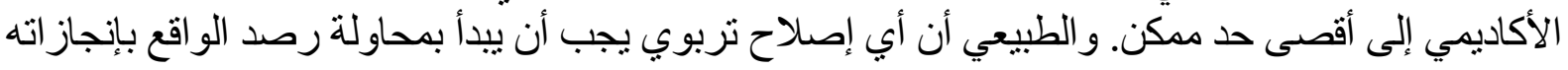

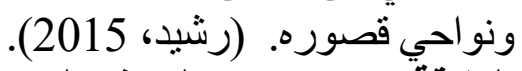
العلاقة بين استخدام الهاتف المحمول و التحصيل (التيل الاكاديمي

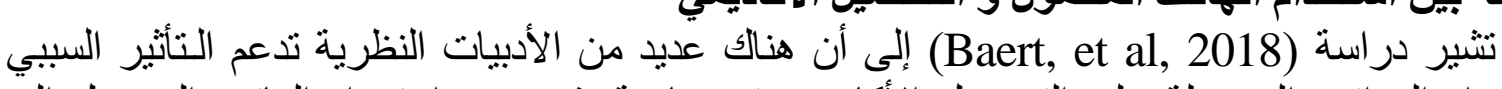

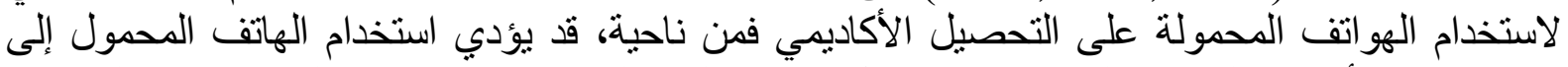

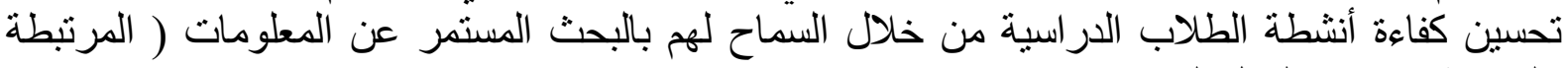

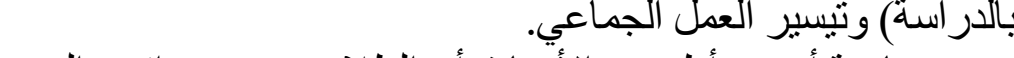
ومن ناحية أخرى أظهرت الأبحاث أن الطلاب يرون هو اتفهم المحمولة في الأساس مصدرًا للترفيه، وليس وليس

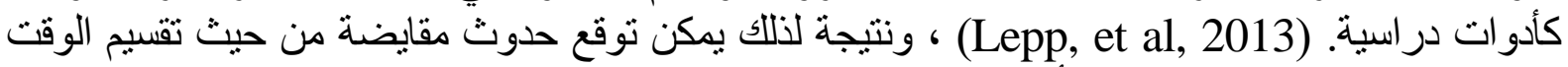

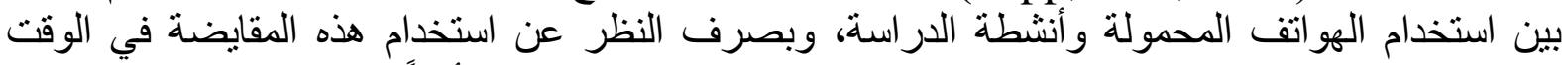

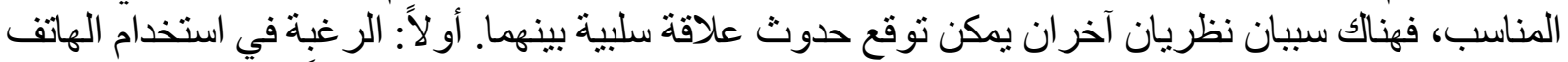

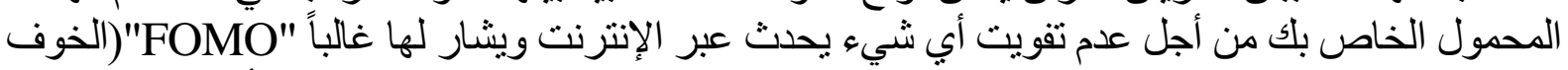

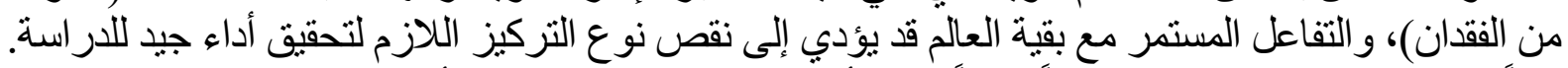

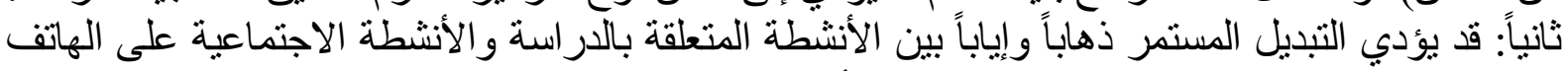

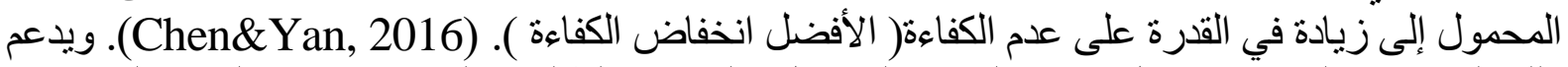

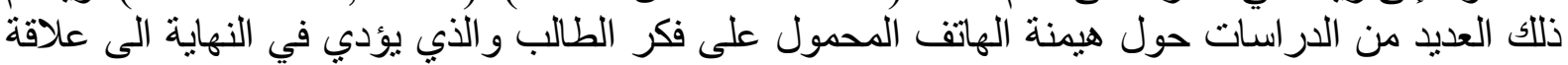

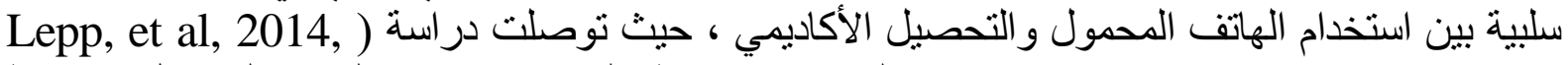
إلى وجود ارتباط سلبي بين استخدام الهاتف المحمول ومتوسط الدرجات الفعلية أو المبلغ عنها ذاتيا ( GPA ) المعدل التر اكمي لطلاب الجامعات.

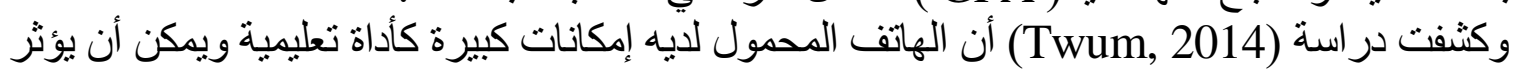
بشكل إيجابي على تعلم العلوم في الجامعات. بمعنى استخدام الهاتف المحمول كخبرة تعليمية معززة للطعلاب.

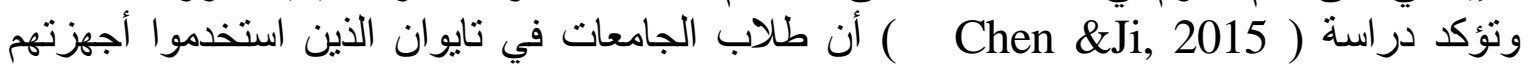

الالكترونية الثخصية بشكل أكبر في الأنشطة غير التعليمية، حصلو ا على معدل تر اكمي أقل للعام التئ الأول.

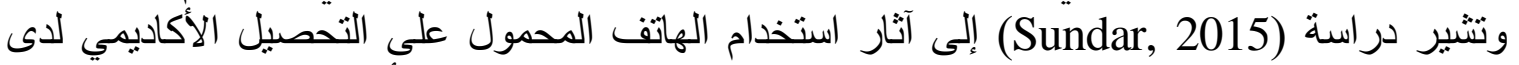

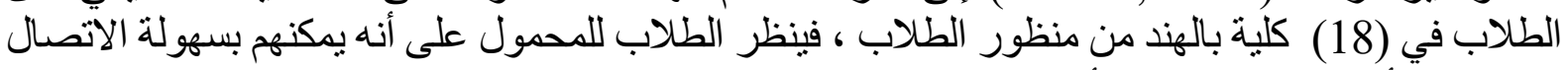

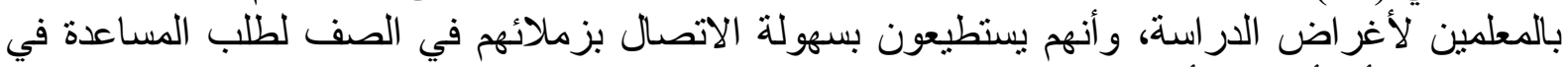

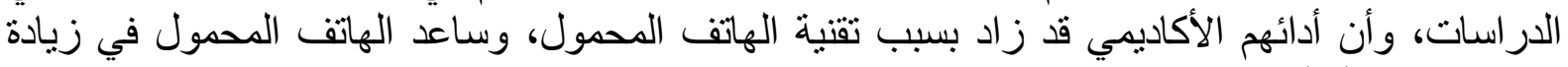

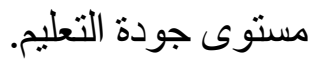




\section{العلاقة بين اضطراب الخوف من فقدان الهاتف المحمول ( النوموفوبيا ) ومستوى التحصيل الأكاديمي لطلاب جامعة الكوات الكويت}

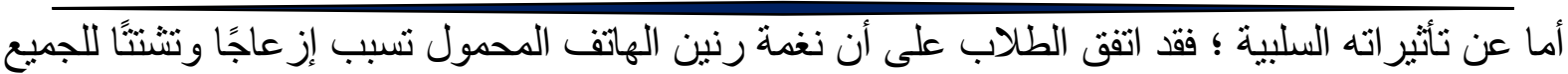
بقاعة المحاضرات، والانشغال بتقفد المكالمات الفائتة بقاعة المحاضرات يسبب انصرة النصراف عن المحاضرة

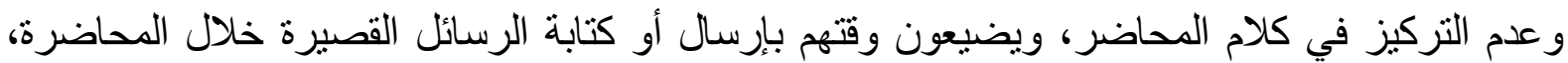

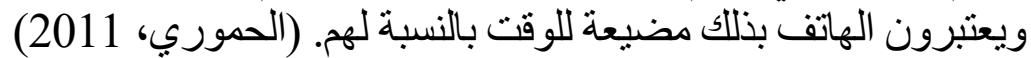

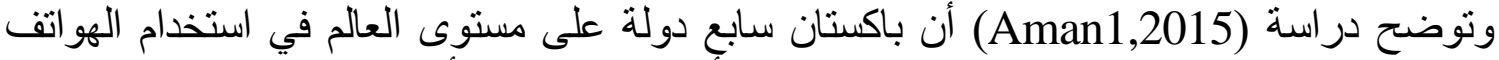

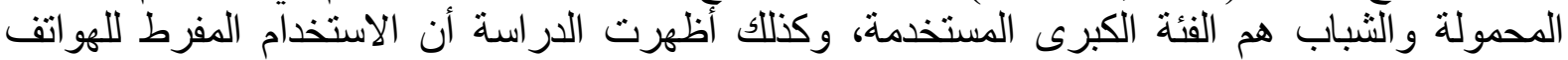

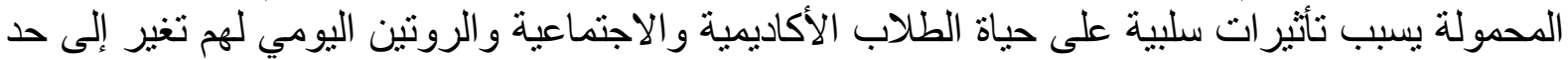

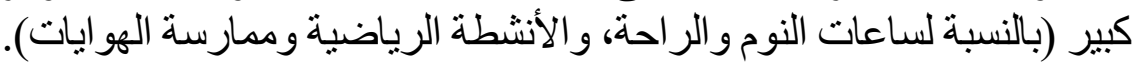

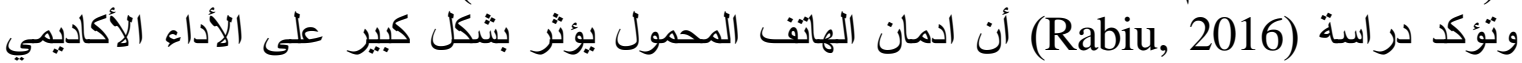

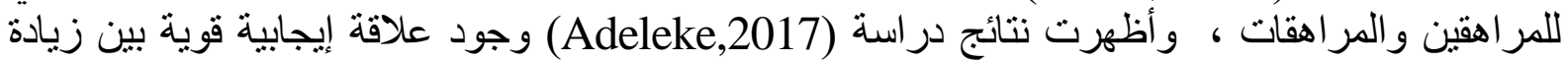
استخدام الهو اتف المحمولة بين الطلاب الجامعيين النيجيريين و انخفاض التحصيل الأكاديمي. وأوضحت نتائج دراسة (Ng,et al,2017) أن للهواتف المحمولة تأنثيرات سلبية على التحئ التحصيل

الأكاديمي للطلاب (GPA) على الرغم من استخدامها لأنشطة التعلم المتعلقة بالدر استة.

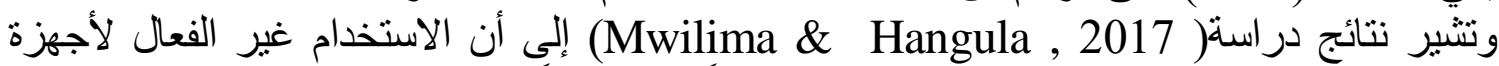

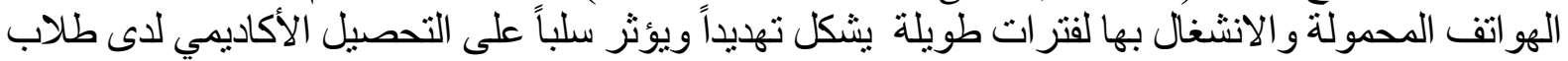

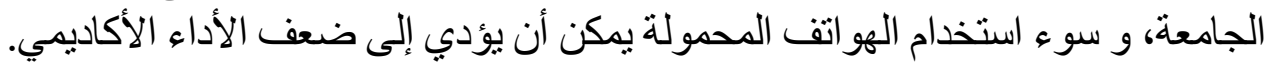

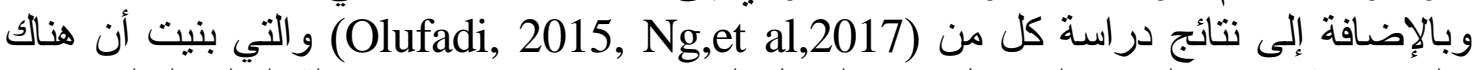

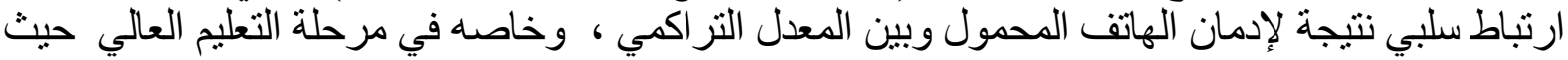
يؤدي ذلك إلى انخفاض المعدل التر اكمي( GPA ) للطلاب في جامعات ماليزيا ونيجيريا.

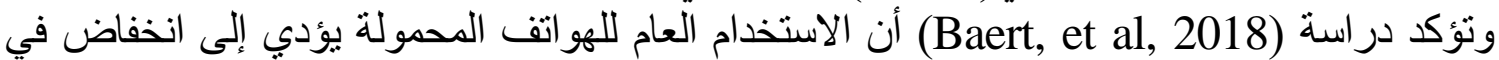
متوسط درجة اختبار طلاب الجامعات في بلجيكا. وتثير در اسة (Felisoni \& Godoi , 2018) إلى أن فقدان طيكان الاتصال بالهاتف المحمول (النوموفوبيا)

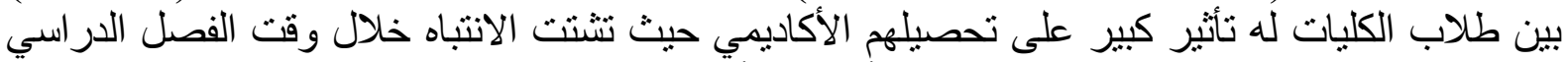
وفقدان التركيز على المحاضر ات وغير لهير ها هن الأنشطة الأكاديمية.

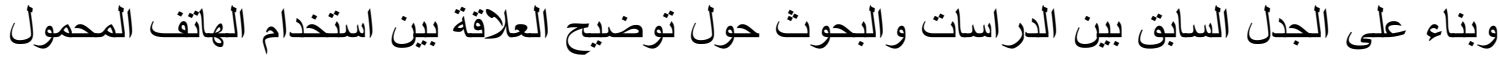

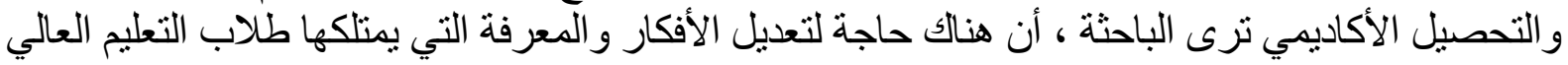
حول تقنيات الهواتف المحمولة، والتي تتطلب التغيير في الممارسات التعليمية للسماح للطناب لتعاب لتعلم كيفية الاستفادة من هذه التقنيات في التعلم . ويمكن لتكنولوجيات الهو اتف المحمولة تعزيز خبرات تعلم العلوم المختلفة التي تنطوي على التعاون و إمكانية الوصول والتكامل مع العالم خارج الفصل الدراسي (Prensky,2005). إلى جانب ذلاتك، يمكن لتكنولوجيات الهواتف المحمولة أن تقدم لطاب العاب العلوم المختلفة فرصاً واسعة للتفاعل مع محاضريهم وزملائهم في الدورة ومحتوى العلوم (Vavolua, 2005). و ويضيف كل من Savill-Smith \& Kent)

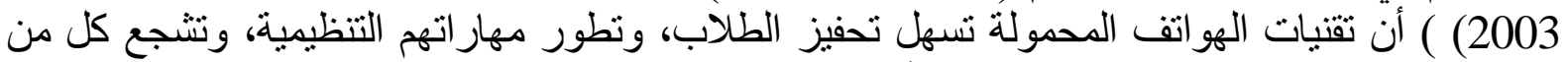
الدراسة المستقلة والتعلم التعاوني، وتعمل كأداة للمر اجعة، وتتبع تقدم الطلاب، كما تقدم التقييم ، ويمكن

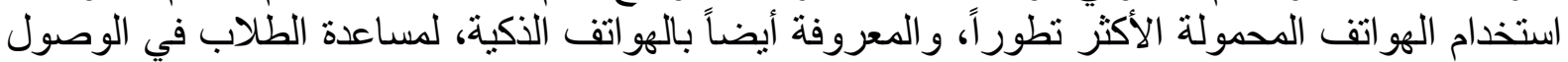
إلى المعلومات من الويب، وتحويلها، ونقلها، والتعاون بين الطلاب، وكذلك خلق نهج أكثر غنى بوسائط

التعليم. (Ferry,2009).

وقد أدت التطور ات الحديثة في تكنولوجيا المعلومات والاتصالات إلى زيادة كبيرة في إمكانات استخدام الهو اتف المحمولة كأدوات تعليمية، بسبب تز ايد قدرات المعالجة و الذاكرة والاتصال التي جعلت هذه التقنيات

أكثر تفاعلاً بشكل كبير. (Pea \& Maldonado,2006). 
العلاقة بين اضطراب الخوف من فقدان الهاتف المحمول ( النوموفوبيا ) ومستوى التحصيل الأكاديمي لطلاب جامعة الكوات الكويت

\section{الإجراعات المنهجية للبحث \\ أولاً منهج البحث البه}

اتبعت الباحثة في الدراسة المنهج الوصفي الارتباطى الفارقى وهو يعد من أكثر المناهج التي تلائم

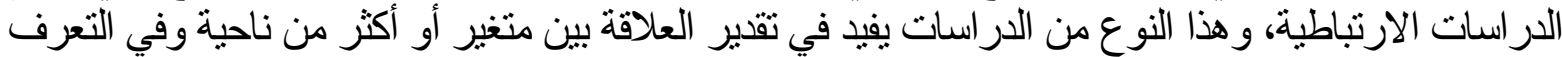

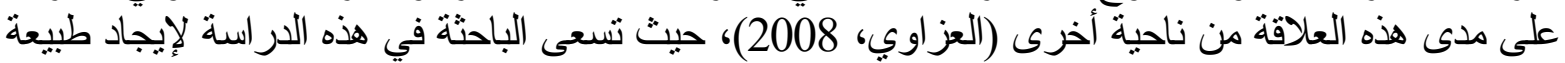

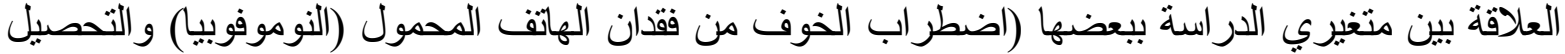

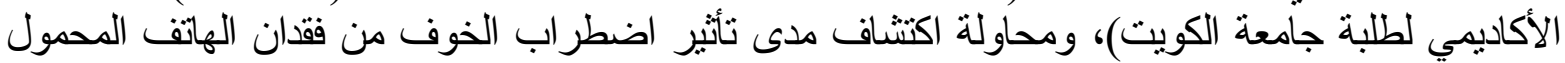

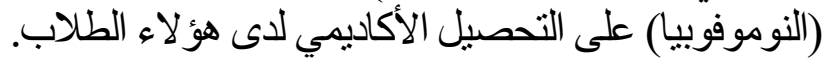

ثانياً: مجتمع الدراسة:

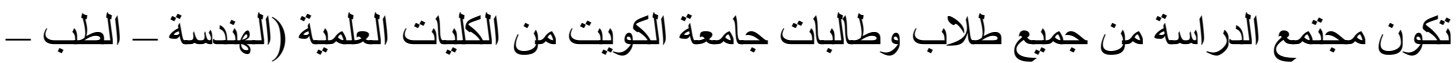

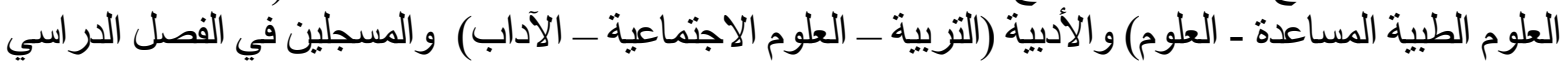

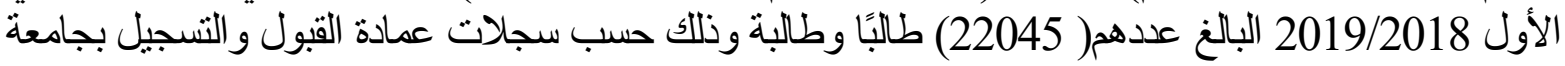

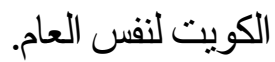

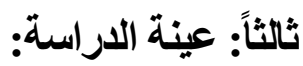

العينة الاستطلاعية: وتكونت من (50) طلباً وطالبة الكليات العلمية والكليات الأدبية، بغرض التحقق من الخصائص السيكومترية لأداتيّ الدر استة.

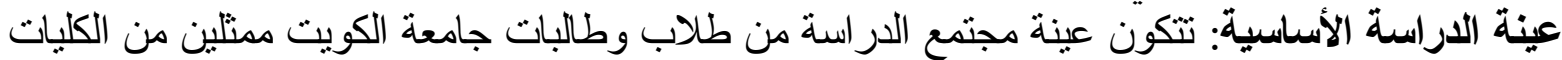

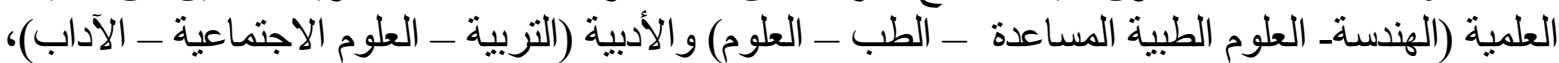

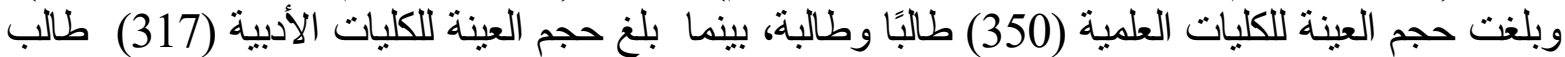

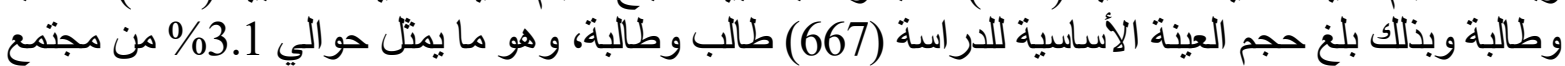
Steven K. ) الدراسة الذي نم اختيار هم بالطريقة العشوائية وذللك حسب معادلة Thompson طلبة هؤلاء الكليات الدذكور ومستوياتهم الدراسية ونحصيأهم الاكاديمي. $n=\llbracket \frac{N \times p(1-p)}{\left.\left.\llbracket N-1 \times\left(d^{2} \div z^{2}\right)\right]+p(1-p)\right]}$ N Z: الدرجة المعيارية المقابلة لمستوى الدلالة (0.95) وتساوي (1.96)

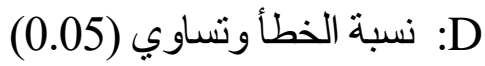
و

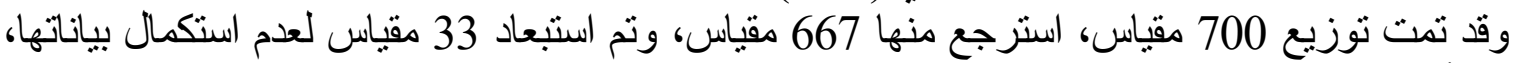

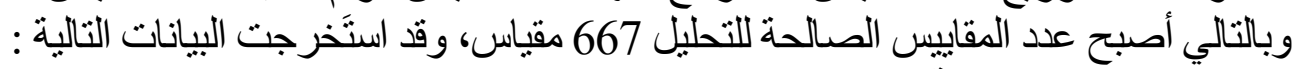

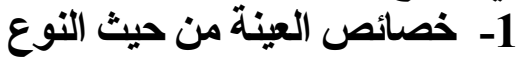

جدول رقم (1) خصائص العينة من حيث النوع

\begin{tabular}{|c|c|c|}
\hline النسبة & العدد & النو ع \\
\hline$\% 47$ & 314 & طلاب \\
\hline$\% 53$ & 353 & طالبات \\
\hline$\% 100$ & 667 & الاجمالي \\
\hline
\end{tabular}


العلاقة بين اضطراب الخوف من فقدان الهاتف المحمول ( النوموفوبيا ) ومستوى التحصيل الأكاديمي لطلاب جامعة الكوات الكويت

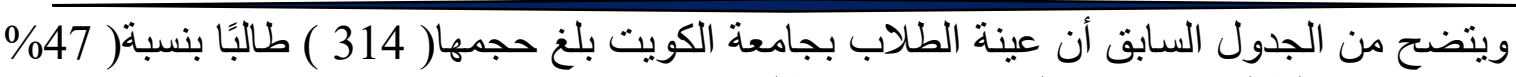

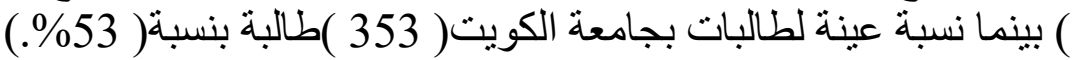

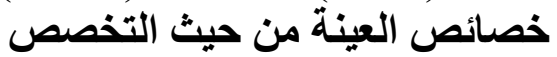
جدول رقم (2) خصائص العينة من حيث التخصص التصص

\begin{tabular}{|c|c|c|c|}
\hline النسبة & العدد & النوع & لتخصص \\
\hline \multirow[t]{2}{*}{$\% 53$} & 164 & طلاب & \multirow[t]{2}{*}{ العلمي } \\
\hline & 178 & طالبات & \\
\hline \multirow[t]{2}{*}{$\% 47$} & 150 & طلاب & \multirow[t]{2}{*}{ الأدبي } \\
\hline & 175 & طالبات & \\
\hline$\% 100$ & 667 & \multicolumn{2}{|c|}{ الإجمالي } \\
\hline
\end{tabular}

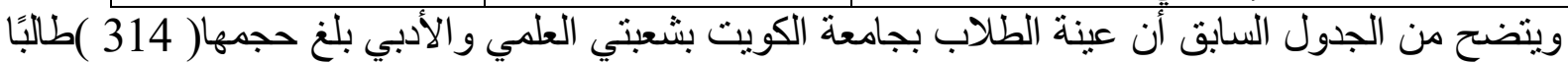

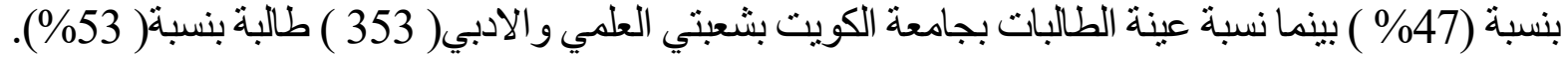

جدول رقم (3) خصائص العينة من حيث العمر

\begin{tabular}{|c|c|c|}
\hline النسبة & العدد & العمر \\
\hline$\% 13$ & 90 & أقل من 20 سنة \\
\hline$\% 30$ & 199 & 21-20 سنة \\
\hline$\% 57$ & 378 & أكثر من 21 سنة \\
\hline$\% 100$ & 667 & الإجمالي \\
\hline
\end{tabular}

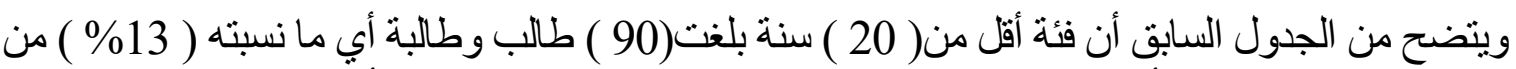

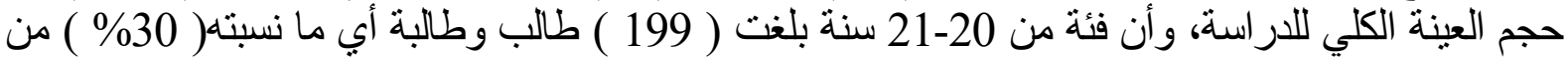

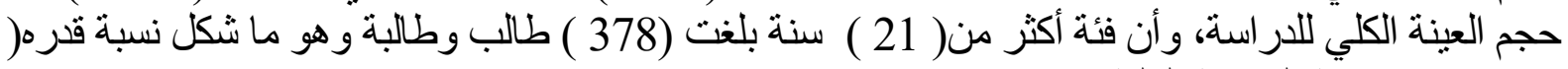
( ) 57 \% من عينة الدراسة الكلية.

جدول رقم (4) خصائص العينة من حيث المعدل التراكمي

\begin{tabular}{|c|c|c|}
\hline النسبة & العدد & العمر \\
\hline$\% 6$ & 43 & أقل من 2 درجة \\
\hline$\% 57$ & 380 & 2-2.99 درجة \\
\hline$\% 37$ & 244 & 3-4 درجة \\
\hline$\% 100$ & 667 & الاجمالي \\
\hline
\end{tabular}

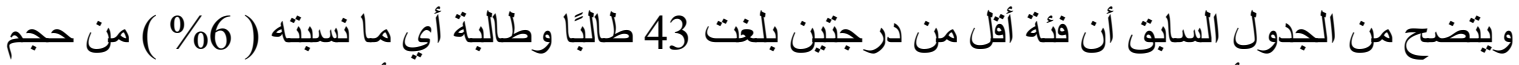

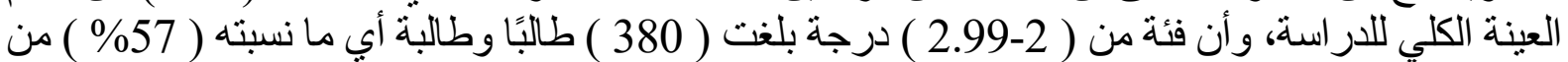

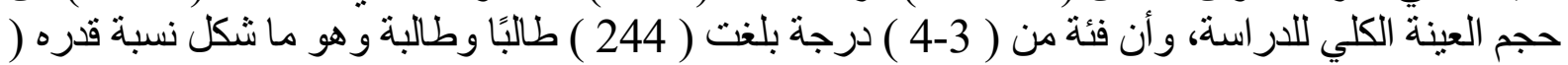
37\% 3 ) من عينة الدراسة الكلية.

$$
\text { رابعاً: أدوات الاراسة : أباتِ }
$$

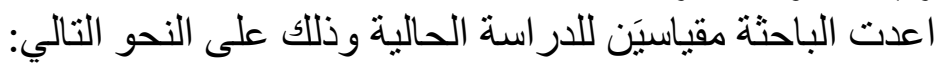
المقياس الأول: التحصيل الأكاديمي إعداد الباحثة 
العلاقة بين اضطراب الخوف من فقدان الهاتف المحمول ( النوموفوبيا ) ومستوى التحصيل الأكاديمي لطلاب جامعة الكواتف الكويت

المقياس الثاني: اضطر اب الخوف من فقدان الهاتف المحمول (النوموفوبيا) إعداد الباحثة.

المقياس الأول: التحصيل الأكاديمي

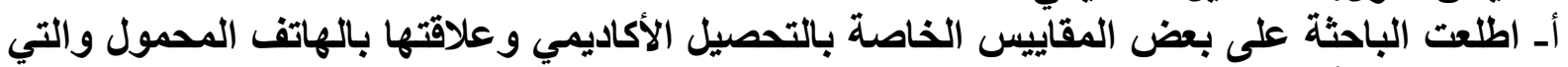

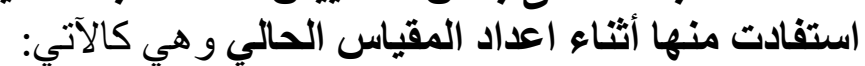

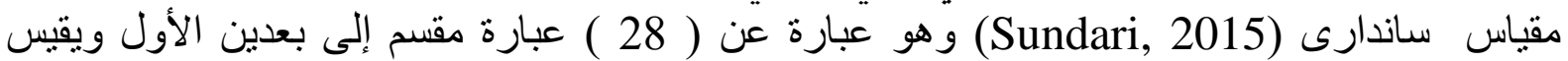

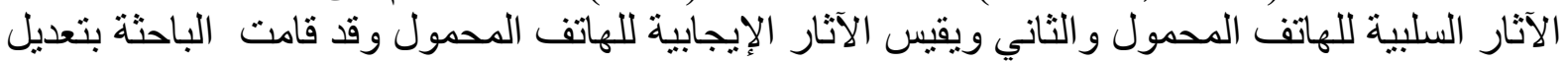
بعض العبار ات و إعادة صياغتها في الْياس المقياس الحالي. .

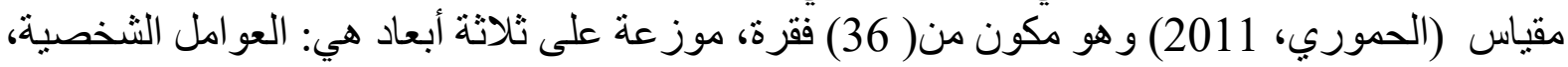

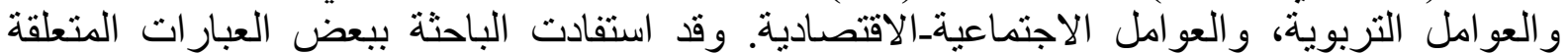
بالعامل الشخصي و الاجتماعي والتربوي بعد تعديلها واعادة صياغتها في المقياس الحالي.

ب- وصف مقياس التحصيل الأكاديمي

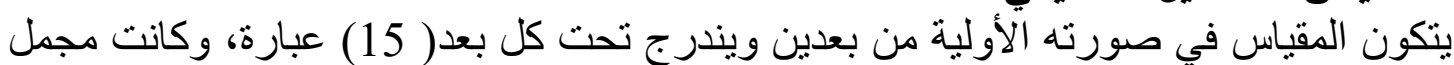

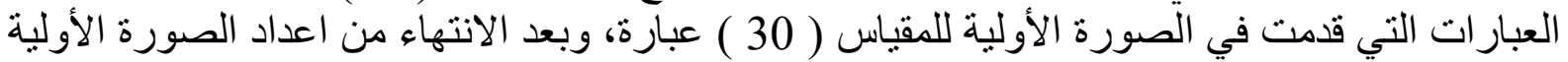

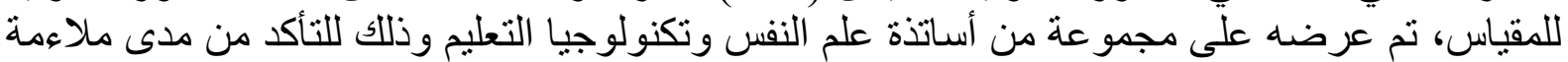

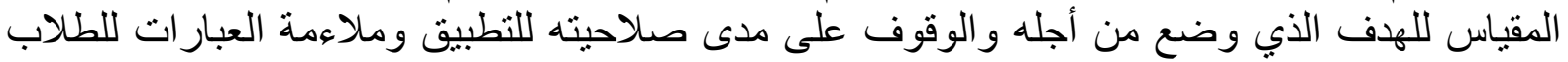

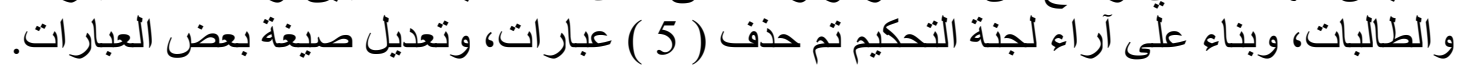

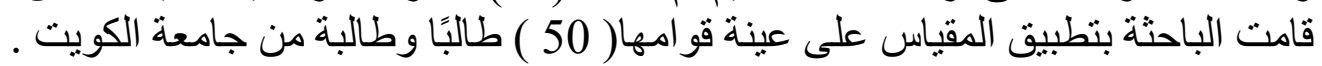

ج-صدق المقياس :

للتحقق من صدق المقياس تم استخدام الطر ائق التالية:

ـالصدق الظاهري للمقياس: وقد تم التحقق منه من خلال عرل عرض المقل المقياس على مجموعة من المحكمين لمعرفة مدى صلاحية المقياس

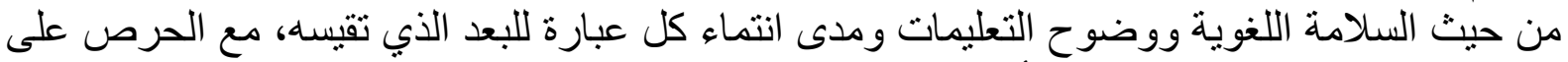

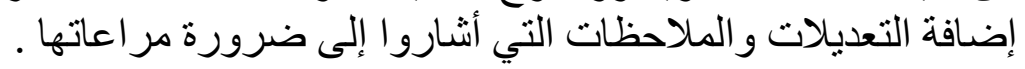

ـالاتساق الاخلي للمقياس:

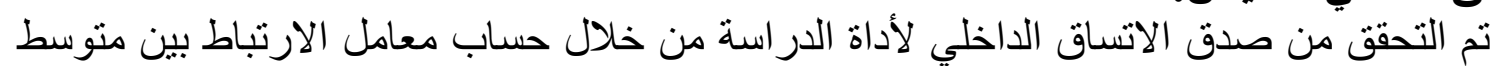

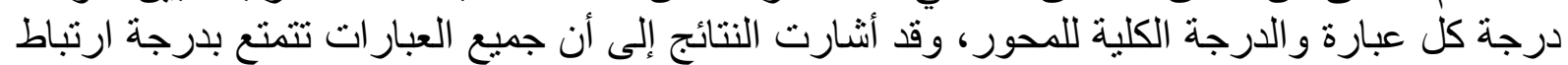

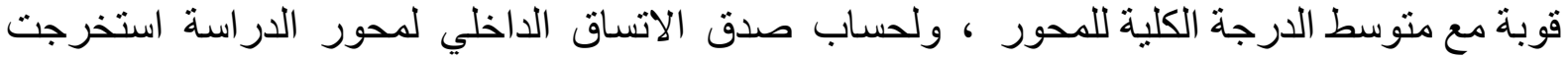

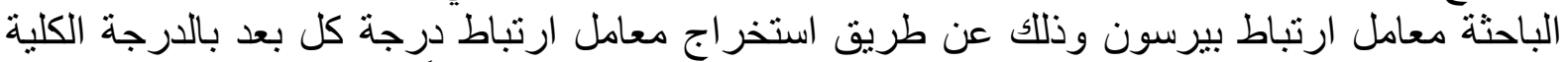

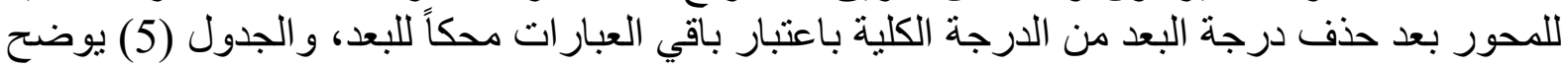

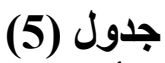

معامل ارتباط بيرسون لأبعاد مقياس التحصيل الأكاديمي لطلبة جامعة الكويث والدرجة الكلية للمقياس

(667 =ن

\begin{tabular}{|c|c|c|}
\hline مقياس التحصيل & \multicolumn{2}{|c|}{ ابعاد مقياس التحصيل الأكاديمي لطلبة جامعة الكويت للمحور } \\
\hline$* * 0.885$ & معامل ارتباط بيرسون & الآثار السلبية للهاتف المحمول على \\
\hline
\end{tabular}


العلاقة بين اضطراب الخوف من فقدان الهاتف المحمول ( النوموفوبيا ) ومستوى التحصيل الأكاديمي لطلاب جامعة الكوانف الكويت

\begin{tabular}{|c|c|c|}
\hline 000 & الدلالة الإحصـائية & التحصيل الأكاديمي لطلبة جامعة \\
\hline \multirow{2}{*}{$\begin{array}{c}* * 0.873 \\
000\end{array}$} & معامل ارتباط بيرسون & \multirow{2}{*}{ الآثار الإيجابية للهاتف المحكيل الإديمي لطلبة جامعة على الكويت } \\
\hline & الدلالة الإحصائية & \\
\hline
\end{tabular}

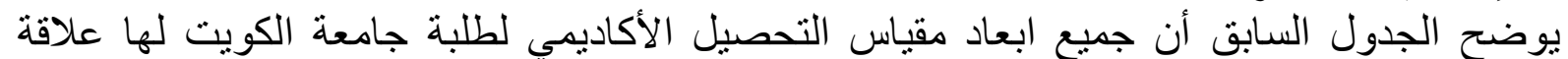

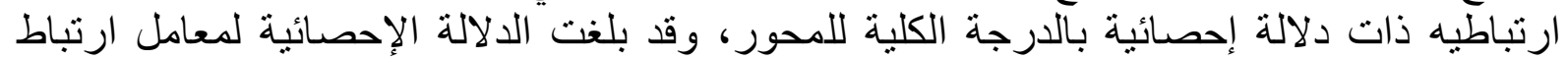

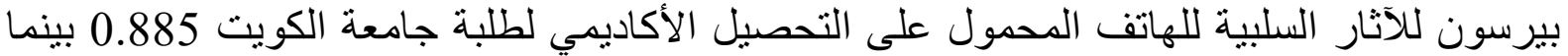

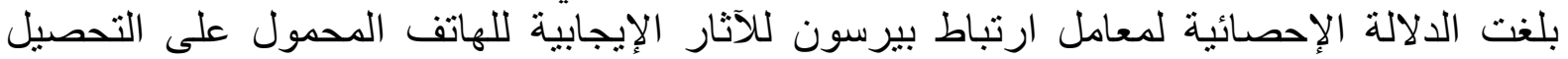

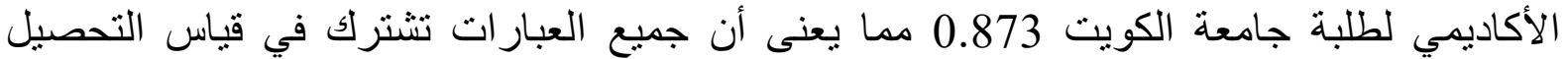

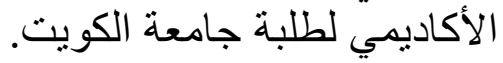

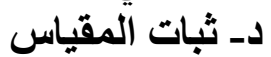
معامل الفا كرونباخ المفاخ قامت الباحثة بحساب ثبات الفا كرونباخ لأبعاد مقياس التحصيل الأكاديمي لطلبة جامعة الكويت،

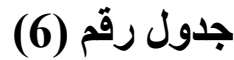
وللمقياس ككل و الجدول رقم (6) يوضح ذللك. قيم معامل الفا كرونباخ لأبعاد مقياس التحصيل الأكاديمي لطلبة جامعة الكويت

\begin{tabular}{|c|c|c|c|c|}
\hline كرونباخ إذا تم & لتصحر نميحه & التباين إذا تم & المت حذف إذ إذا & مقياس التحصيل الأكاديمي \\
\hline 0.851 & 0.787 & 194.838 & 173.01 & 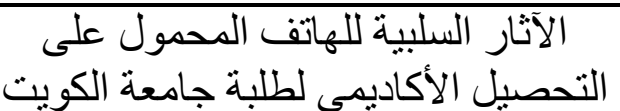 \\
\hline 0.870 & 0.774 & 202.568 & 169.84 & 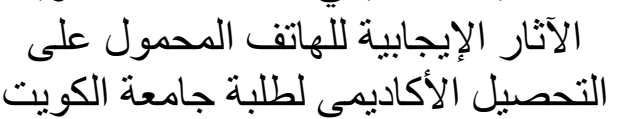 \\
\hline 0.706 & 1.000 & 58.516 & 114.28 & مقياس التحصيل الأكاديمي \\
\hline 0.882 & \multicolumn{4}{|c|}{ ثبات مقياس التحصيل } \\
\hline
\end{tabular}

يوضح الجدول السابق نتائج اختبار الفا كرونباخ لأبعاد مقياس التباسي التحصيل الأكاديمي لطلبة جامعة الكويت

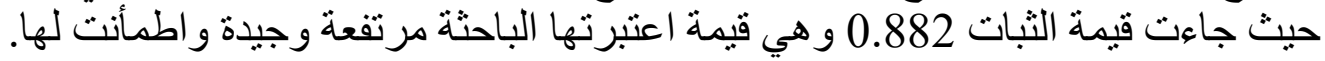
المقياس الثاني: اضطراب الخوف من فقدان الهات الهاتف المحمول (النوموفوبيا).

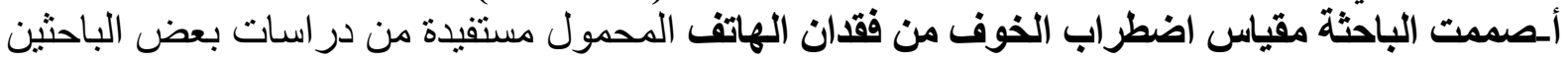

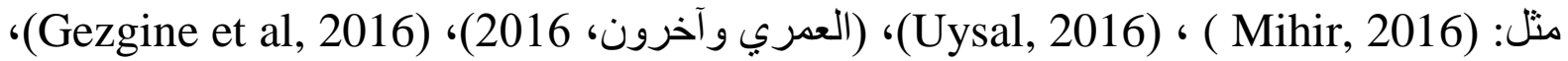

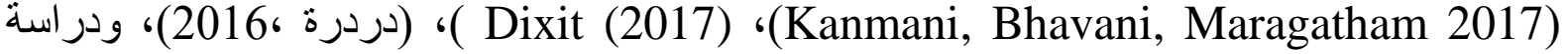
المومني و العكور( 2019م)، واطلعت الباحثة على بعض الكتابات التي تم نوضيحها في الإطار النظري للادر اسة مثل در اسة:

، ( Lepp, et al, 2013, Lepp, Andrew, 2015, Chen\&Ji, 2015) (Baert, et al, 2018 ) (Prasad Monika et al , 2017) ، ( Mwilima \& Hangula, 2017) 
العلاقة بين اضطراب الخوف من فقدان الهاتف المحمول ( النوموفوبيا ) ومستوى التحصيل الأكاديمي لطلاب جامعة الكوات الكويت

ب-علاوة على ذلك اطلعت الباحثة على بعض المقاييس الخاصة اضطراب الخوف من فقان ألهان الهاتف المحمول (النوموفوبيا) والتي استفادت منها أثناء اعداد المقياس المقاس الحالي وهي كالآتي:

دراسة (Yildirim, 2014) وتضمنت الدر اسة أربعة أبعاد لرهاب الخوف من فقدان الاتصال بالهاتف

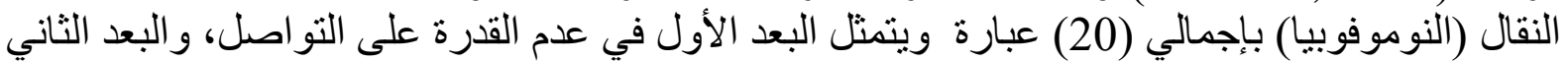

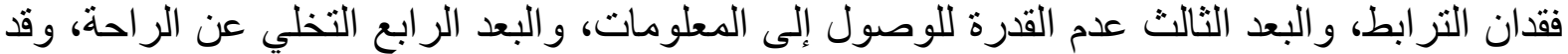

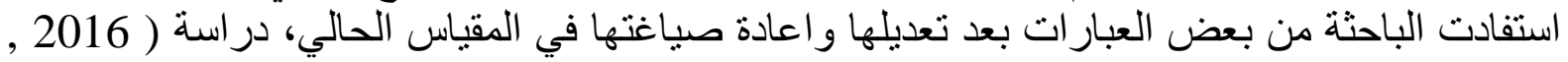
( Mihir et al

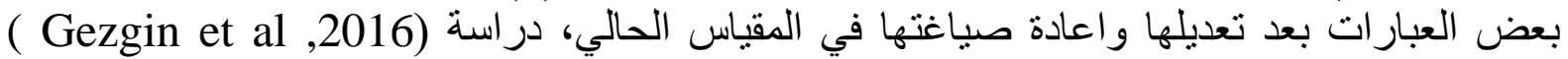

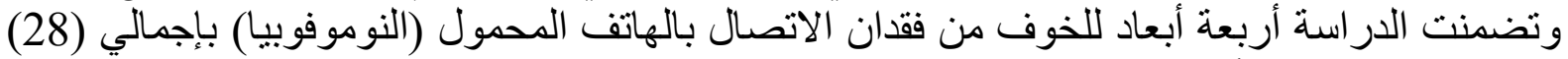

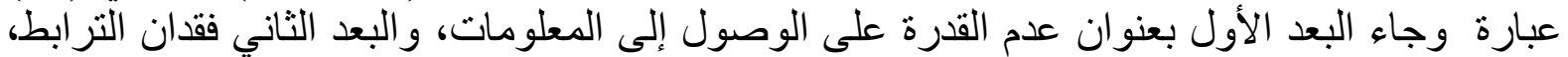

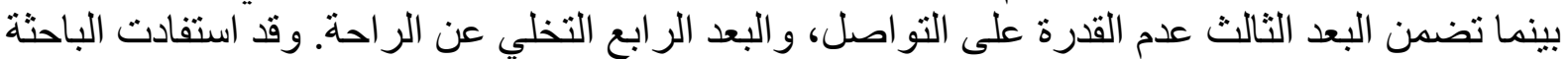
من بعض العبار ات بعد تعديلها و إعادة صياغتونها في المقياس الحالي.

ج-وصف مقياس اضطر اب الخوف من فقدان الهاتف المحمول (النوموفوبيا)

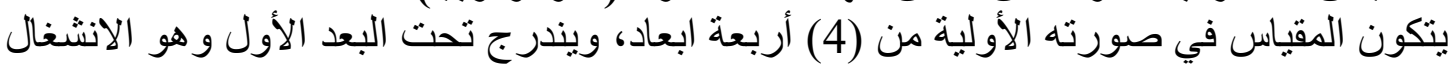

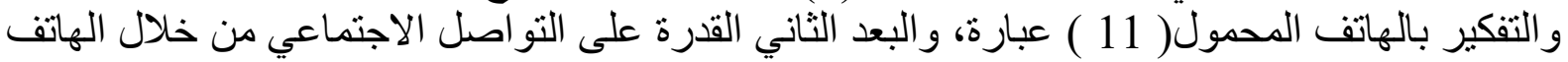

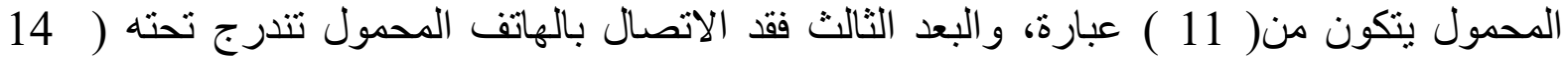

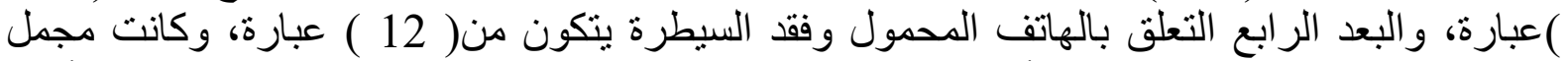

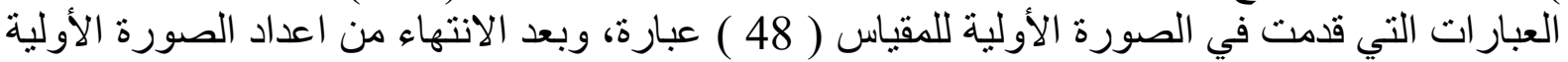

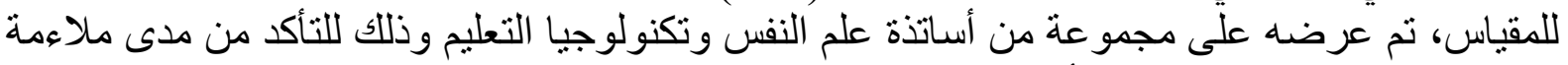

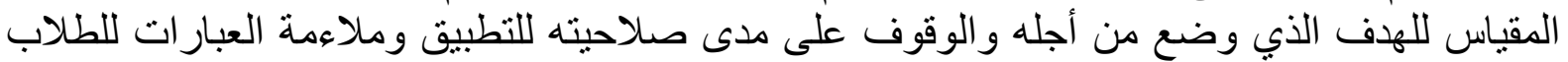

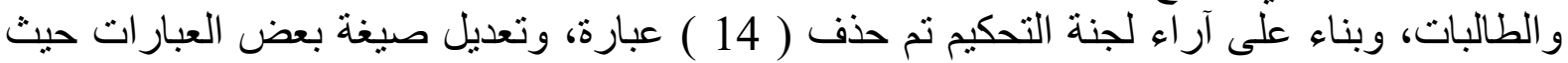

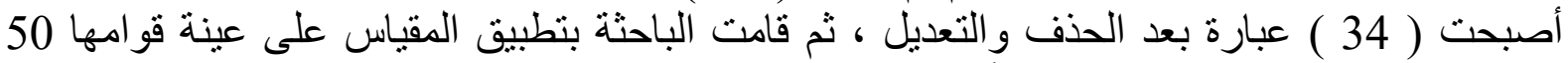
طالب وطالبة من جامعة الكويت ، و أصبح المقياس في صورته النهائية من (4) ابعاد وذلك على النى النحو التالي: - n

بُعد الانشغال و التفكير بالهاتف الدحمول (9 بنود).

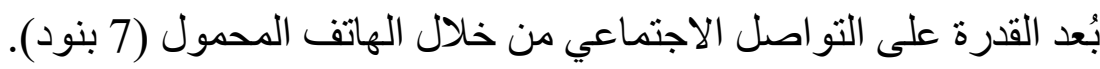

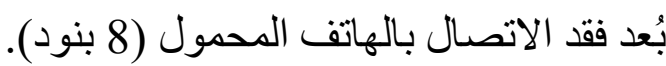

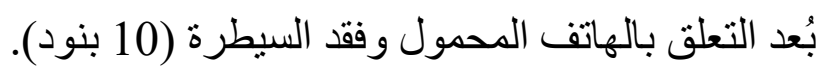

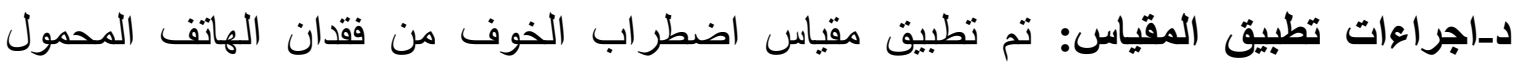

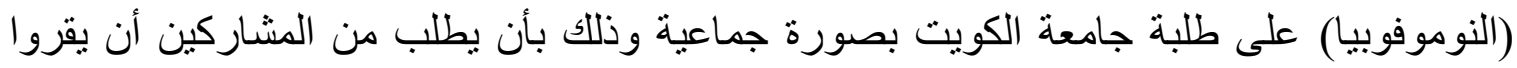

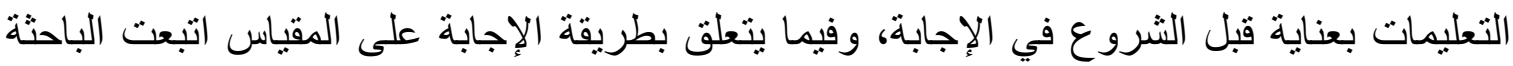

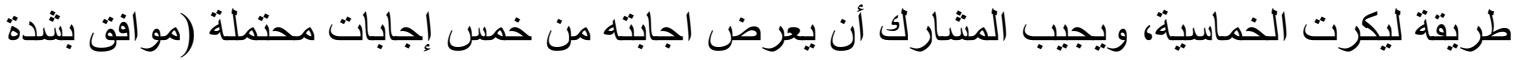

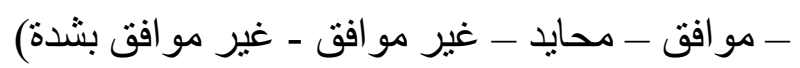

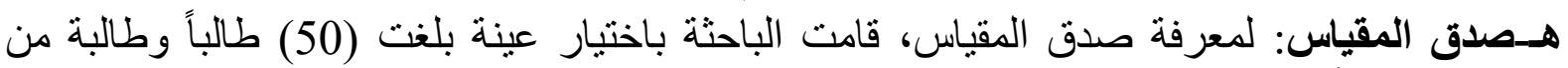

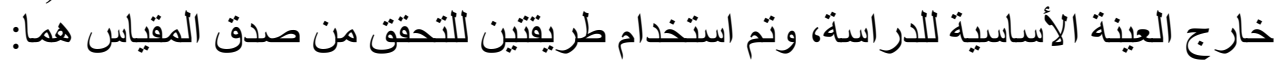

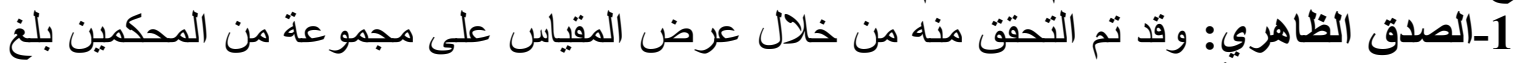

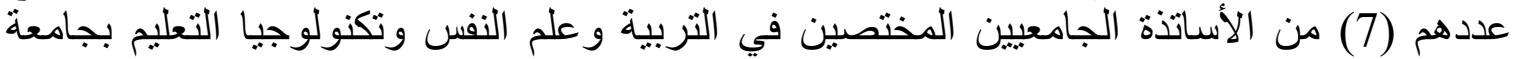
الكويت لمعرفة مدى صلاحية المقياس من حيث السلامة اللغوية ووضوح النية التعليمات ومدى انتماء كل 
العلاقة بين اضطراب الخوف من فقدان الهاتف المحمول ( النوموفوبيا ) ومستوى التحصيل الأكاديمي لطلاب جامعة الكوات الكويت

عبارة للبعد الذي تقيسه، مع الحرص على إضافة التعديلات و الملاحظات التي أشاروا إلى ضرورة

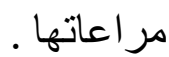

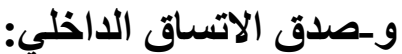

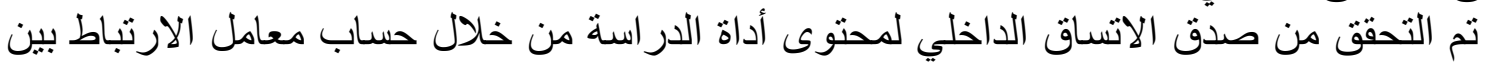

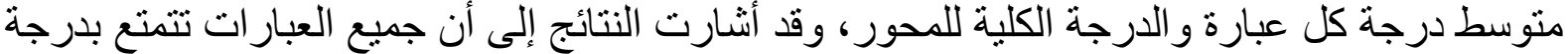

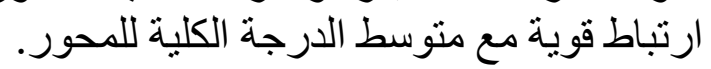

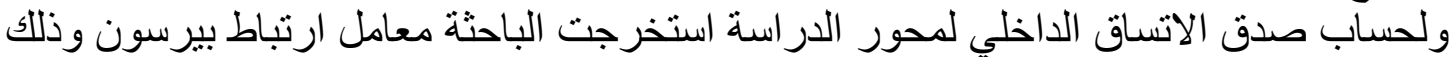

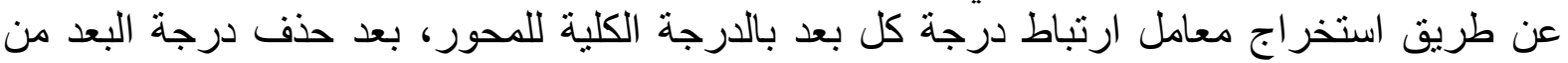

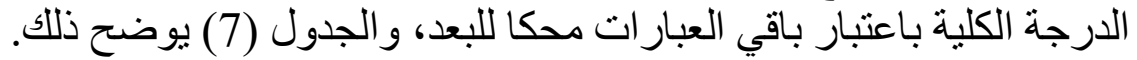

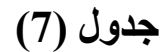

معامل ارتباط بيرسون لأبعاد مقياس (النوموفوبيا ) لطلبة جامعة الكويت والدرجة الكلية للمقياس (667 =ن)

\begin{tabular}{|c|c|c|}
\hline مقياس النوموفوبيا & \multicolumn{2}{|c|}{ ابعاد مقياس النوموفوبيا } \\
\hline $\begin{array}{l}0779 . * * \\
000 .\end{array}$ & معامل ارتباط بيرسون & الانشغال و التفكير بالهاتف \\
\hline $0.754 * *$ & معامل ارتباط بيرسون & القدرة على التو اصل \\
\hline 000 . & الدلالة الإحصائية & آلمحمول \\
\hline $\begin{array}{l}0.881^{* *} \\
000\end{array}$ & معامل ارتباط بيرسون & فقد الاتصال بالهاتف \\
\hline $\begin{array}{l}0.850^{* *} \\
000 .\end{array}$ & معامل ارتباط بيرسون الإلحصئة & التعلق بالهاتف المحمول وفقد \\
\hline
\end{tabular}

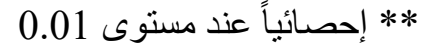

هيضح من الجدول السابق أن جميع ابعاد مقياس اضطراب الخوف من فقدان الهاتف المحمول

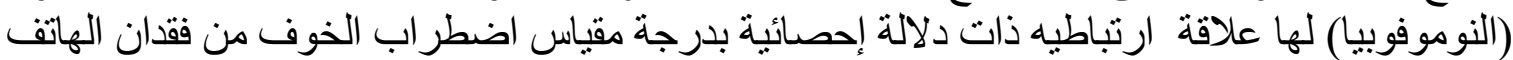

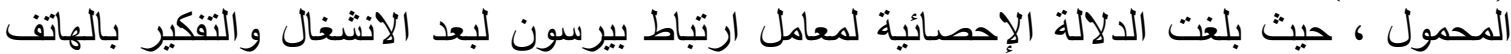

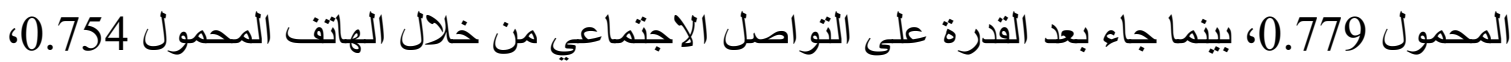

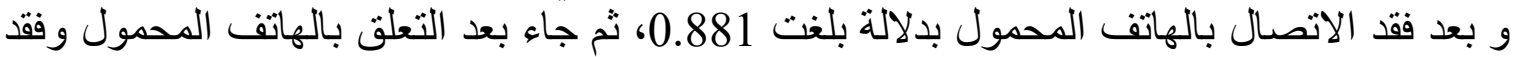

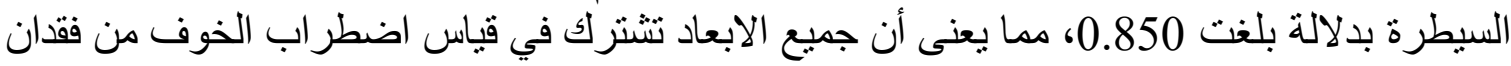

الهاتف المحمول (النوموفوبيا). ي-ثبات المقياس الفا كرونباخ آناخ

قامت الباحثة بحساب ثبات الفا كرونباخ لأبعاد مقياس اضطر اب الخوف من فقدان الهاتف المحمول، و الجدول رقم (8) يوضح ذلتك.

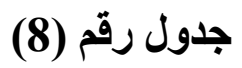

قيم معامل الفا كرونباخ لأبعاد مقياس (النوموفوبيا) لطلبة جامعة الكويت

\begin{tabular}{|c|c|c|c|c|c|}
\hline מ & & & & & دان \\
\hline
\end{tabular}


العلاقة بين اضطراب الخوف من فقدان الهاتف المحمول ( النوموفوبيا ) ومستوى التحصيل الأكاديمي لطلاب جامعة الكوات الكويت

\begin{tabular}{|c|c|c|c|c|}
\hline حذف العنصر & تُمحيحه & العنمر حذف & إلذف & \\
\hline 0.807 & 0.608 & 279.443 & 85.96 & الانشغال و التفكير بالهاتف المحمول \\
\hline 0.810 & 0.623 & 315.274 & 94.83 & القدرة خلال الهاتف التو المحمول الاجتماعي \\
\hline 0.737 & 0.757 & 234.861 & 90.33 & فقد الاتصال بالهاتف المحمول \\
\hline 0.776 & 0.678 & 235.775 & 82.99 & السيطرة بالهاتف المحمول وفقد \\
\hline 0.830 & \multicolumn{4}{|c|}{ ثبات مقياس اضطر اب الخوف من فقدان الهاتف المحمول النوموفوبيا } \\
\hline
\end{tabular}

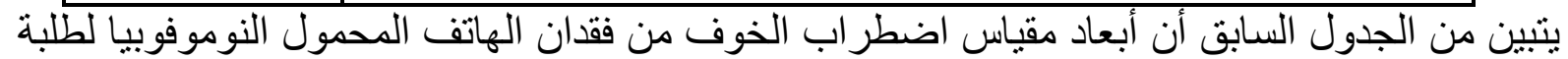

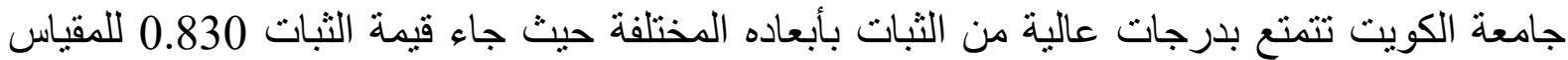

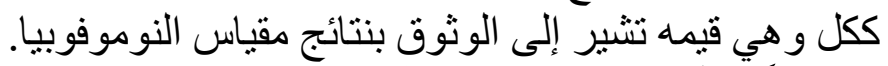

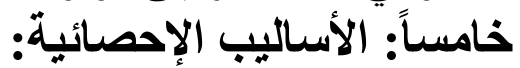

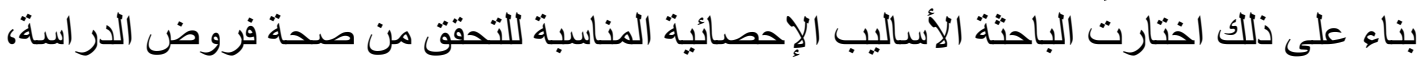
باستخدام برنامج الحزمة الإحصائية للعلوم الاجتماعية SPSS الإلصدارية الإلية (21) في إدخال البيانات وتحليلها، واستخدمت الأساليب التالية:

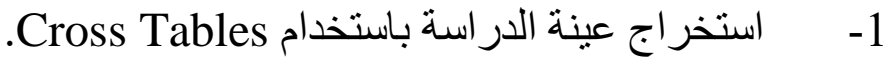
2-2 - المتوسط الحسابي و الانحر اف المعياري. 3- - معامل ارتباط بيرسون (Pearson Correlation).

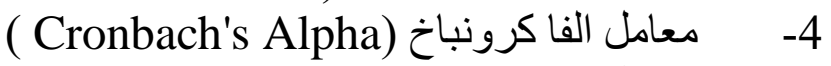

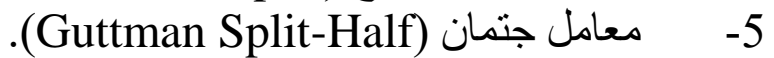

6-7 8- اختبار كروسكال و الز (Wallis-Kruskal) للعينات المستقلة.

نتائج الاراسة ومناقشتها

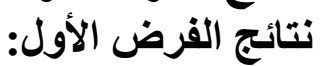

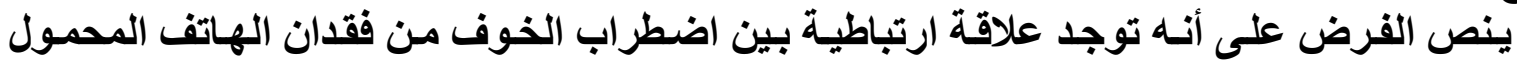

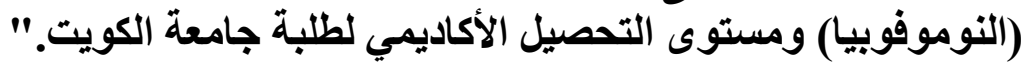

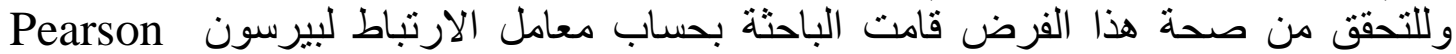

Correlation

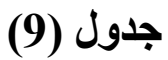

معامل ارتباط بيرسون لبيان العلاقة بين النوموفوبيا التحصيل الأكاديمي (n=667)

\begin{tabular}{|c|c|c|c|}
\hline الخوف الهاس اضن فقدان المحمول & التحصيل & & \\
\hline $\begin{array}{c}-0.711 * * \\
0.000\end{array}$ & 1 & معامل ارتباط بيرسونة الإلإية & مقياس التحصيل الأكاديمي \\
\hline 1 & $-0.711 * *$ & معامل ارتباط بيرسون & مقياس اضطر اب الخوف من فقدان \\
\hline
\end{tabular}


العلاقة بين اضطراب الخوف من فقدان الهاتف المحمول ( النوموفوبيا ) ومستوى التحصيل الأكاديمي لطلاب جامعة الكواب الكويت الكمب

الهاتف المحمول النوموفوبيا

0.01 * 0.0

يتضح من نتائج الجدول السابق ما يلي

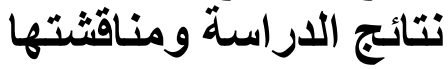

تشير النتائج إلى وجود ارتباط سلبى دال عند مستوى (0.01) بين مقياس التحصيل الأكاديمي و مقياس اضطراب الخوف من فقدان الهاتف المحمول النوموفوبيا حيث بلغت فئت قيمة معامل الارتباط

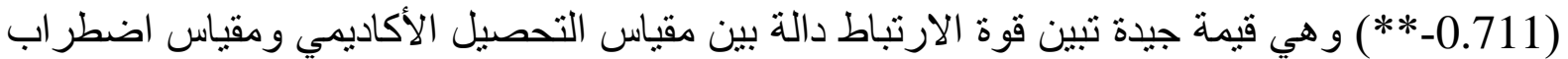

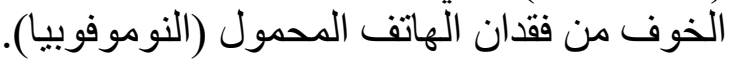

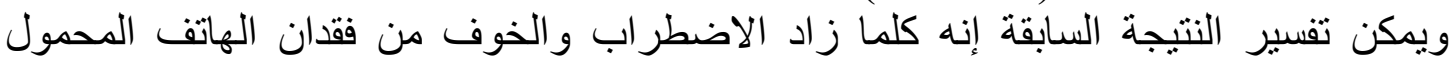

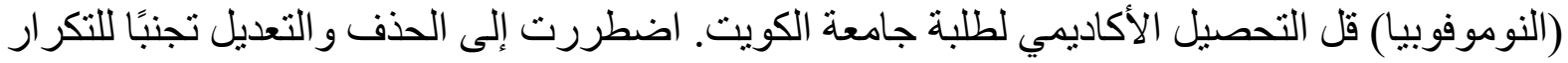

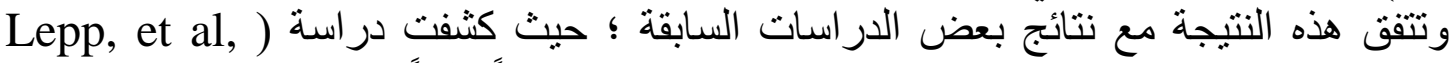
(2014, Lepp, et al, 2015, Chen \&Ji, 2015 الدرجات الفعلية لطلاب الجامعات، كذللك تتفق هذه النتيجة مع در اسة ( Rabiu, 2016 (

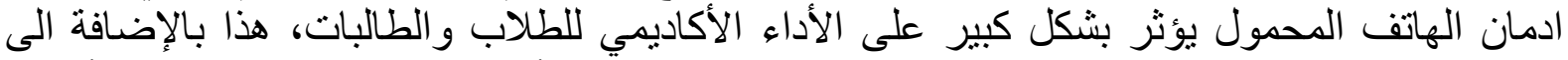

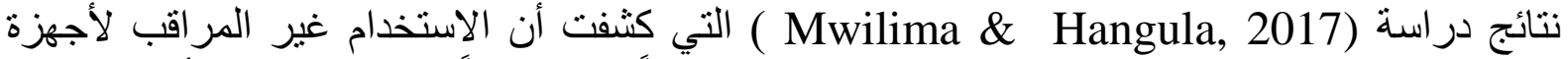

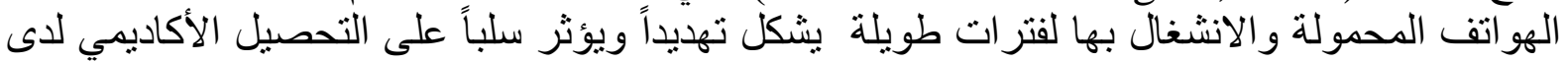
طلاب الجامعة و هذا ما أكدته دراسة 2018 (Baert, et al,) حيث توصلت إلى ألى أن التعلق بالهاتف المحمول وفقد السيطرة يؤدي إلى انخفاض في متوسط درجة اختبار طلاب الجامعات في بلجيكا، وتشير دراسة ( Felisoni \& Godoi , 2018 إلى أن فقد الاتصال بالهاتف المحمول بين طلبة الكليات له له

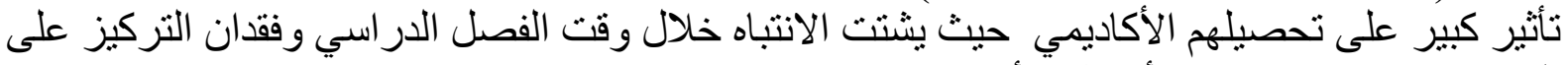

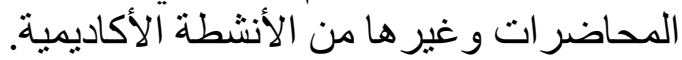

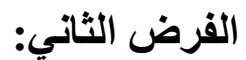
ينص الفرض على أنه: " لاتوجد فروق بين الطلاب والطالبات في اضطر اب الخوف من فقدان

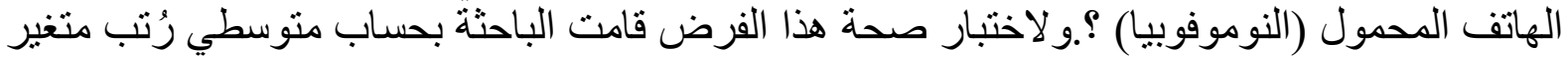

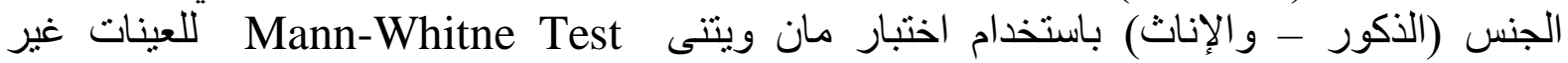

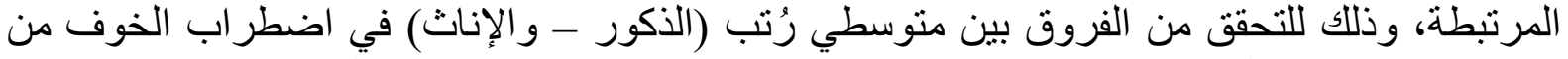

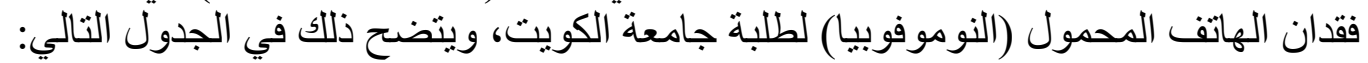

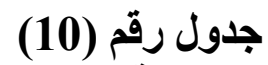

نتائج اختبار Mann-Whitney Test للالائة الفروق بين متوسطي رتب الأكور والاناث في اضطراب الخوف من فقدان الهاتف المحمول (النوموفوبيا) لطلبة جامعة الكويت

\begin{tabular}{|c|c|c|c|c|c|c|}
\hline الإحصائية الدلاية & وعامل مان & الرجموع & المتوسط رتبة & ن & & الجنس \\
\hline \multirow[b]{2}{*}{0.000} & \multirow[b]{2}{*}{43539.000} & 116758.00 & 371.84 & 314 & ذكر & \multirow{2}{*}{$\begin{array}{l}\text { فقدان الهاتف الب الخوف محمول } \\
\text { النوموفوبيا) }\end{array}$} \\
\hline & & 106020.00 & 300.34 & 353 & انتى & \\
\hline
\end{tabular}

مستوي الدلالة عند (0.01)

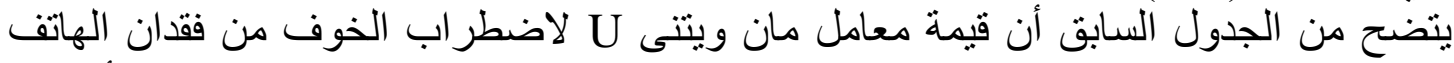

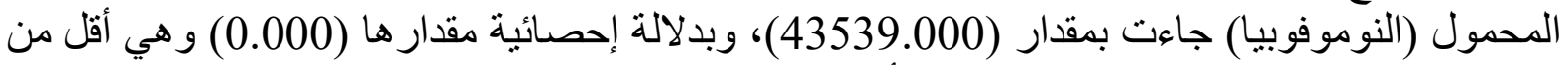

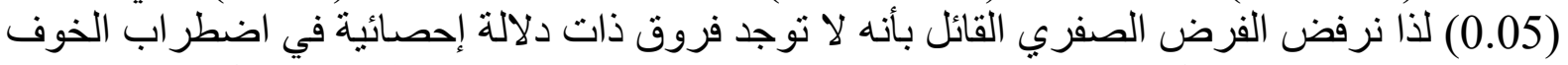

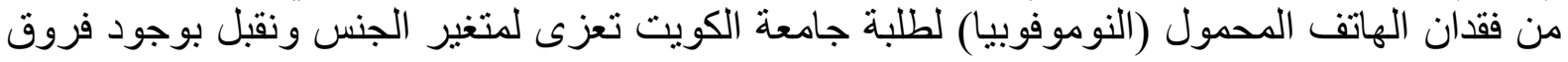
بين منوسط رتب الذكور والإناث، لصالح الذكور في اضطر اب الخوف من فقدان الهاتف المحمول 
العلاقة بين اضطراب الخوف من فقدان الهاتف المحمول ( النوموفوبيا )

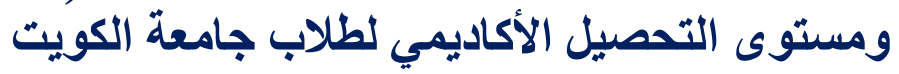

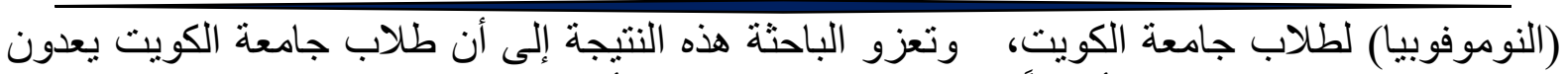

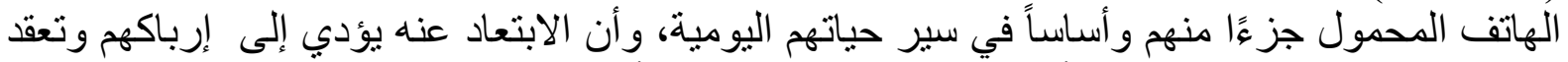

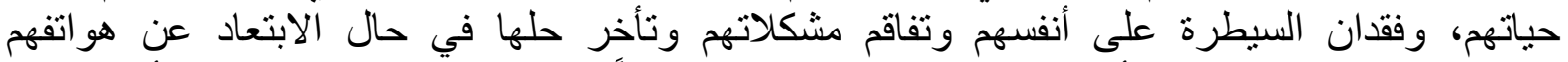

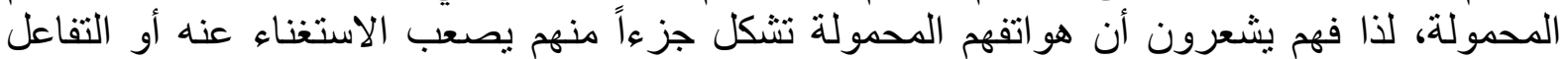

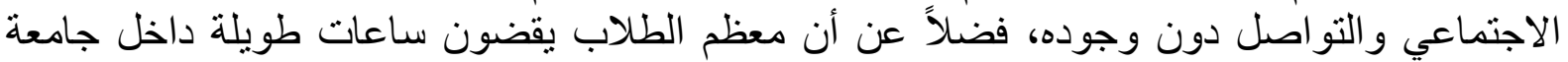

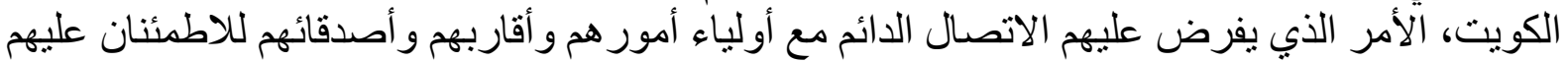

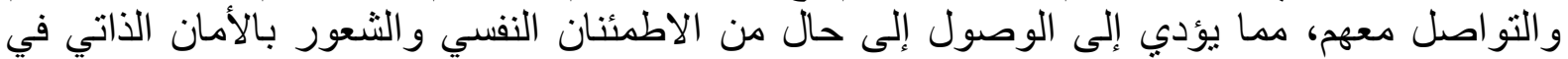

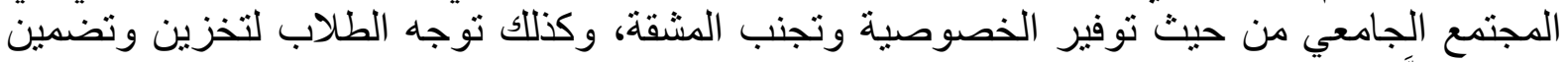

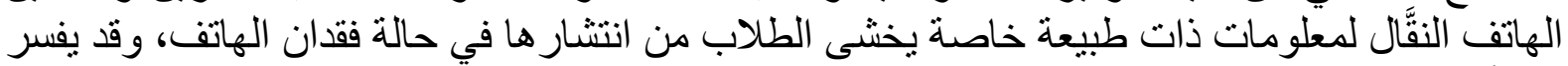

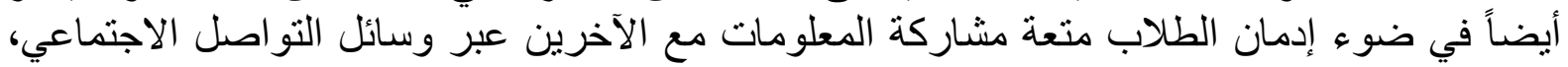

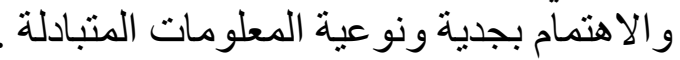

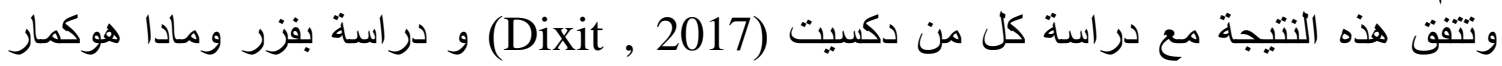

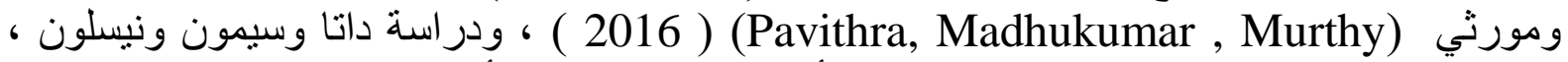
اله Datta, Simon ،Nelson

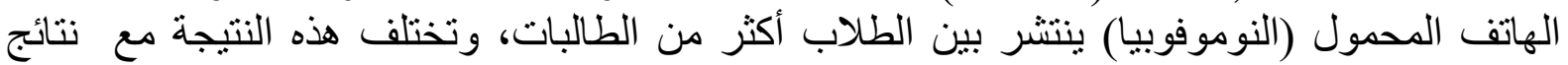

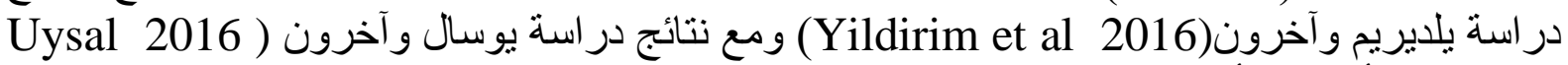

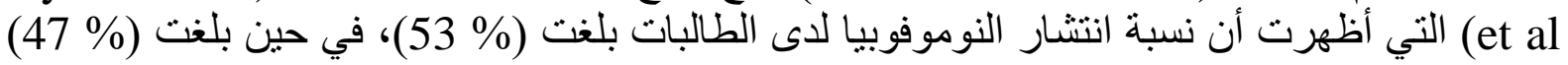

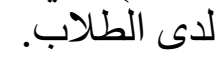

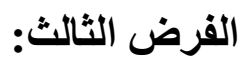
ينص الفرض على أنه: "لا توجد فروق بين طلاب التخصصات الأدبية وطلاب التخصصات العلمية في

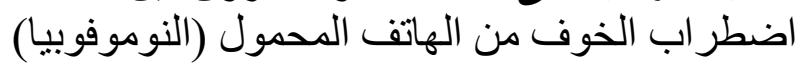

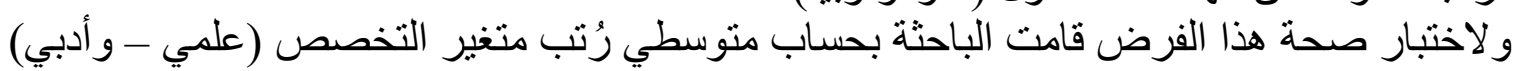

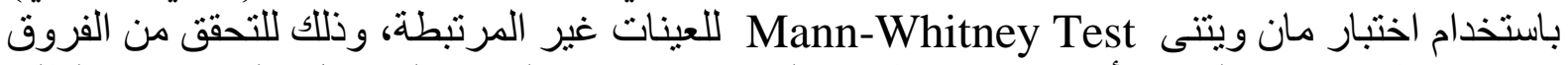

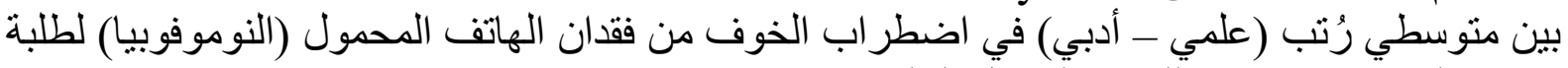

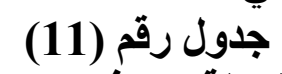
جامعة الكويث، ويتضح ذلّك في الجدولَ التالي:

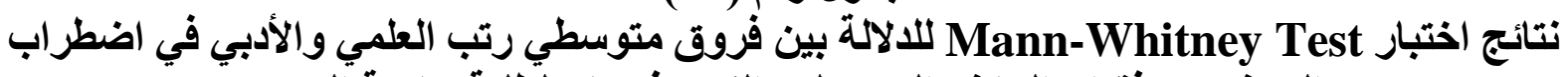

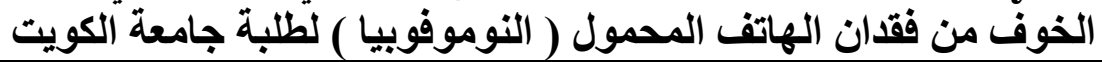

\begin{tabular}{|c|c|c|c|c|c|c|}
\hline الإحصائية & ويتنى Uامل مان & مجموع الرتب & المتوسطة & ن ن & \multicolumn{2}{|c|}{ التخصص } \\
\hline & & 127827.50 & 365.22 & 350 & علمي & بعد اضطر اب \\
\hline 0.000 & 44547.500 & 14950.50 & 299.53 & 317 & ادبي & فقدان الهوف من الندول \\
\hline
\end{tabular}

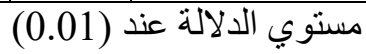

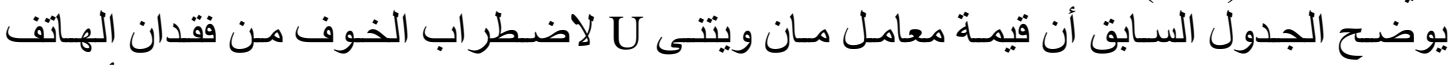

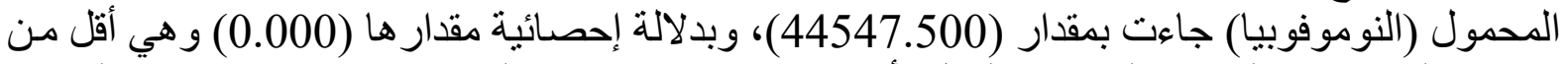

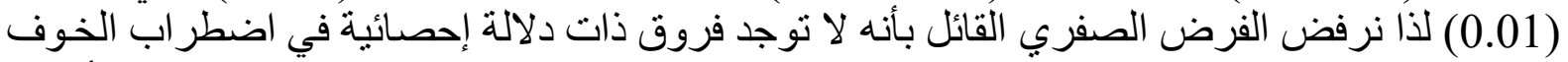

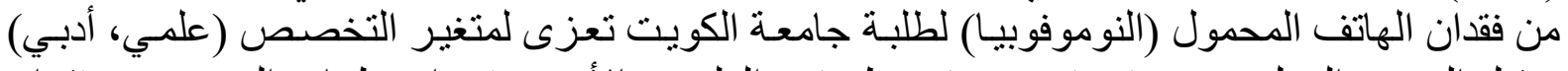

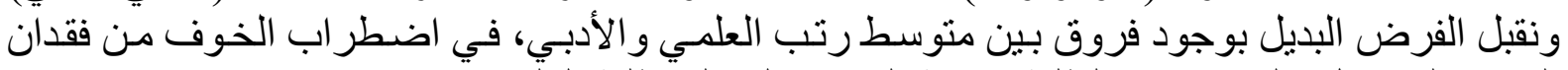

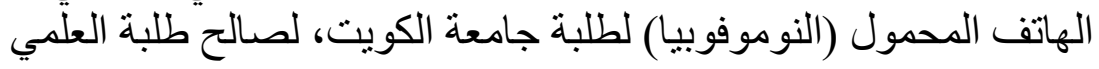


العلاقة بين اضطراب الخوف من فقدان الهاتف المحمول ( النوموفوبيا ) ومستوى التحصيل الأكاديمي لطلاب جامعة الكواب الكويت الكمب

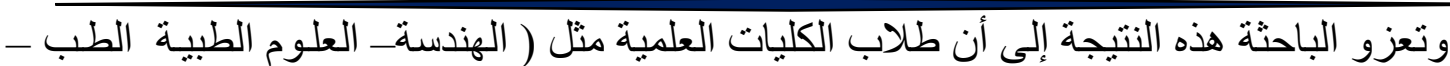

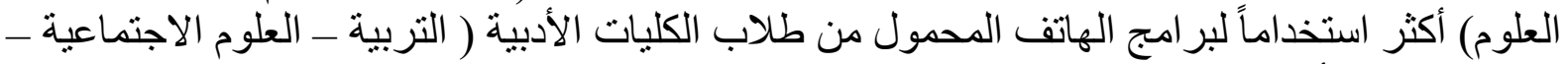

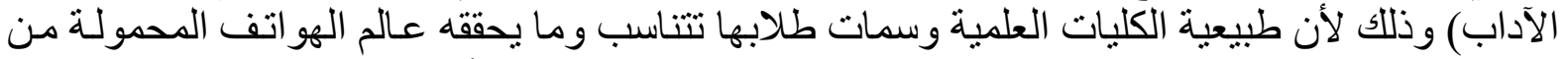

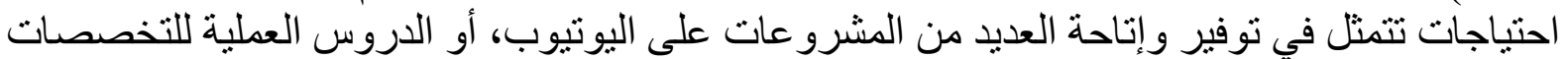

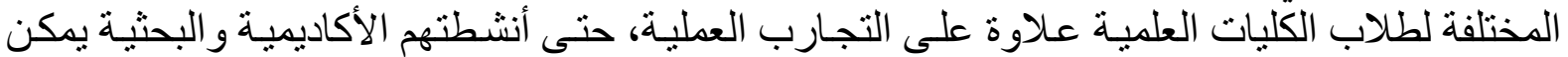

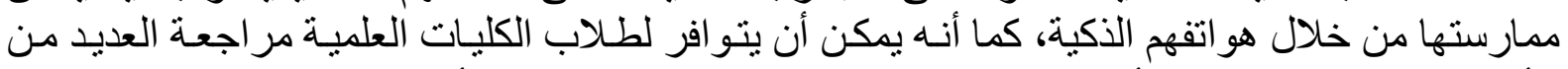

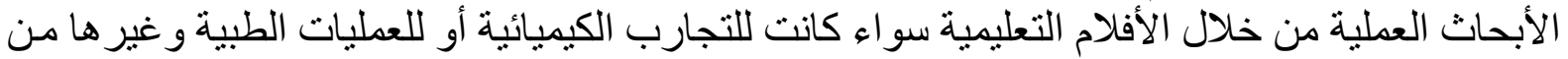

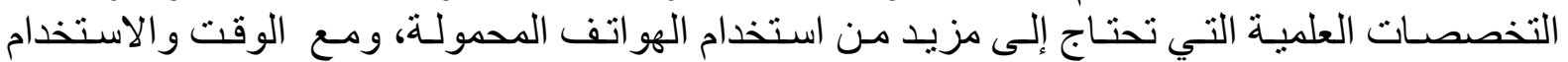

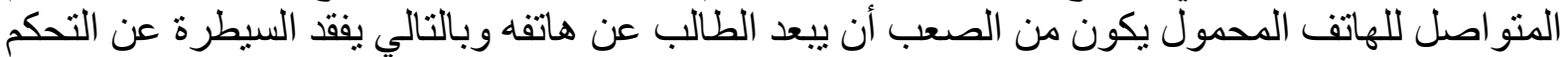

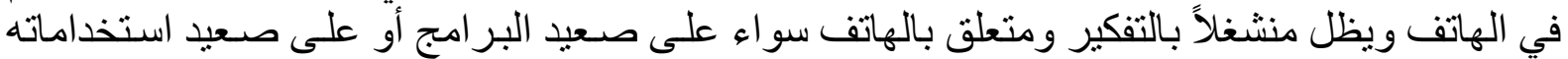

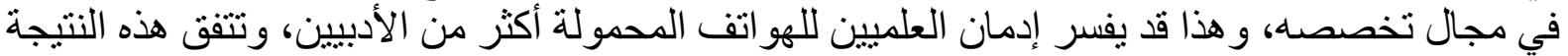

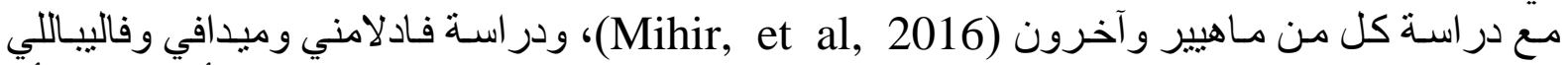

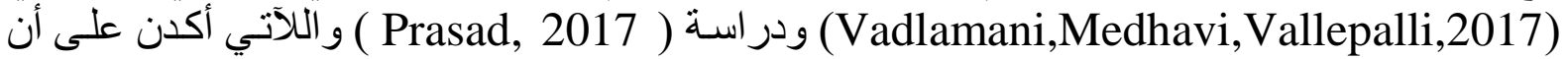
طلاب كلية الطب يستخدمون هو اتفهم المحمولة في در استهم العملية.

الفرض الرابع: - ابع ينص الفرض: على أنه: لا توجد فروق بين المرتفعين في المعدل التراكمي والمنخفضين في

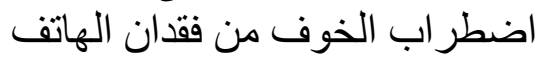
و لاختبار صحة هذا الفرض قامت البت الباحثة بحساب منوسطات رُتب متغير المعدل التر اكمي (أقل من ون

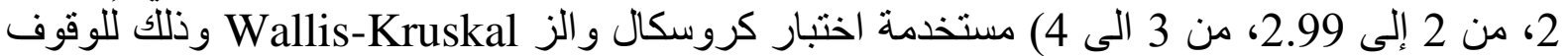

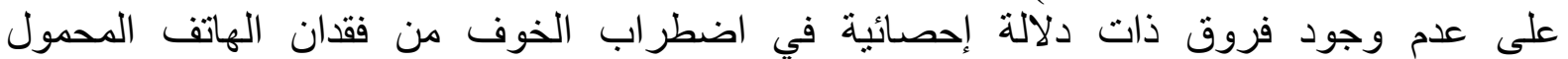
(النوموفوبيا) لطلبة جامعة الكويت تعزى للمعدل التر اكمي والجدول فئل التول التالي يوضح ذلك جدول (12)

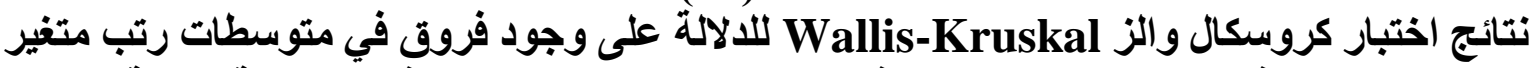
المعدل التراكمي في اضطراب الخوف من فقدان الهاتف المحمول (النوموفوبيا) لطلبة جامعة الكويت فئري

Test Statisticsa,b

\begin{tabular}{|c|c|c|c|c|c|c|}
\hline الاحصائية الالية & الحرجة & كاي & متوسط الرتبة & العدد & يدل التر اكمي & \\
\hline \multirow{3}{*}{0.000} & \multirow{3}{*}{2} & \multirow{3}{*}{18.019} & 367.36 & 43 & اقل من 2 & \multirow{3}{*}{ 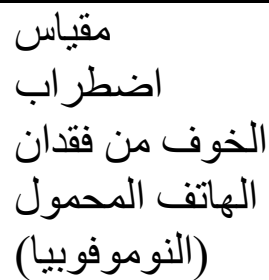 } \\
\hline & & & 356.91 & 380 & $\begin{array}{l}2 \text { من الى } 2.99 \\
\text { من }\end{array}$ & \\
\hline & & & 292.44 & 244 & من 3 الى 4 & \\
\hline
\end{tabular}

a. Kruskal Wallis Test

b. Grouping Variable: المعدل التر اكمي

تشير نتائج اختبار كروسكال والز Wallis-Kruskal للالالة على وجود فروق في متوسطات رنب التب

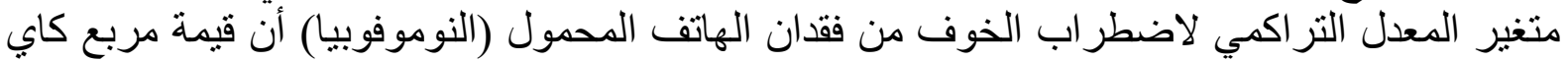

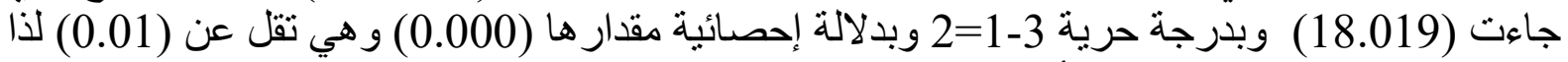

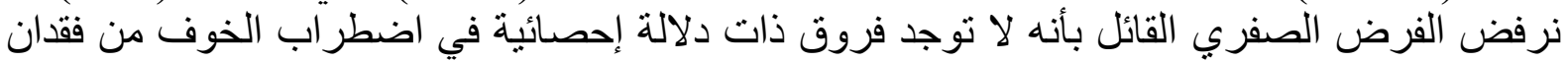

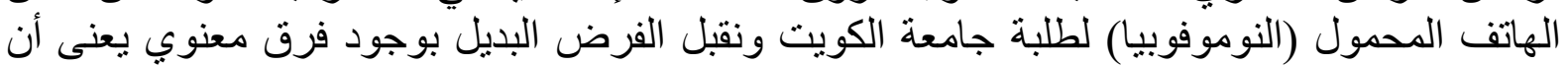

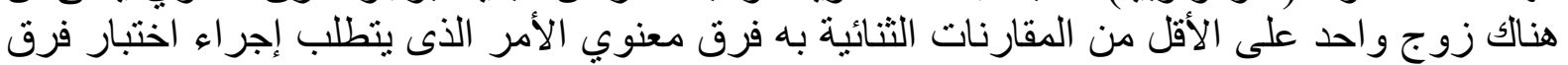

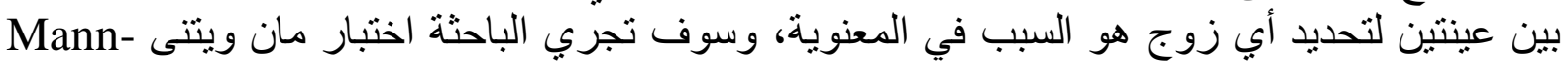


العلاقة بين اضطراب الخوف من فقدان الهاتف المحمول ( النوموفوبيا ) ومستوى التحصيل الأكاديمي لطلاب جامعة الكوات الكويت

Whitney Test

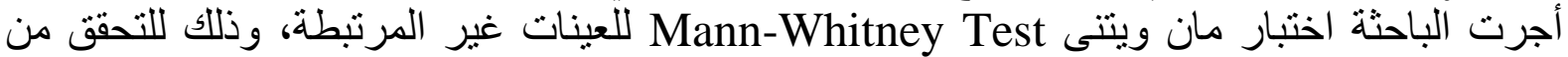
الفروق بين متوسطي رُتب كل مجمو عنين من مجمو عات متغير المعدل التر اكمي و الجدول التالي يوضح

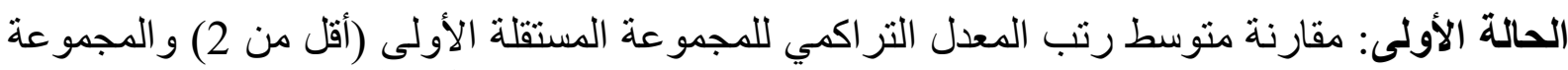

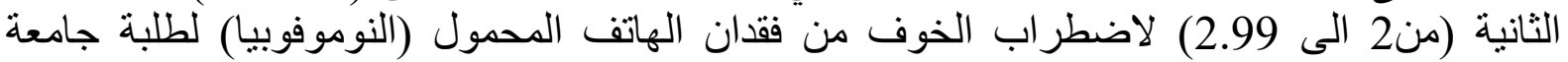

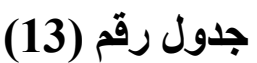

الكويت

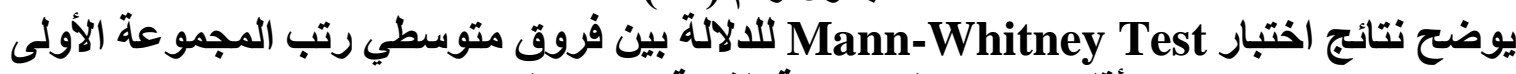
(أقل من 2) والمجموعة الثانية (من 2 الى لى منى 2.99)

Test Statisticsa

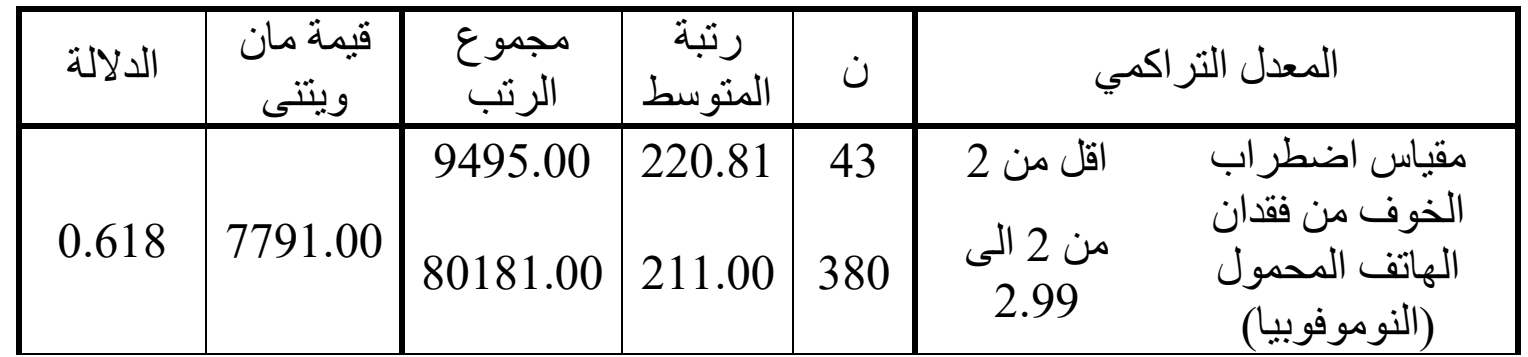

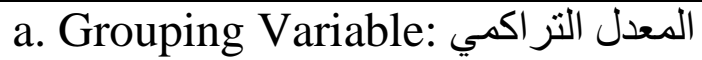

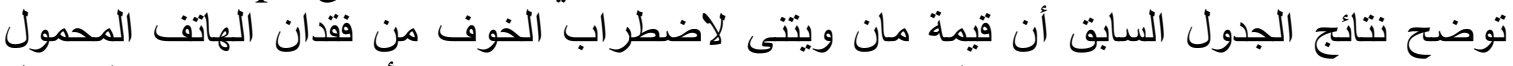

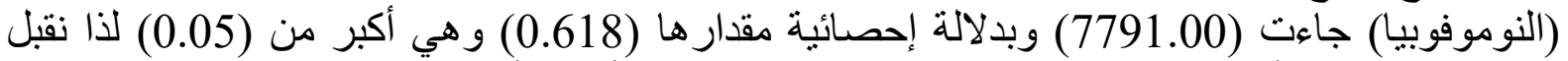

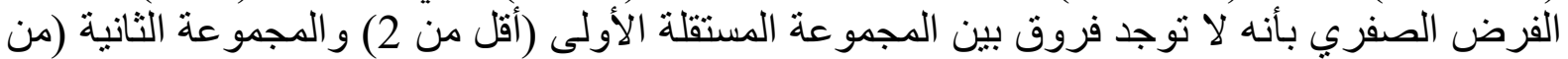

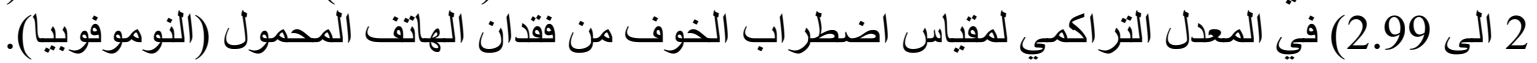

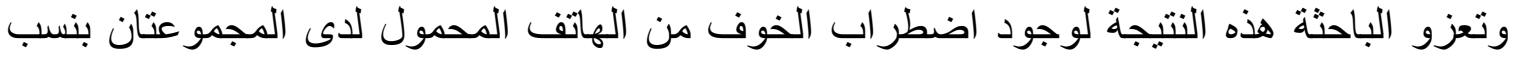

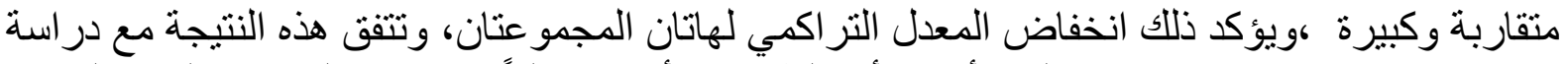

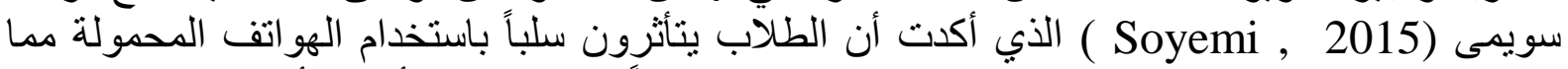

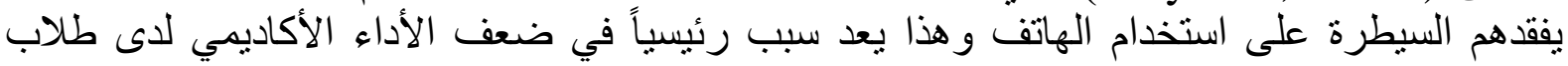

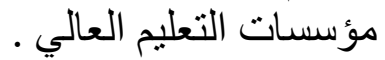

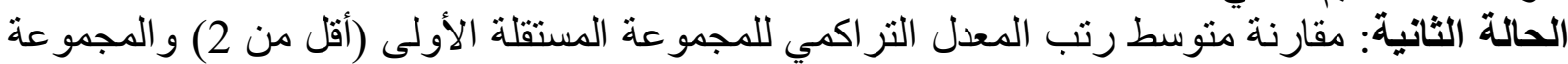

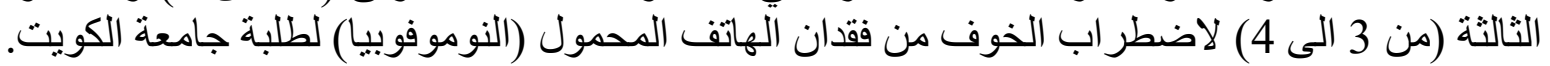

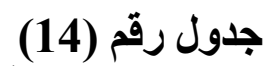

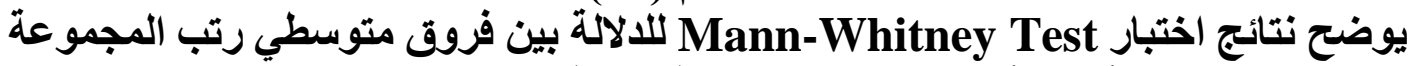
الأولى (أقل من 2) والمجموعة الثالثة (من 3 الى 4)

Test Statisticsa

\begin{tabular}{|c|c|c|c|c|c|c|}
\hline 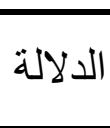 & قويتة مان & مجموع & المتوسطة & ن ن & \multicolumn{2}{|c|}{ المعدل التر اكمي } \\
\hline & & 7247.00 & 168.55 & 43 & اقل من 2 & مقياس اضطر اب \\
\hline 0.35 & 4212.000 & 3480.00 & 139.67 & 244 & من 3 الى 4 & الهاتف المحمول \\
\hline
\end{tabular}

a. Grouping Variable: المعدل التراكمي 
العلاقة بين اضطراب الخوف من فقدان الهاتف المحمول ( النوموفوبيا )

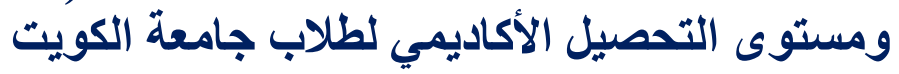

توضح نتائج الجدول السابق أن قيمة مان ويتنى لاضطر اب الخوف من فقدان الهاتف المحمول

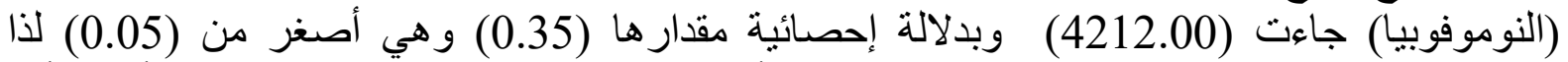

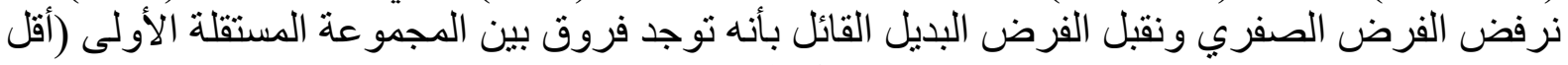

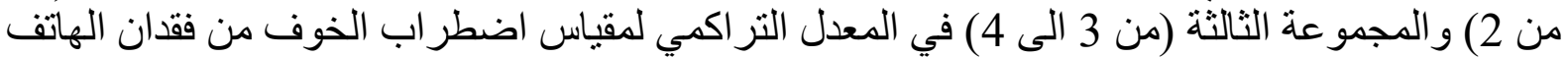

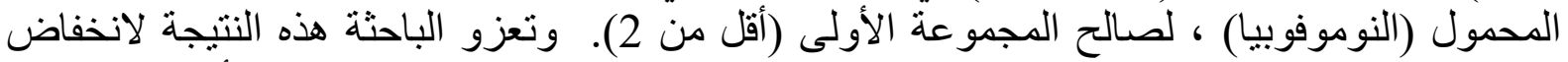

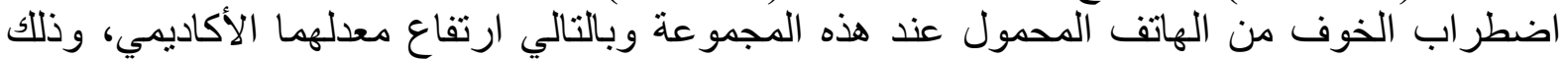

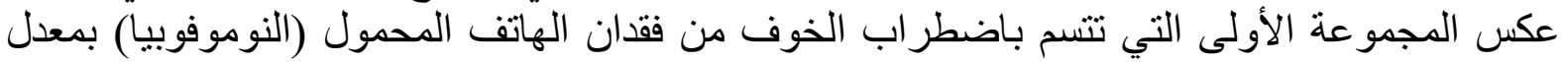

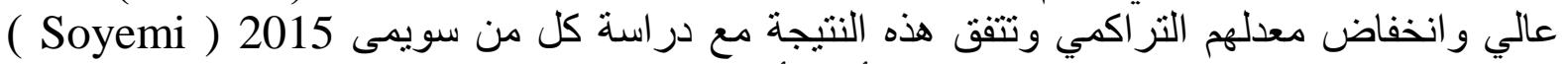

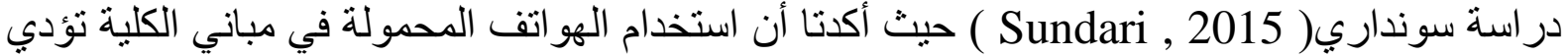
إلى انخفاض الاداء الأكاديمي. الثالثة (من 3 الى 4) لاضطر اب الخوف من فقدان الهاتف المحمول (النوموفوبيا) لطلبة جامعة الكويت.

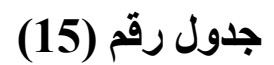

يوضح نتائج اختبار Mann-Whitney Test (للالالة بين فروق متوسطي رتب المجموعة الثانية (من 2 الى 2.99) والمجموعة الثالثة (من 3 الى 4)

\begin{tabular}{|c|c|c|c|c|c|c|}
\hline لة & مان ويتنى & الرتب مجموع & بة المتو سط & ن & & اكمي \\
\hline $\begin{array}{l}0.0 \\
\quad 00\end{array}$ & $\begin{array}{r}3727 \\
6.00\end{array}$ & $\begin{array}{r}12783 \\
4.00 \\
67166 . \\
00\end{array}$ & $\begin{array}{l}33 \\
6.41 \\
27 \\
5.27 \\
\end{array}$ & 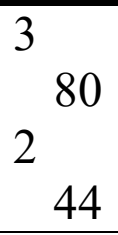 & الى 2.99 من 2.99 & 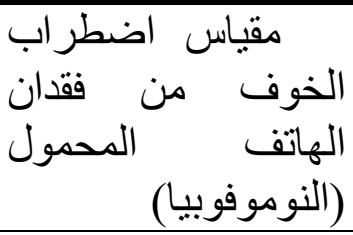 \\
\hline
\end{tabular}

المعدل التراكمي

توضح نتائج الجدول السابق الفروق بين متوسطي رتب المجموعة الثانية (من 2 الى الى 2.99)

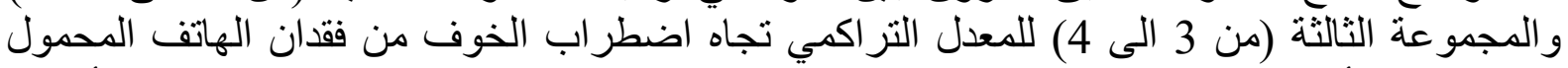

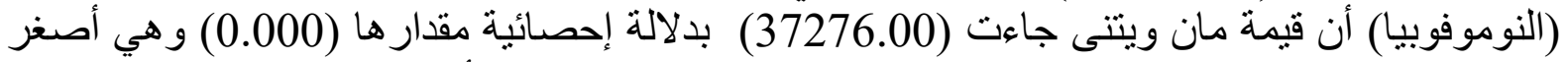

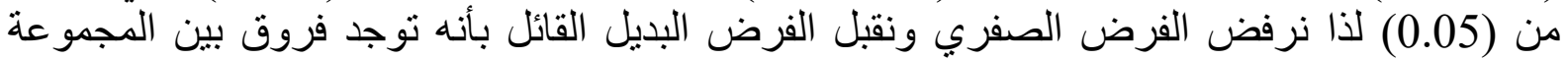

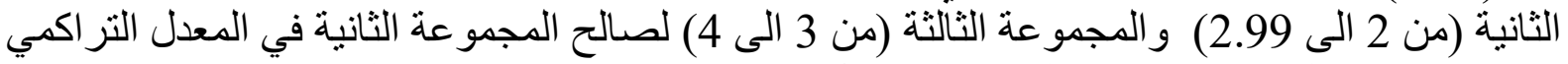

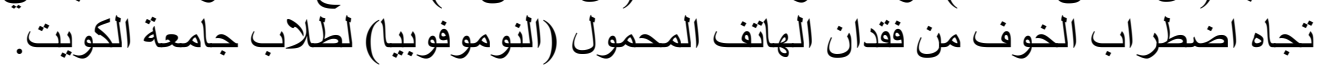

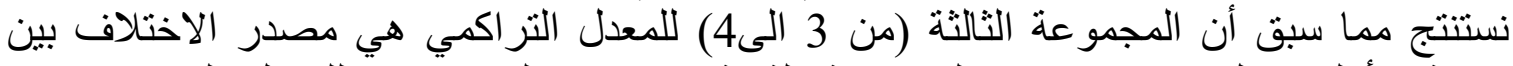

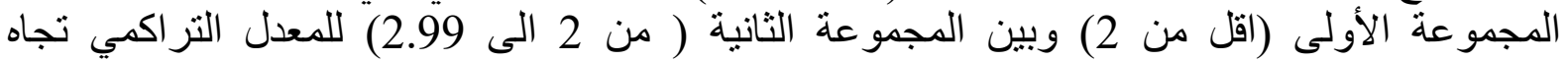

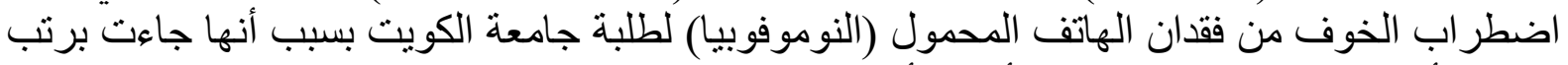

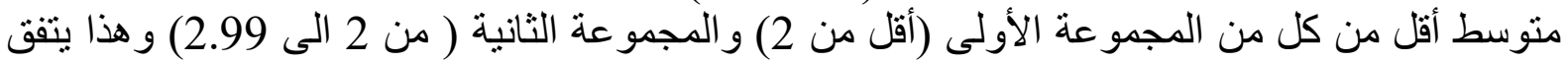

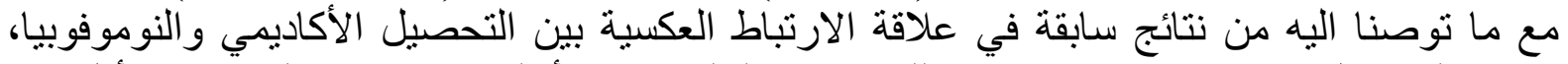

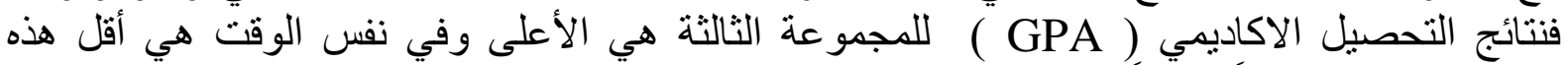

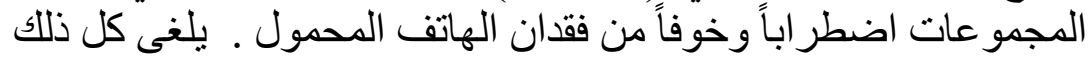

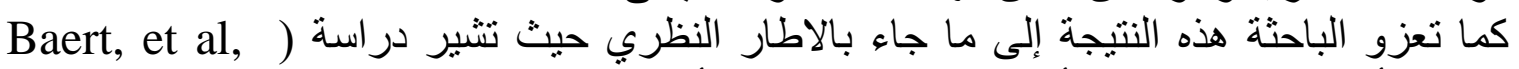

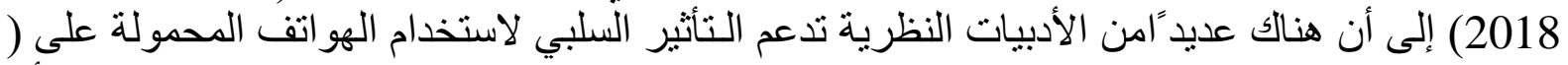

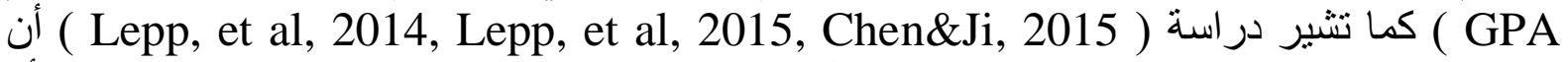
هناك ارتباطا سلبيا بين الاستخدام والانشغال بالهاتف المحمول ومتوسط الدرجات الفعلية أو 
العلاقة بين اضطراب الخوف من فقدان الهاتف المحمول ( النوموفوبيا ) ومستوى التحصيل الأكاديمي لطلاب جامعة الكوات الكويت

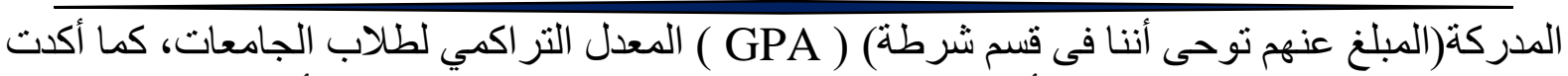

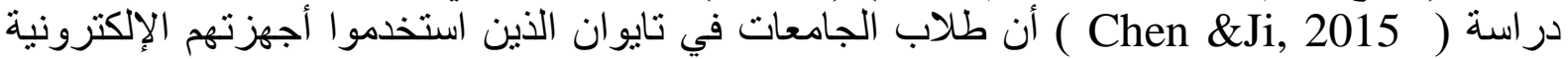

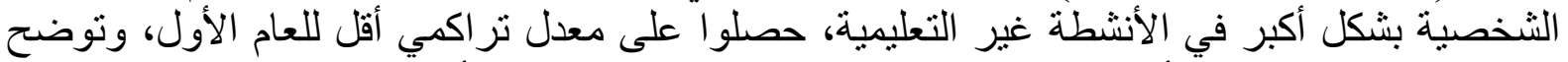

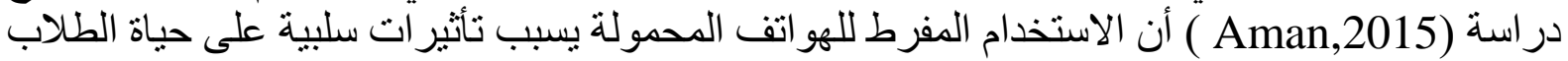

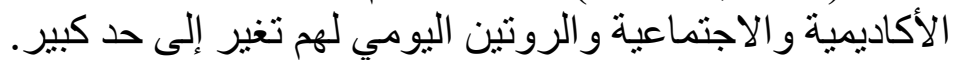

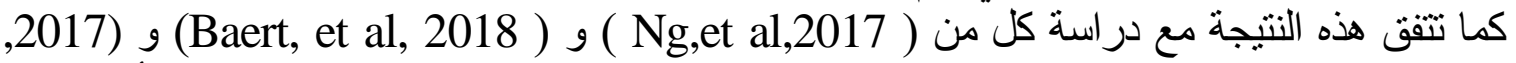
وجن Hangula وجود علاقة ارتباطيه عكسية بين معدل استخدام والانشغال بالهاتف المحمول وانخفاض المعدل التراكمي (

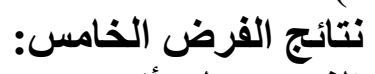
( GPA

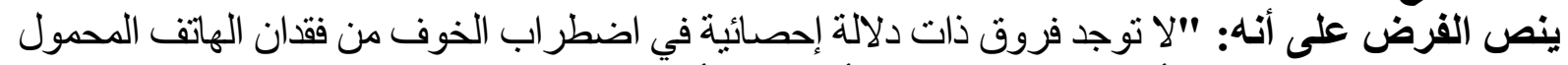
( النوموفو بيا ) و التحصيل الأكاديمي بين الطلاب الأصغر و الأكبر عمرًا.

و لاختبار صحة هذا الفرض قامت الباحثة بحساب منوسطات رُنب مجمو عات متغير العمر (أقل من 20 من 20

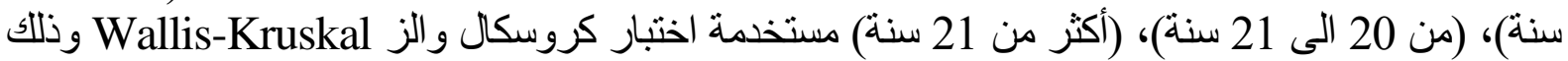
للوقوف على وجود فروق ذات دلالة إحصائية في اضطر اب الخوف من فقدان الهاتف المحمول (النوموفوبيا) لطلبة جامعة الكويت و الجدول التالي يوضح ذلآلك.

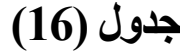

نتائج اختبار كروسكال والز Wallis-Kruskal للالالة على وجود فروق في متوسطات رتب متغير العمر في اضطراب الخوف من فقدان الهاتف المحمول (النوموفوبيا) لطبة جامعة الكويت فئريت

Test Statisticsa,b

\begin{tabular}{|c|c|c|c|c|c|c|}
\hline الاحصائية & الحرجة & مربع كاي & متوسط & العدد & \multicolumn{2}{|c|}{ العمر } \\
\hline \multirow{3}{*}{0.002} & \multirow{3}{*}{2} & \multirow{3}{*}{12.585} & 383.23 & 90 & أقل من 20 سنة & \multirow{3}{*}{ 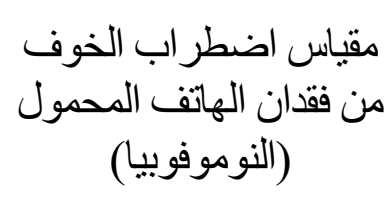 } \\
\hline & & & 352.91 & 199 & من 20 إلى 21 سنة & \\
\hline & & & 312.32 & 378 & أكثر من 21 سنة & \\
\hline
\end{tabular}

a. Kruskal Wallis Test

b. Grouping Variable: العمر

تشير نتائج اختبار كروسكال و الز Wallis-Kruskal للالالة على وجود فروق في متوسطات رتب متغير

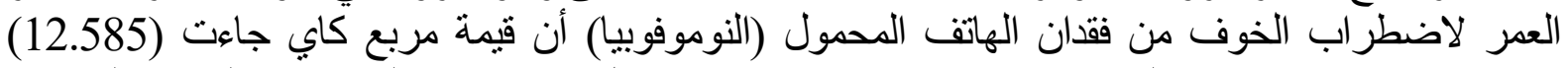

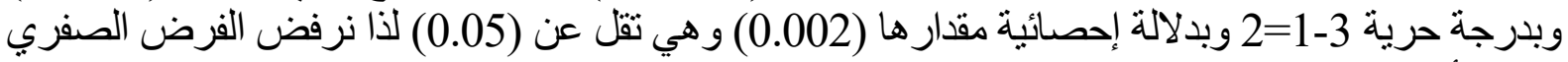

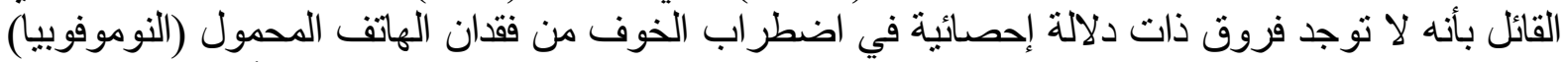

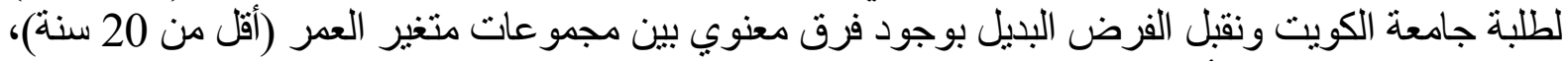

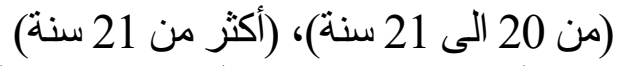

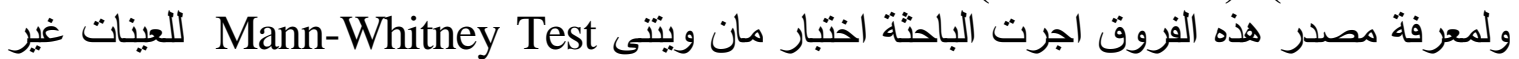

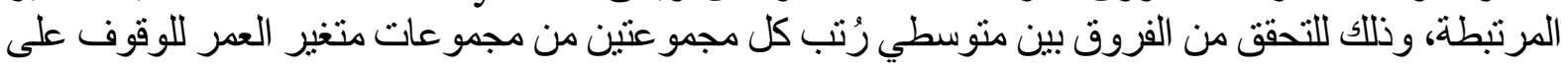

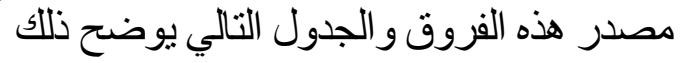

الحالة الأولى: مقارنة متوسطر رتب متغير العمر للمجموعة المستقلة الأولى (أقل من 20 سنة) والمجمو عة الثانية (من 20 إلى 21) لاضطر اب الخوف من فقدان الهاتف المحمول (النوموفوبيا) لطلبة جامعة الكوليت. 
العلاقة بين اضطراب الخوف من فقدان الهاتف المحمول ( النوموفوبيا ) ومستوى التحصيل الأكاديمي لطلاب جامعة الكوات الكويت

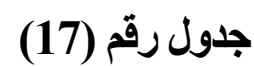

يوضح نتائج اختبار Mann-Whitney Test وللالآة بين فروق متوسطي رتب المجموعة الأولى (أقل

Test Statisticsa

من 2) والمجموعة الثانية (من 2 الى فروف 2.99)

\begin{tabular}{|c|c|c|c|c|c|c|}
\hline الدلالة & قويمة مان & مجموع & المتوسطة & ن ن & \multicolumn{2}{|c|}{ العمر - ل العم } \\
\hline \multirow{3}{*}{0.407} & \multirow{3}{*}{8410.500} & 13549.00 & 151.05 & 90 & أقلّ من 20 سنة & مقياس اضطر اب \\
\hline & & & & & & الخوف من فقدان \\
\hline & & 28310.00 & 142.49 & 199 & من 20 الى 21 & الالنه موفو بيا) \\
\hline
\end{tabular}

a. Grouping Variable: العر

توضح نتائج الجدول السابق أن قيمة مان ويتنى لاضطراب الخوف من فقدان الهاتف المحمول

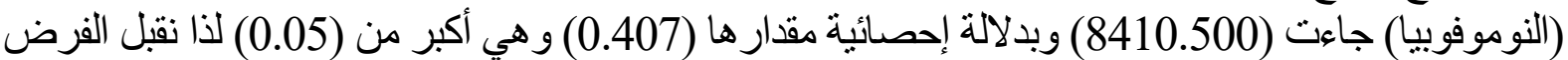

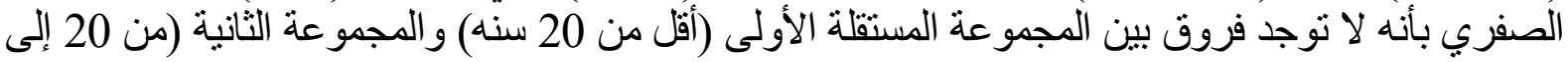

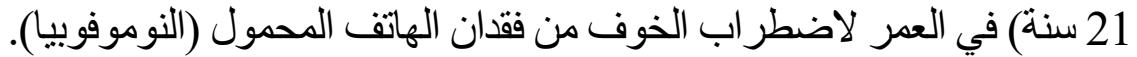

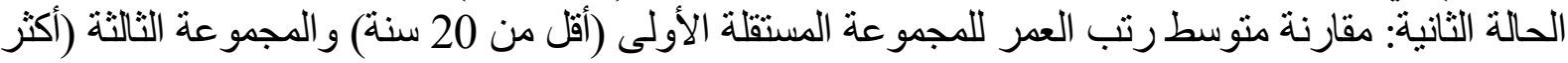
من 21 سنه) لاضطر اب الخوف من فقدان الهاتق المحمول (النوموفوبيا) لطلبة جامعة الكويت.

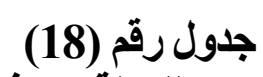

يوضح نتائج اختبار Mann-Whitney Test للالالة بين فروق متوسطي رتب المجموعة الأولى (اقل Test Statisticsa

$$
\text { من } 20 \text { سنة) والمجموعة الثالثة (أكثر من } 21 \text { سنة) }
$$

\begin{tabular}{|c|c|c|c|c|c|}
\hline الدلالة & قويتمة مان & مجموع & المتوسطة & ن & العر \\
\hline 0.001 & 13123.500 & $\begin{array}{l}24919.50 \\
84754.50\end{array}$ & $\begin{array}{l}277.68 \\
224.22\end{array}$ & $\begin{array}{l}90 \\
378\end{array}$ & 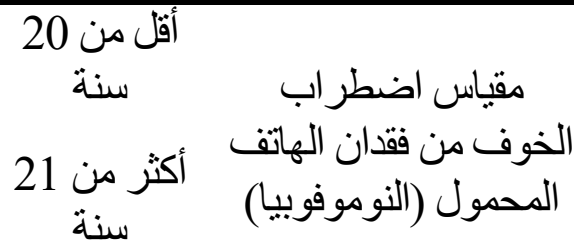 \\
\hline
\end{tabular}

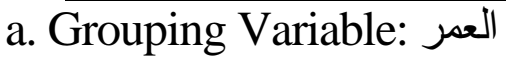

توضح نتائج الجدول السابق أن قيمة مان ويتنى لاضطراب الخوف من فقدان الهاتف المحمول

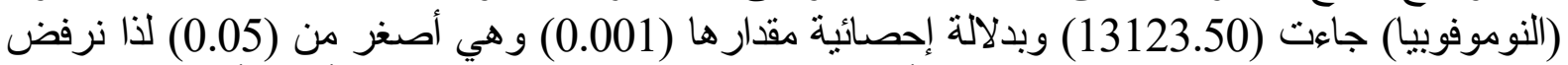

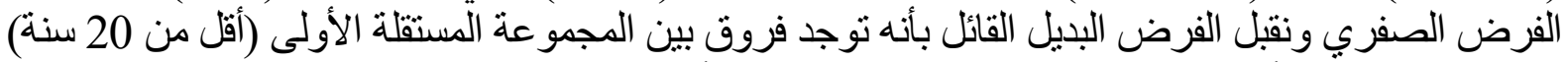

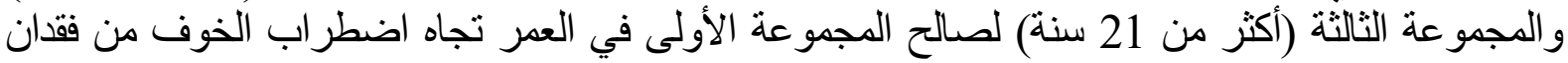
الهاتق المحمول (النوموفوبيا). 
العلاقة بين اضطراب الخوف من فقدان الهاتف المحمول ( النوموفوبيا ) ومستوى التحصيل الأكاديمي لطلاب جامعة الكوات الكويت

الحالة الثالثة: مقارنة متوسط رتب العمر للمجموعة الثانية (من 20 إلى 21 سنة) و المجموعة الثالثة (أكثر من 21 سنة) لاضطر اب الخوف من فقدان الهاتف المحمول (النوموفوبيا) لطلاب جامعة الكويت.

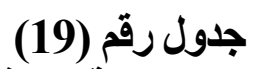

يوضح نتائج اختبار Mann-Whitney Test لدالة بين فروق متوسطي رتب المجموعة الثانية (من

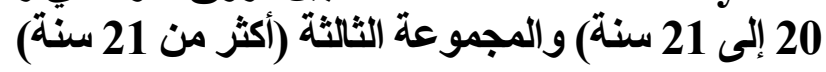

Test Statisticsa

\begin{tabular}{|c|c|c|c|c|c|c|}
\hline الدلالة & قيمة مان ويتتى & مجموع الرتب & رالمتوسط & ن & & العمر \\
\hline 0.024 & 33303.000 & $\begin{array}{r}61819.00 \\
104934.00\end{array}$ & $\begin{array}{l}310.09 \\
277.60\end{array}$ & $\begin{array}{l}199 \\
378\end{array}$ & أكثر من 21 سنة 21 إلى 21 & الخاتق المن فمول النوان \\
\hline
\end{tabular}

a. Grouping Variable: العمر

توضح نتائج الجدول السابق لاضطر اب الخوف من فقدان الهاتف المحمول (النوموفوبيا) أن قيمة مان

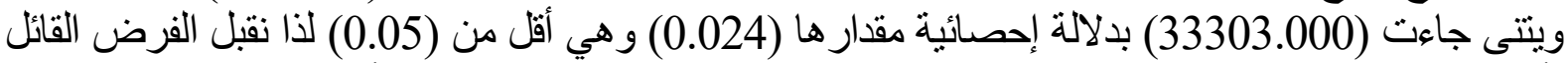

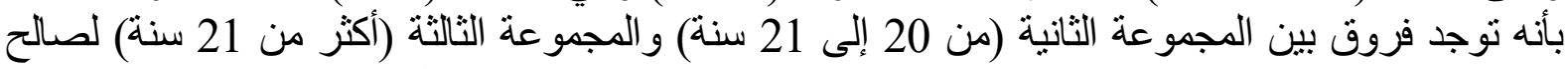
المجموعة الثانية في العمر تجاه اضطراب الخوف من فقدان الهاتف المحمول (النوموفوبيا) لطلبة جامعة الكويت.

نستنتج مما سبق أن الفروق في الرتب كانت بين المجموعة الأولى (أقل من 20 سنة) و المجموعة الثالثة

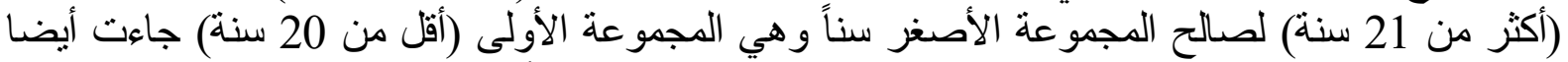

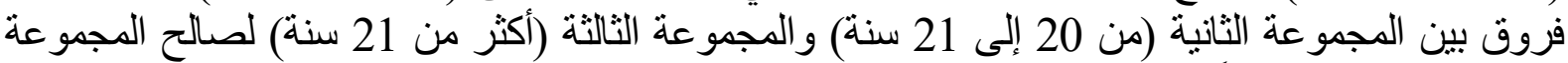

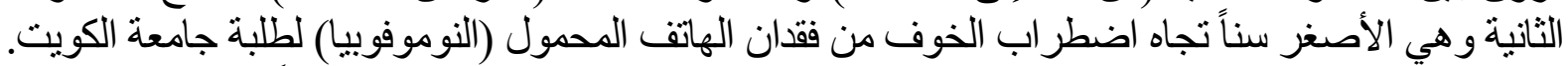

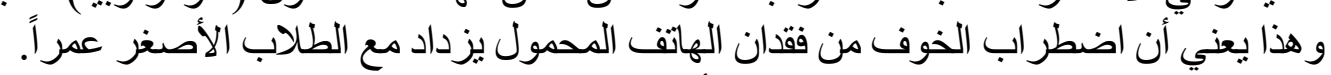

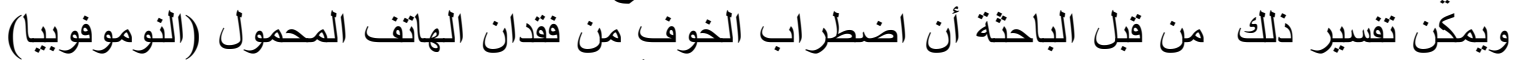

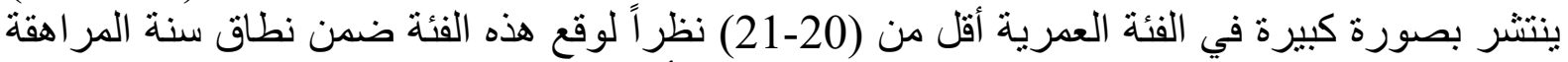

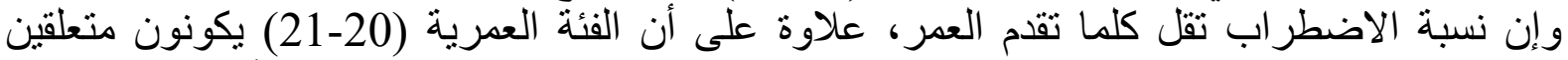

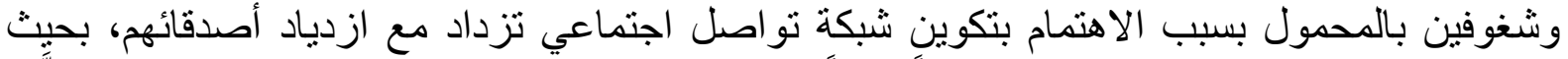

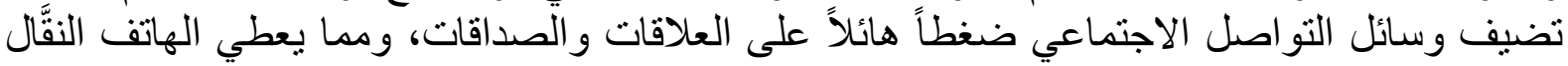

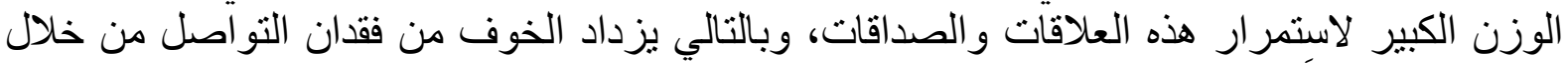

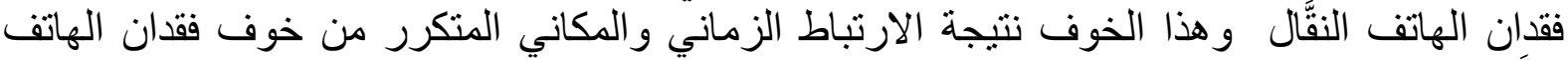

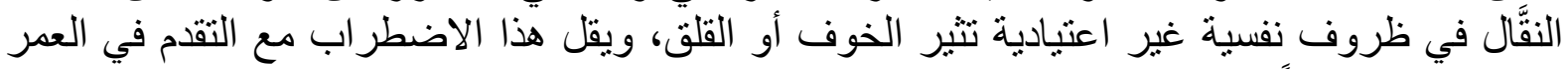

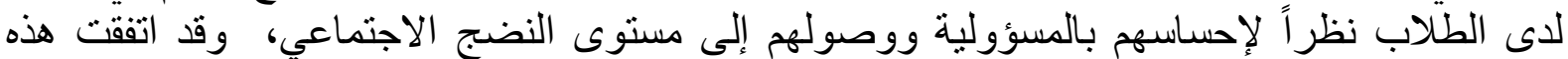

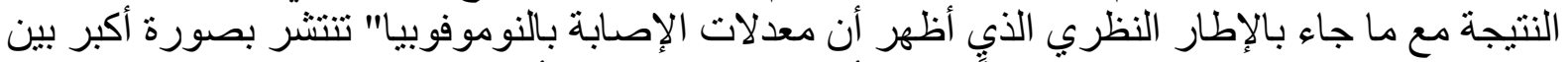

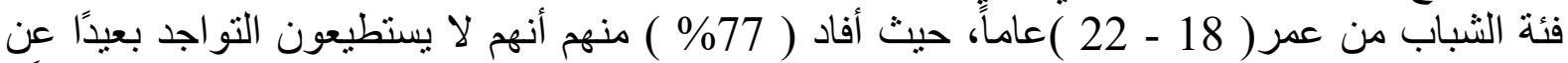

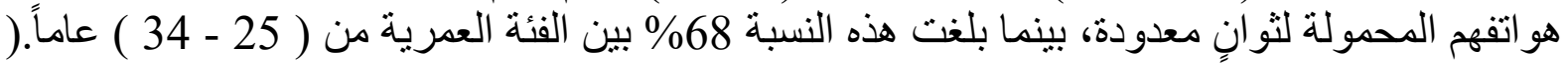

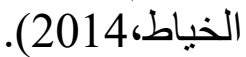


العلاقة بين اضطراب الخوف من فقدان الهاتف المحمول ( النوموفوبيا ) ومستوى التحصيل الأكاديمي لطلاب جامعة الكوات الكويت

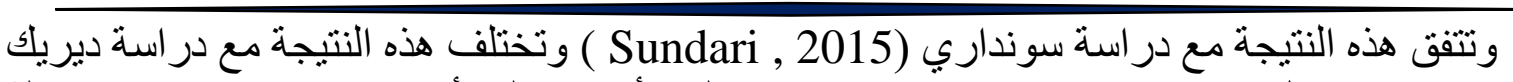

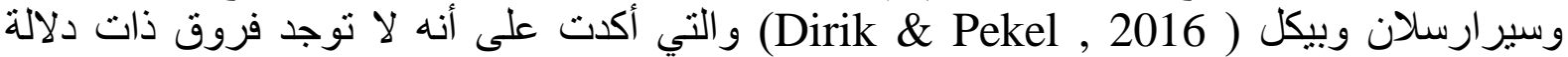
إحصائية بين إدمان الهو اتف الذكية للمشاركين المر اهقين و أعمار هم.

\section{التوصيات}

في ضوء ما توصلت إليه الدراسة من نتائج يمكن صياغة التوصيات التالية:

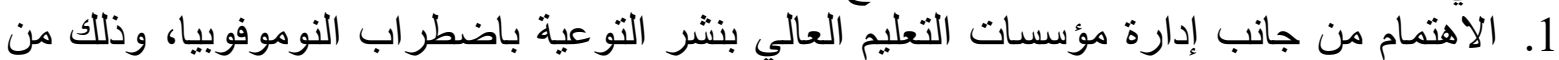

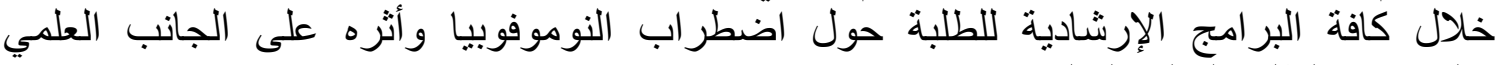

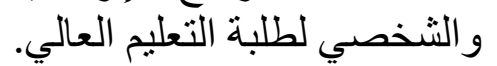

2. اهتمام الآباء بأبنائهم وبشكل خاص لئلئ في المراحل العمرية المبكرة وذلك من خلال إمداد الأبناء بكل

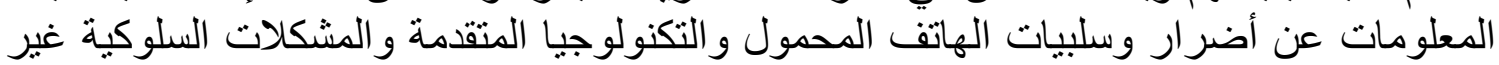

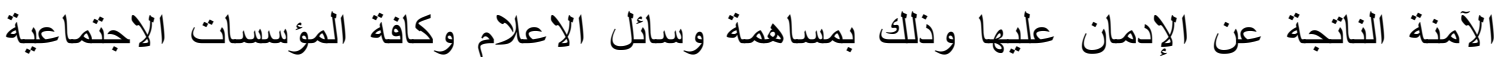

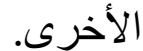
3. اصدار العديد من النشرات وعقد العديد من ورش العمل والندوات لزيادة وعي طلاب التعليم

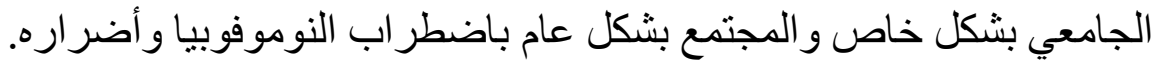

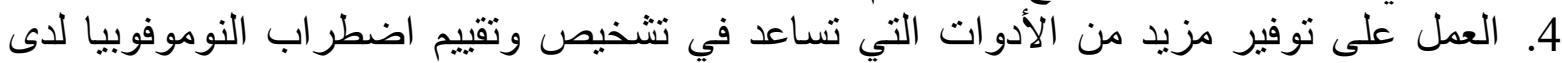
المصابين في الوطن العربي. 5. تدريب المختصين في علم النفس على كيفية تشخيص اضطراب النوموفوبيا وكيفية التعامل معه النها

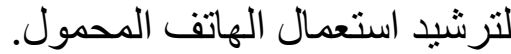
6. ادخال مفاهيم "الخوف المرضيدي من فقدان الهاتف المحمول" و و"سوء استعمال الهاتف المحمول"

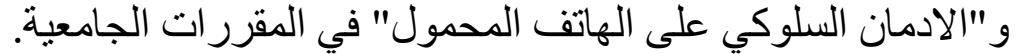

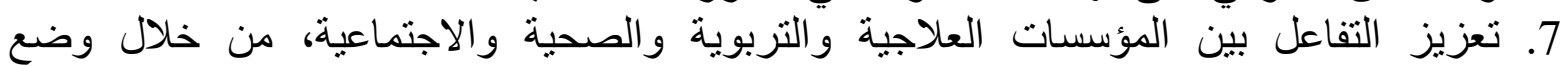
استر اتيجيات للحد من الإدمان المرضي للهاتف الفرئ المحمول.

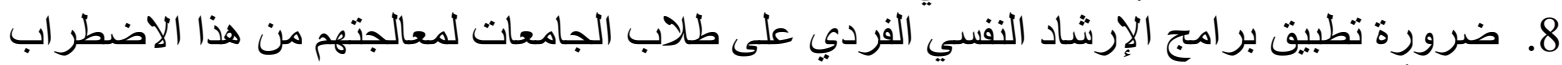

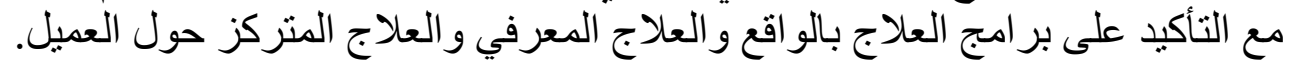

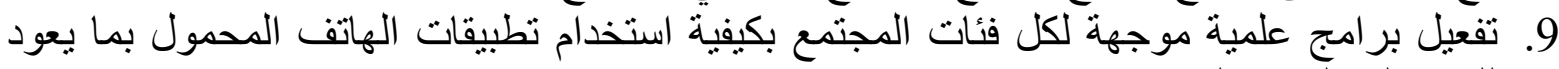

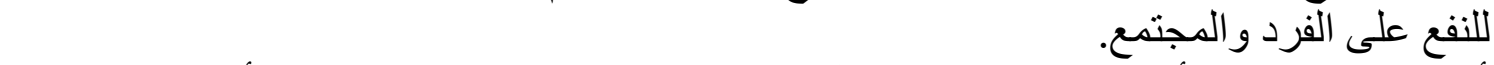

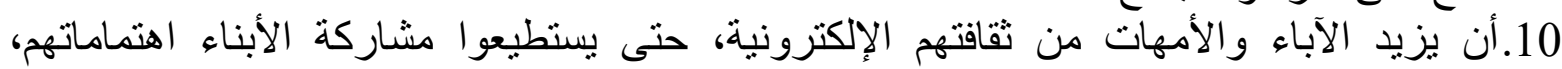

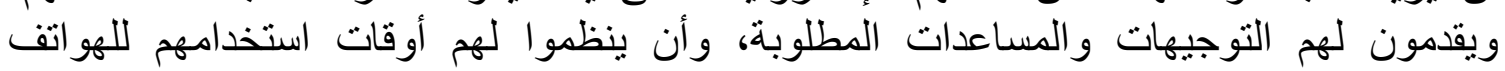
المحمولة. 


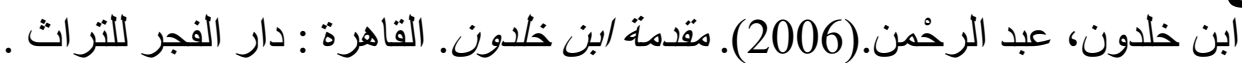

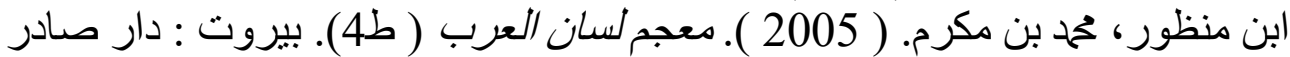

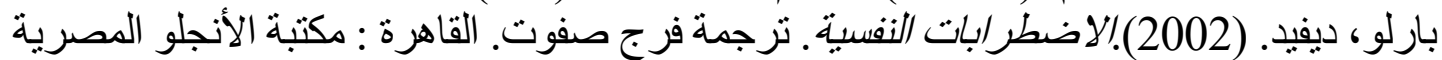

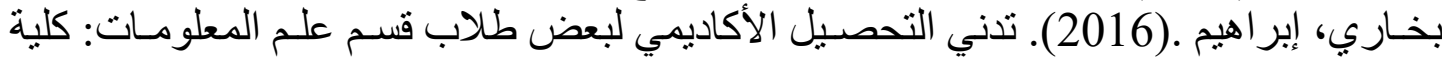

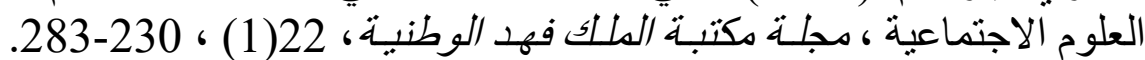

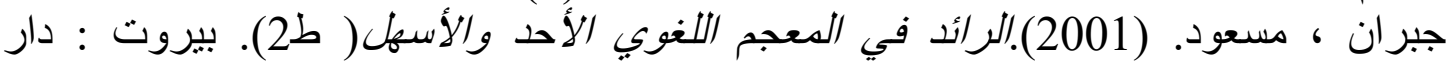
المعارف للملايين. الحموري، خالد عبد الله.(2011). العوامل المؤثرة سلبا في التحصيل الأكاديمي لاى طلبة السنة

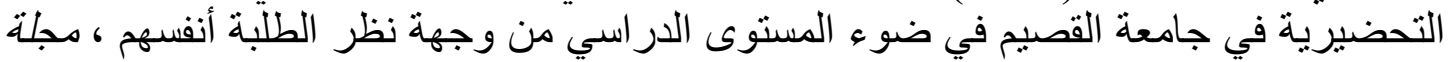

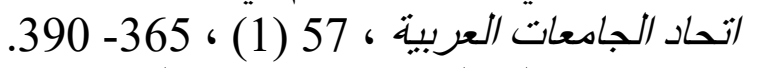

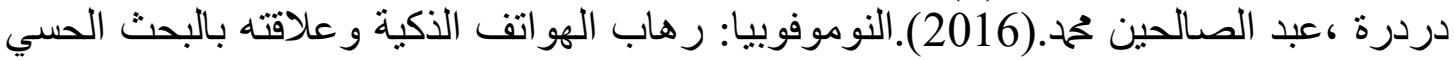

و القلق الاجتماعي: در اسة استكثافية ـ مجلة دراسات نفسية.

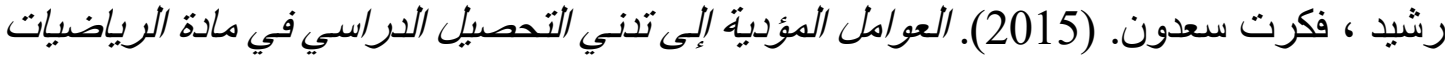

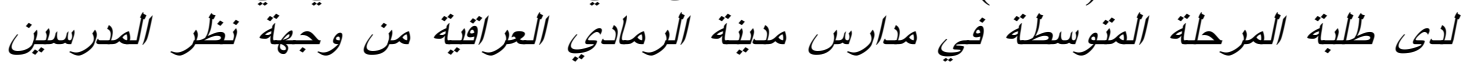

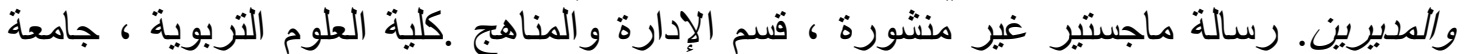

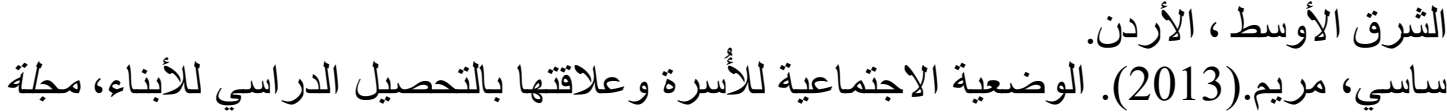

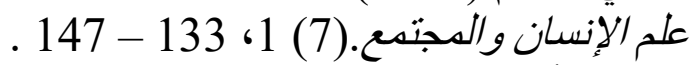

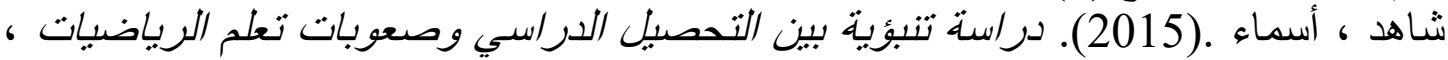

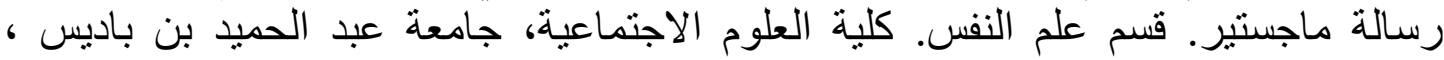

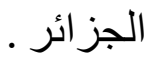

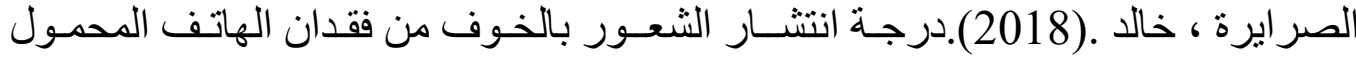

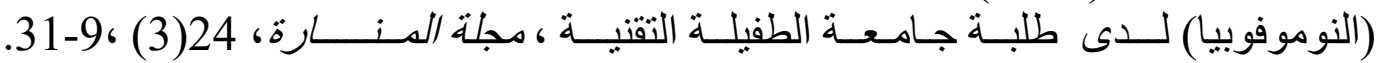

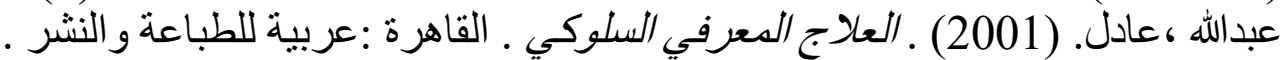

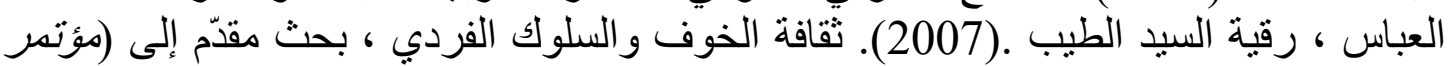
فيلادلفيا الدولي الحادي عشر) تحت عنوان ثقافة الذوف، في الفترة 24 - 26 نيسان (أبريل) ،

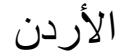
عبد الوهاب جودة، عبد الوهاب. (2006). التأثيرات الاجتماعية لاستخدامات الهاتف المحمول

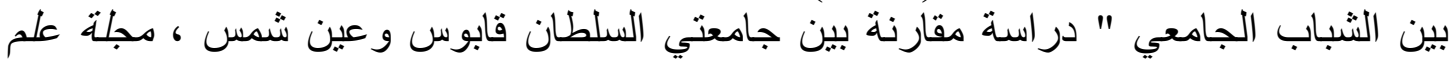

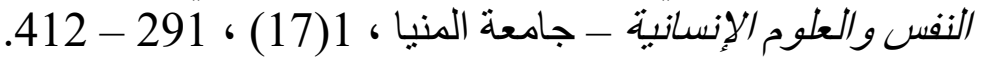

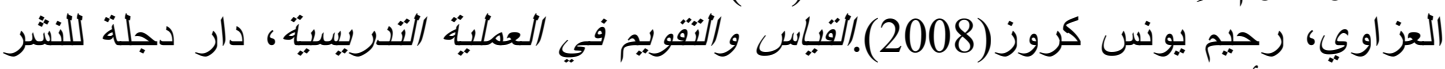

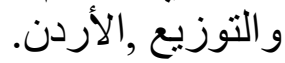




\section{العلاقة بين اضطراب الخوف من فقدان الهاتف المحمول ( النوموفوبيا ) ومستوى التحصيل الأكاديمي لطلاب جامعة الكويت الكوليت}

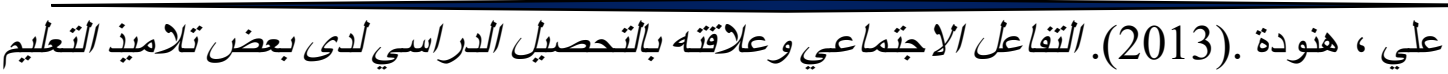

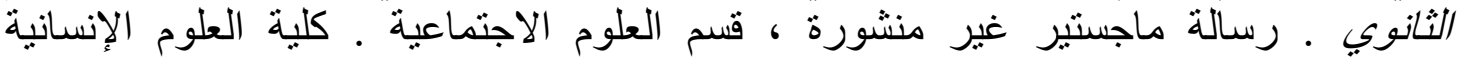

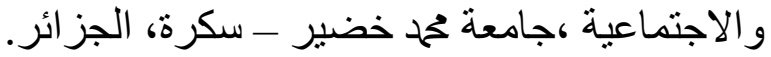

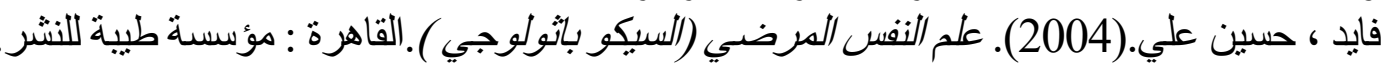

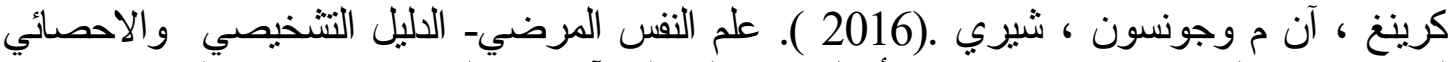

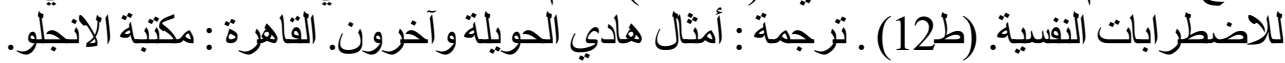

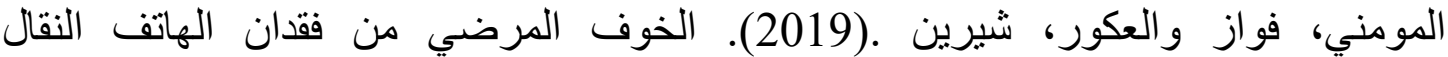

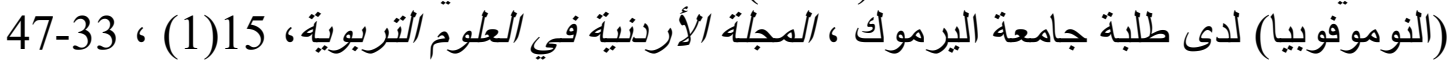

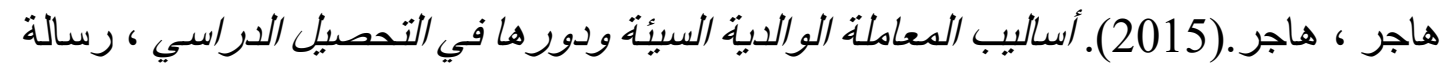

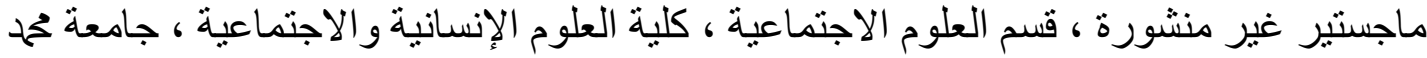

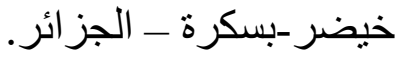
يحيي ، مححد لطفي حمحة. ( 2003). استخدام السيكودر/ما في تخفيف الفوبيا الاجتماعية لدى أطفال

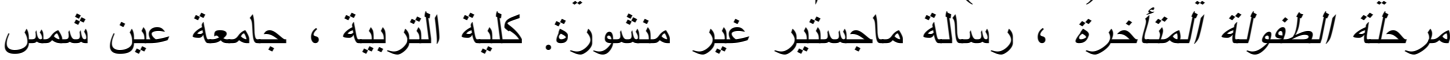
يمينة، مدوري. (2015). انكالية النعلق لدى الطفل. مجلة الدراسات والبحوث الاجتماعية ، جامعة الثهيد حمه لخضر ، الو ادي، الجزائر، ع لـ 14/13، 66- 80.

\section{References:}

Al-Balhan, E. M. et.al. (2018). Psychometric evaluation of the Arabic version of the nomophobia questionnaire: confirmatory and exploratory factor analysis - implications from a pilot study in Kuwait among university students, Psychology Research and Behavior Management 11. pp471-482.

Adeleke, Ayobami Gideon.( 2017). Influence of Time-on-phone on Undergraduates Academic Achievement in Nigerian Universities. American Journal of Educational Research, 5 ( 5) , pp564-567.

Aman, T., Shah1, N., Hussain, A., Khan1, A., Asif, S.\& Qazi1, A. (2015). Effects of Mobile Phone use on the Social and Academic Performance of Students of A public Sector Medical College in Khyber Pakhtunkhwa Pakistan Tauseef Aman1. KJMS January-April 2015, 8( 1), pp99 -103.

Arpaci, I. \& et al. (2016). Individual Differences in the Relationship Between Attachment and Nomo phobia Among College Students: The Mediating Role of Mindfulness, Journal of Medical internet Research,.(19).12.pp1-12.

Attewell, J. (2005). Mobile Technologies and Learning: a technology update and m-learning project summary. London: Learning and Skills Development Agency. Retrieved from date 12/4/2018 Available at: www.LSDA.org.uk.

Baert, S., \& et al.( 2018).Smartphone Use and Academic Performance: Correlation or Causal Relationship?. IZA Discussion Retrieved from date 15/4/2018 Available at : https://ssrn.com/abstract=3170244, PP,1-23. 


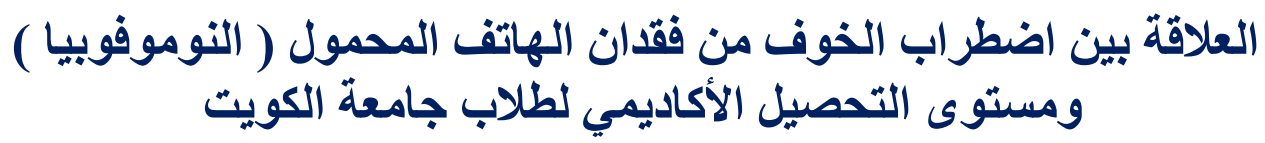

Bourne ‘E. J. (2011). The Anxiety \& Phobia , 5th ed, New Harbinger Publications, Oakland.

- Brenner, J. Pew Internet: Mobile. Pew Internet and American Life Project, Retrieved from date 10/4/2018 Available at,.http://pewinternet.org/Commentary/2012/February/Pew-InternetMobile.aspx

Bragazzi,N. \& Puente, G. (2014). A proposal for including nomophobia in the new DSM-V. Psychology Research and Behavior Management . 7(2), pp155- 160.

- Brown, A.L., \& Bransford, J. (1999). How people learn: brain, mind, experience and school. Washington, D.C: National Academy Press.

- Brown, T. H. (2005). Towards a model for m-learning in Africa, International Journal on E-Learning, 4(3), pp299-316.

- Chen, Q., Yan, Z. (2016). Does multitasking with mobile phones affect learning? A review. Computers in Human Behaviors, 54(3), pp34-42.

- Chen, R. S., Ji, C. H. (2015). Investigating the relationship between thinking style and personal electronic device use and its implications for academic performance, Journal Computers in Human Behavior, 52(9), pp177-183.

- Derks, D. \& et al .(2014). "Switching on and off: Does smart phone use obstruct the possibility to engage in recovery activities?," European Journal of Work and Organizational Psychology. 23(1), pp. 80-90 .

- Datta ,Sumit, Nelson, V, Simon, S.(2016). mobile phone use pattern and Self - reported Health Problems Among Medical Students, Journal Evolution Med Dent. 5 (21).pp1105-1119.

- Dirik, K, Serarslan, M, and PEKEL, A .(2016). Analysis of Smart Phone Addiction among Adolescents In Terms Of Various Variables, The International Journal of Social Sciences and Humanities Invention 3 (12) pp.3087-3095.

- Dixit,S., Shukla,H., Bhagwat, A., Bindal, A. (2017). A Study to Evaluate Mobile Phone Dependence Among Students of a Medical College and Associated Hospital of Central India, Indian Journal of Community Medicine, 35(2) pp343-349.

- Felisoni, D. \& Godoi, A. (2018). Cell Phone Usage and Academic Performance: An Experiment. Computers \& Education , Journal of International Technology. 117(3), pp175-187.

Ferry, B. (2009). Using mobile phones to enhance teacher learning in environmental education. In J. Herrington, A. Herrington, J. Mantei, I. Olney, \& Ferry, B. (Eds.), New technologies, new pedagogies: Mobile learning in higher education, pp. 45-55.

- Gezgin, D, Summer, E, Arslan, O, \& Yildurim, S.(2016). Nomophobia Prevalence among Pre-service Teachers: A case of Trakya University, Trakya Universities Egotism Faculties Dirges. 

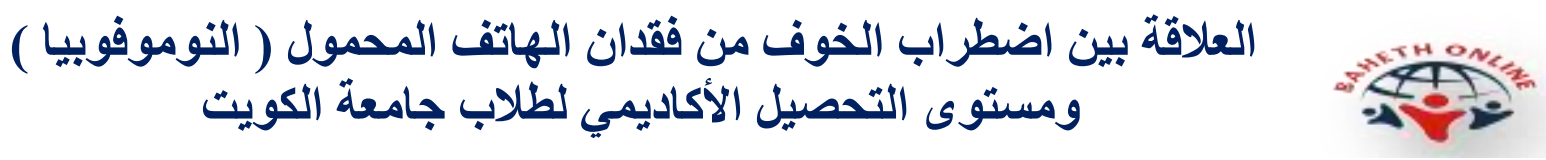

Haythornwaite, C., Andrews, R., Fransman,J. \& Meyers,E. (2016). The Sage Handbook of E-learning, Research. Great Britain: Sage Publications Ltd .

Kanmani, Aparna \&, Bhavani,\& Maragatham R .(2017). Nomophobia - An Insight into Its Psychological Aspects in India, The International Journal of Indian Psychology, 4(2),pp1-15.

- Kibona, L \& Mgaya, G.(2015). Smartphones Effects on Academic Performance of Higher Learing Students , Journal of Multidisciplinary Engineering Science and Technology . 2 ,pp777- 784.

- Kwon M, \& et al . (2013).Development and validation of a Smartphone addiction scale (SAS),8(2).pp 1-7

- Lepp, A., Barkley, J., Karpinski, A. (2014): The relationship between cell phone use, academic performance, anxiety, and satisfaction with life in college students, Computers in Human Behavior, 31, pp343-350.

- Lepp, A., Barkley, J., Sanders, G., Rebold, M. ,\& Gates, P.(2013): The relationship between cell phone use, physical and sedentary activity, and cardiorespiratory fitness in a sample of U.S. college students. International Journal of Behavioral Nutrition and Physical Activity, 10(1), pp79-93

- Lepp, A , Barkley , J., Karpinski ,A.(2015). The Relationship Between Cell Phone Use and Academic Performance in a Sample of U.S. College Students, The global eLearning Journal, (1), PP119-126.

- Mihir, P.\& et al.,(2016).Cross-Sectional Study on Mobile Phone Involvement Among Medical Students of A Tartary Care Teaching Hospital of Western India, National Journal of Community Medicine, 7 (7), pp609613.

- Ng , S.., Hassan, N, Nor, N, \& Malek N.(2017). The Relationship Between Smartphone Use and Academic Performance: A Case of Students in a Malaysian Tertiary Institution .Malaysian Online, Journal of Educational Technology.5(4),pp59-70.

- Olufadi, Y. (2015): A configurational approach to the investigation of the multiple paths to success of students through mobile phone use behaviors, Journal of Computers \& Education, 86, pp84-104.

- Pavithra, M , Madhu k, Murthy T,.(2016).A Study on Nomophobia - Mobile Phone Dependence, Among Students of A Medical College in Bangalore, National Journal of Community Medicine, 6(2).PP340-344.

- Pea, R., \& Maldonado, H. (2006).WILD for learning: Interacting through new computing devices anytime anywhere. In Sawyer, K. (Ed.). Cambridge handbook of the learning sciences. New York: Cambridge University Press .pp 427-442.

- Pooja ,et al.(2016). Are Students Becoming Slaves of Technology?, International Journal of Advanced Research, 4(9),pp 601-605. 


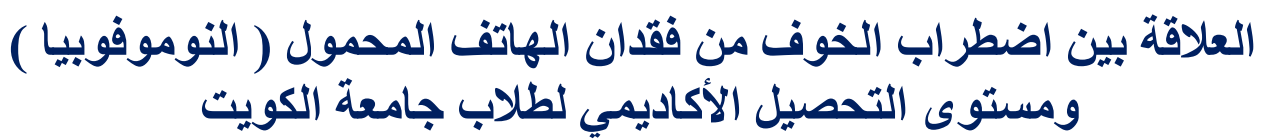

Prasad, M, et al,(2017). Nomo phobia: A Cross-sectional Study to Assess Mobile Phone Usage Among Dental Students, Journal of Clinical and Diagnostic Research, India., 11 (2).pp34-39.

Prasyatiani, T, Hijriarahmah, D, Solamat, L.(2017). Seven Magic Days to Prevent Nomophobia, Proceedings of Intcess 20174th International Conference on Education and Social Sciences, 6-8 February 2017Istanbul, Turkey

- Prensky, M. (2005). Listen to the natives. Educational Leadership, 63(4), pp9-13.

- Pundir ,P, Andrews, B ,Teddy, V. (2016). Association of problematic mobile phone use with psychological distress and self-esteem among college students in South India: a cross-sectional study, International, Journal of Community Medicine and Public Health, 3(.10).pp203-211.

- Rabiu, H. , Muhammed, A.,\& Ahmed, H..(2016). Impact of Mobile Phone Usage on Academic Performance Among Secondary School Students In Taraba State, Nigeria. European Scientific Journal.12(1 ),pp 1857 - 7881 .

- Rush, S. (2011). Problematic Use of Smartphones in the Workplace: An Introductory Study. Master's degree in psychology, Central Queensland University, Rockhampton. Australia.

- Salehan, M.\& Negahban, A.(2013).Social networking on smartphones: When mobile phones become addictive. Computers in Human Behavior, 29, pp2632-2639.

- Savill,S. \& Kent, P. (2003). The use of palmtop computers for learning: A review of literature. United Kingdom: Learning and Skills Development Agency. Retrieved from www.m-learning .org/docs/the_use_of_palmtop computers_for_learning_sept03.pdf.

- Sakiroglu ,M,\& et all (2017). The Mediator Effect of Mindfulness Awareness on The Relationship Between Nomophobia and Academic University Adjustment Levels in College Students, International Journal of Psycho-Educational Sciences, 6 (3).pp69-79.

- Scientists Study Nomophobia.(2015) Fear of Being without a Mobile Phone, Iowa State University, Washington, D.C: National Academy Press

- Sharma, N., Sharma, P., Sharma, N. \& Wavare, R. (2015). Rising concern of nomophobia amongst Indian medical students. International Journal of Research in Medical Sciences, 3(3), pp705-707.

- Soyemi, J.(2015). Analysis of Mobile Phone Impact on Student Academic Performance in Tertiary Institution, International Journal of Emerging Technology and Advanced Engineering, 5(1), pp361-367.

- Srivastava, L. (2005). Mobile phones and the evolution of social behavior. Behavior and Information Technology, 24, pp111-129. 


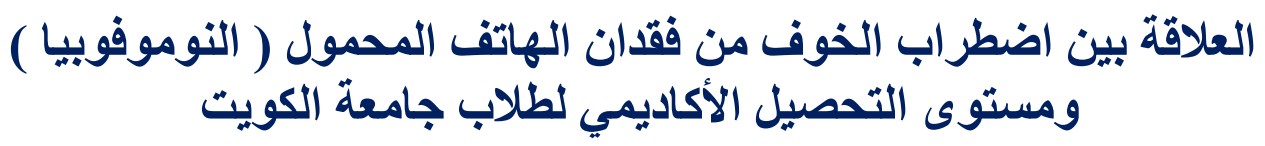

Sudarji, S.(2017). Hubungan Antara Nomophobia Dengan Kepercayaan Diri,. Journal Psychology Psibernetika. 10 (1), pp51 -61.

- Sundari, T. (2015). Effects of mobile phone use on academic performance Sundari, of college going young adults in India, International Journal of Applied Research 1(9).pp 898-905.

- Twum,R.( 2014). Influence of mobile phone technologies on science student's academic performance in selected Ghanaian public universities A Research Thesis submitted fulfillment of the requirements for the award of the degree of doctor of philosophy in the school of education , Kenyatta ,university educational communication and technology department.

- Uysal, Ş, Ozen, H, Madenoglu,C.(2016). Social Phobia in Higher Education: The Influence of Nomophobia on Social Phobia, The Global eLearning Journal, 5(2),.PP1-8.

- Vadlamani,S \& Madhavi „B. Devi ,Vi,.(2017).Assessment of Mobile Phone Dependence and Self Perceived Effects Among Students of Medical College, Visakhapatnam .Journal of Dental and Medical Sciences . 16, 45- 48.

- Vavolua, G. (2005). Report on literature on mobile learning, science and collaborative learning. European Commission. Kaleidoscope Jeirp Mobile Learning in Informal settings. European Network of Excellence. Retrieved from http://hal.inria.fr/docs/00/19/01/75/ PDF/VavoulaKaleidoscope-2005.pdf.

- Walsh, S \& White, K. \& Young, R,.(2009).The phone connection :A qualitative exploration of how belongingness and social identification relate to mobile phone use amongst Australian youth, Journal of Community \& Applied Social Psychology, 19(3).pp225- 240.

- Yildirim C ,\&, Correia, A.(2015).Exploring the dimensions of monophobia: Development and validation of a self-reported questionnaire, Article in Computers in Human Behavior . August 2015. pp130-138.

- Yildirim ,C.(2016).Exploring the dimensions of monophobia: Developing and validating a questionnaire using mixed methods research, A thesis submitted to the graduate faculty in partial fulfillment of Master of Science, Lowa State University Ames. Lowa. 


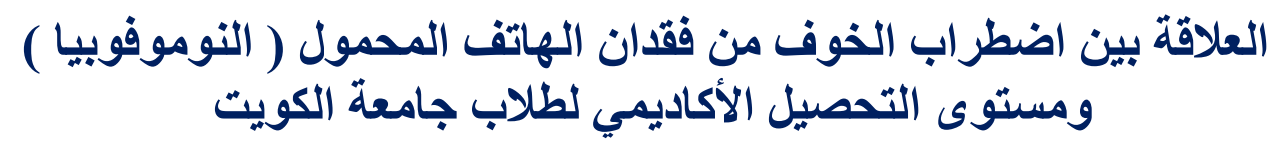

\section{The relationship between no- mobile- phone phobia (nomophobia) and the level of academic achievement of Kuwait University students \\ Qairwan Abdullah abushaibah \\ Master Degree-Department of Educational Psychology Master Degree \\ Faculty of Education.Kuwait University, Kuwait \\ qairwanabushaibah@gmail.com}

\section{Prof. Dr. Issa Muhammad Al-Balhan \\ Department of Educational Psychology \\ Faculty of Education - Kuwait University - Kuwait}

\section{Abstract}

The current study aimed to identify the nature of the correlation and to indicate the statistically significant differences between the no- mobile - phone phobia (nomophobia) and the level of academic achievement of Kuwait University students according to (gender, specialization, cumulative average, and age variable), and to achieve these goals the researcher used the descriptive analytical approach. , The study population consisted of "7" colleges, and the study sample amounted to 667 male and female students, of which (350) for the scientific colleges and (317) for the literary colleges. As for the study tools, the researcher applied two scales: the first is academic achievement, the second scale : the no - mobile- phone phobia (nomophobia) and they are prepared by the researcher. The study found a negative (inverse) correlation between the academic achievement scale and the nomophobia scale, and there are statistically significant differences in the no- mobile- phone phobia (nomophobia), Nomophobia for Kuwait University students between males and females in favor of males, and there are also statistically significant differences in the no- mobile- phone phobia (nomophobia) for students of University of Kuwait. For Kuwait attributed to the variable of specialization (scientific, literary) in favor of the scientific students, there are also statistically significant differences in the no- mobile- phone phobia (nomophobia) for students of Kuwait University due to the variable of cumulative average, and there are also statistically significant differences in the no- mobile- phone phobia (nomophobia)for Kuwait University students due to the variable of age." The study made several recommendations, the most important of which are: Inviting the university administration to pay more attention to spreading awareness of nomophobia, through counseling programs for students about the behavior of nomophobia and its impact on the students' academic and personal life.

Keywords: no- mobile- phone phobia - nomophobia - mobile phone - academic achievement - Kuwait University students 